Universidade de São Paulo

Faculdade de Odontologia de Ribeirão Preto

CARMEN VICTORIA TORRES TORO

Prevenção da degradação da dentina radicular exposta ao ácido clorídrico

Ribeirão Preto

2015 


\section{Prevenção da degradação da dentina radicular exposta ao ácido clorídrico}

Tese apresentada à Faculdade de Odontologia de Ribeirão Preto da Universidade de São Paulo, para a obtenção do título de Doutora em Ciências.

Programa: Odontologia Restauradora Área de Concentração: Odontologia Restauradora

Opção: Dentística

Orientadora: Profa. Dra. Regina Guenka Palma Dibb

Versão corrigida

Ribeirão Preto 
Autorizo a reprodução e divulgação total ou parcial deste trabalho, por qualquer meio convencional ou eletrônico, para fins de estudo e pesquisa, desde que citada a fonte.

Ficha catalográfica preparada pela Seção de Tratamento da Informação do Serviço de Biblioteca

Faculdade de Odontologia de Ribeirão Preto da Universidade de São Paulo

Toro, Carmen Victoria Torres

Prevenção da degradação da dentina radicular exposta ao ácido clorídrico. Ribeirão Preto, 2015.

94p. : il. ; $30 \mathrm{~cm}$

Tese de Doutorado (Versão corrigida da Tese. A versão original se encontra disponível na Unidade que aloja o Programa), apresentada à Faculdade de Odontologia de Ribeirão Preto/USP. Área de concentração: Odontologia Restauradora - Opção: Dentística

Orientadora: Palma-Dibb, Regina Guenka

1. Prevenção. 2. Degradação. 3. Dentina. 4. Erosão. 5. Abrasão. 6. Desgaste. 


\section{Folha de Aprovação}

Toro, CVT. Prevenção da degradação da dentina radicular exposta ao ácido clorídrico. Tese apresentada à Faculdade de Odontologia de Ribeirão Preto da Universidade de São Paulo para a obtenção do título de Doutora em Ciências. Programa: Odontologia Restauradora. Área de Concentração: Odontologia Restauradora. Opção Dentística. Ribeirão Preto, 2015.

Data da Aprovação:_31/03/2015

\section{Banca Examinadora}

Prof. Dr.

Instituição:

Julgamento: Assinatura:

Prof. Dr.

Instituição:

Julgamento: Assinatura:

Prof. Dr.

Instituição:

Julgamento: Assinatura:

Prof. Dr.

Instituição:

Julgamento: Assinatura:

Prof. Dr.

Instituição:

Julgamento: Assinatura: 


\section{Dedicatória}




\section{Dedicatória}

Este Trabalho é Dedicado:

À Deus que sempre está presente em cada momento da minha vida.

Aos meus amados pais Maria del Carmen e Javier, que sempre estão em cada passo da minha vida e com amor me incentivam a seguir em frente.

Ao pastor Juan, pelo apoio e carinho.

À minha amada irmã Cristina pela força, apoio e amor.

Aos meus queridos tios Juan Carlos e Cristina, por todo amor, carinho, ensinamentos e dedicação.

Aos meus primos Juan Carlos, Paola, Arturo, Marcelo, Alejandro e Alioth, por todo carinho e apoio. 
Agradecimento Especial 


\section{Agradecimento Especial}

À professora Dra Regina Guenka Palma Dibb, pela amizade, ensinamentos, conselhos e apoio ao longo da minha jornada, contribuindo para meu crescimento profissional e pessoal. Grande professora, pesquisadora e orientadora.

Muito Obrigada!

À Dra. Juliana Jendiroba Faraoni Romano, pela amizade, ajuda e apoio durante a realização deste trabalho. Sempre lembrarei com carinho todos os agradáveis momentos que dividimos. 
Agradecimentos 


\section{Agradecimentos}

À Deus por estar sempre me guiando cada momento da minha vida.

À minha família, pelo amor e apoio que cada dia me ajuda a seguir em frente.

Aos meus amigos de laboratório, agradeço pela amizade e companheirismo: Juliana dos Reis Derceli, Julia Olien Sanches, Renata Siqueira Scatolin, Taísa Penazzo Lepri, Julia Barone, Camila Scatena, Késsia Mesquista Guimarães.

À Faculdade de Odontologia de Ribeirão Preto da Universidade de São Paulo, representado pelo Diretor Professor Dr. Valdemar Mallet da Rocha Barros e pela ViceDiretora Profa. Dra. Léa Assed Bezerra da Silva.

À coordenação geral de Pós- Graduação da Faculdade de Odontologia de Ribeirão Preto da Universidade de São Paulo, na pessoa do Prof. Dr. Arthur Belém Novaes Júnior.

À coordenação do Curso de Pós-Graduação em Odontologia Restauradora da Faculdade de Odontologia de Ribeirão Preto da Universidade de São Paulo, pessoa do Prof. Dr. Manoel Damião de Souza Neto.

Ao chefe de Departamento de Odontologia Restauradora da Faculdade de Odontologia de Ribeirão Preto da Universidade de São Paulo, na pessoa do Prof. Dr. Marcelo Oliveira Mazzetto.

À Comissão de Pesquisa da Faculdade de Odontologia de Ribeirão Preto da Universidade de São Paulo, na pessoa da Profa. Dra. Maria Cristina Borsatto.

Ao comitê de Ética em Pesquisa da Faculdade de Odontologia de Ribeirão Preto da Universidade de São Paulo, na pessoa da Profa. Dra. Simone Cecílio Hallak Regalo. 
Ao Biobanco de Dentes da Faculdade de Odontologia de Ribeirão Preto da Universidade de São Paulo, na pessoa Profa. Dra. Silmara Aparecida Milori Corona.

Aos professores membros da minha banca de exame de qualificação: Profa. Dra. Regina Guenka Palma Dibb, Prof. Dr. César Bataglion, Dra. Juliana Jendiroba Faraoni Romano.

Ao Prof. Dr. Luciano Bachmann, Professor do Departamento de Física. Agradeço a colaboração para o desenvolvimento do trabalho.

À técnica Patrícia Marchi, pela amizade e auxílio.

À Débora Fernandes Costa Guedes, técnica do Laboratório de Gerenciamento de Resíduos Odontológicos da Faculdade de Odontologia de Ribeirão Preto da Universidade de São Paulo, pela ajuda no desenvolvimento deste trabalho.

À Isabel Cristina Galino Sola e Regiane Cristina Moi Sacilotto, secretárias da Seção de Pós-Graduação da Faculdade de Odontologia de Ribeirão Preto da Universidade de São Paulo.

Ao Carlos Feitosa dos Santos, secretário do curso de Pós-Graduação do Departamento de Odontologia Restauradora da Faculdade de Odontologia de Ribeirão Preto da Universidade de São Paulo.

À Maria Isabel e Amália, secretárias do Departamento de Odontologia Restauradora da Faculdade de Odontologia de Ribeirão Preto da Universidade de São Paulo.

À Seção de Atendimento Social de Ribeirão Preto na Universidade de São Paulo.

À CAPES (Coordenação de Aperfeiçoamento de Pessoal de Nível Superior), pelo apoio financeiro para meu trabalho.

À FAPESP (Fundação de Amparo à Pesquisa do Estado de São Paulo), pelo auxílio financeiro no meu trabalho (Processo 2012/06711-3). 
Resumo 


\section{Resumo}

Toro CVT. Prevenção da degradação da dentina radicular exposta ao ácido clorídrico [tese]. São Paulo: Universidade de São Paulo, Faculdade de Odontologia de Ribeirão Preto, 2015. $94 \mathrm{p}$.

O objetivo deste estudo foi avaliar os efeitos dos tratamentos com fosfopeptídeo de caseínafosfato de cálcio amorfo (CPP-ACP) e pasta experimental (a base de caseína) associados ou não aos lasers Nd:YAG e Diodo na dentina erodida com $\mathrm{HCl}$ líquido e $\mathrm{HCl}$ gasoso associada ou não à abrasão. Foram obtidos fragmentos de dentina radicular $(4 \times 3 \times 2 \mathrm{~mm})$ a partir de molares humanos hígidos. Cada fragmento foi isolado com resina composta deixando apenas a metade da superfície externa exposta $(2 \times 3 \mathrm{~mm}) .280$ fragmentos foram selecionados e após erosão inicial com $\mathrm{HCl}$ líquido (pH1,2) (20s e 3x), foram divididos em 4 grupos (n=10): G1 - HCl líquido, G2 - HCl líquido + Abrasão, G3 - HCl gasoso, G4 - HCl gasoso + abrasão. Cada grupo foi dividido em 7 subgrupos $(n=10)$ : SgA - Controle, SgB CPP-ACP (GC Tooth Mousse), SgC - CPP-ACP + laser Nd:YAG (SmartFile, Deka), SgD - CPPACP + laser Diodo (Einstein DL), SgE - Pasta experimental, SgF - Pasta experimental + laser Nd:YAG, SgG - Pasta experimental + laser Diodo. Os tratamentos preventivos foram aplicados da seguinte maneira: pasta CPP-ACP por $5 \mathrm{~min}$, pasta experimental (caseína) por $5 \mathrm{~min}$, laser Nd:YAG $(0,4 \mathrm{~W}, 40 \mathrm{~mJ}, 10 \mathrm{~Hz}$, sem contato) por 15s e laser Diodo $(0,5 \mathrm{~W}, 200 \mu \mathrm{s}$, sem contato) por 15s. Posteriormente, foram realizados os procedimentos erosivos ou erosivos/abrasivos: $\mathrm{HCl}$ líquido (pH1,2, 6x/dia/20s), HCl líquido/escovação (2x/dia/10s), $\mathrm{HCl}$ gasoso (pH1,2, 6x/dia/20s) e $\mathrm{HCl}$ gasoso escovação (2x/dia/10s) durante 5 dias. Realizou-se as análises de perda de volume, degrau, perfil de desgaste, rugosidade, número de túbulos, diâmetro e perímetro do lúmen dos túbulos, os quais foram realizados através da microscopia confocal a laser 3D (LEXT OLS4000, Olympus). Para a análise das alterações químicas no infravermelho com transformada de Fourer (FTIR) (Nicolet 380, Thermo Electron Corporation) após tratamentos preventivos foram selecionados 28 espécimes e outros 21 espécimes foram utilizados na análise morfológica no microscópio eletrônico de varredura (MEV) (Philips XL30 FEG), todos os espécimes foram aleatoriamente divididos de 
acordo com os tratamentos preventivos propostos $(n=3)$. Os dados foram submetidos à análise de variância (ANOVA) a dois critérios e teste de Tukey $(\mathrm{p}<0,05)$. Os dados do FTIR foram avaliados de forma descritiva e as imagens de MEV foram avaliadas qualitativamente. $\mathrm{Na}$ análise dos resultados observou-se que o desgaste da dentina foi maior no G1 e G2 que os outros grupos, a perda de volume, degrau e perfil de desgaste foi menor nos subgrupos $\mathrm{SgB}$ e SgD $(\mathrm{p}<0,05)$. Na rugosidade, o G3 mostrou maiores valores que os outros grupos $(\mathrm{p}<0,05)$ e o SgE apresentou maior rugosidade que os outros subgrupos $(\mathrm{p}<0,05)$. Com relação ao número de túbulos, o G1 mostrou maior valor que os outros grupos $(\mathrm{p}<0,05)$ e os subgrupos $\mathrm{SgB}, \mathrm{SgD}$, $\mathrm{SgE}$ e $\mathrm{SgF}$ apresentaram os valores semelhantes $(\mathrm{p}<0,05)$. A área e perímetro do lúmen dos túbulos foi menor no G2 $(\mathrm{p}<0,05)$ e os subgrupos $\mathrm{SgD}$, $\mathrm{SgC}$ e $\mathrm{SgF}$ apresentaram os menores valores $(p<0,05)$. Na análise no FTIR, houve diminuição da razão da amidaIII/fosfato no SgD, SgF e SgG e diminuição do carbonato/fosfato no SgB. Nas imagens da MEV observou-se oclusão parcial dos túbulos no $\mathrm{SgC}, \mathrm{SgD}$ and SgF. Pode-se concluir que o CPP-ACP combinado com a irradiação do laser Diodo promoveu maior resistência da dentina à degradação quando foi exposta à erosão associada ou não com a abrasão e todos os tratamentos preventivos realizados mostraram pouco efeito para diminuir a degradação quando a dentina foi exposta ao HCl líquido/abrasão.

Palavras-chave: 1. Prevenção. 2. Degradação. 3. Dentina. 4. Erosão. 5. Abrasão. 6. Desgaste. 


\begin{abstract}
Toro CVT. Prevention of degradation on root dentin exposed to hydrochloric acid [thesis]. São Paulo: Universidade de São Paulo, Faculdade de Odontologia de Ribeirão Preto, 2015. $94 \mathrm{p}$.
\end{abstract}

The aim of this study was to evaluate the effects of treatments with casein phosphopeptideamorphous calcium phosphate (CPP-ACP) and experimental paste (casein) associated or not to $\mathrm{Nd}$ : YAG and diode lasers on eroded dentin with $\mathrm{HCl}$ liquid and $\mathrm{HCl}$ gas associated or not with abrasion. 329 root dentin fragments $(4 \times 3 \times 2 \mathrm{~mm})$ from human molars was obtained. Each fragment was isolated with composed resin and the half of buccal face was maintained exposed $(2 \times 3 \mathrm{~mm})$. After, 280 were selected samples after initial erosion with $\mathrm{HCl}$ liquid (pH1.2) (3x for 20s). Then, they were divided into 4 groups: G1 - HCl liquid, G2 $\mathrm{HCl}$ liquid + abrasion, G3 - $\mathrm{HCl}$ gaseous, G4 - $\mathrm{HCl}$ gaseous + abrasion. Each group was divided in 7 subgroups ( $\mathrm{n}=10)$ : SgA - Control, SgB - CPP-ACP (GC Tooth Mousse), SgC - CPPACP + Nd: YAG laser (SmartFile, Deka), SgD - CPP-ACP + Laser Diode (Einstein DL), SgE experimental paste, $\mathrm{SgF}$ - experimental paste $+\mathrm{Nd}$ : YAG laser, $\mathrm{SgG}$ - experimental paste + laser Diode. The preventive treatments was applied as follows: CPP-ACP and experimental paste for $5 \mathrm{~min}, \mathrm{Nd}$ : YAG laser ( $0.4 \mathrm{~W}, 40 \mathrm{~mJ}, 10 \mathrm{~Hz}$, without contact) for $15 \mathrm{~s}$ and laser diode $(0.5 \mathrm{~W}, 200 \mu \mathrm{s}$, without contact) for $15 \mathrm{~s}$. Later, specimens were exposed to erosive or erosive/abrasive challenges: $\mathrm{HCl}$ liquid (pH1.2) (6x/day/20s), $\mathrm{HCl}$ liquid (6x/day/20s)/brushing (2x/day/10s), $\mathrm{HCl}$ gaseous (pH1.2) (6x/day/20s) and $\mathrm{HCl}$ gaseous/ brushing, for a period of 5 days. After, volume loss, step, profilometry, roughness and tubules (number, diameter and perimeter) were analyzed with the 3D confocal laser microscopy (LEXT OLS4000, Olympus). Then, the analysis after treatment was performed, $28(n=3)$ specimens were selected for chemical changes analysis through the Fourier Transform Infrared Spectrometer (FTIR) (Nicolet 380, Thermo Electron Corporation) and other $21(\mathrm{n}=3)$ specimens were used for morphological analysis in the scanning electron microscope (SEM) (Philips XL30 FEG). Two-way analysis of variance (ANOVA) and Tukey test $(p<0.05)$ were used for data analysis. FTIR data were analyzed descriptively and SEM 
images were qualitatively evaluated. The results showed that G1 and G2 had the higher values of dentin wear and volume lost, step and profilometry were lower in SgD and SgB than the other subgroups $(\mathrm{p}<0.05)$. The surface roughness was higher in G3 than the other groups $(\mathrm{p}<0.05)$ and was higher in SgE than the other subgroups $(\mathrm{p}<0.05)$. The number of tubules was higher in G1 than the other groups $(\mathrm{p}<0.05)$ and was lower in $\mathrm{SgB}, \operatorname{SgD}, \operatorname{SgE}$ and $\mathrm{SgF}$ than the other subgroups $(\mathrm{p}<0,05)$. The area and perimeter of the lumen of the tubules was lower in G2 $(\mathrm{p}<0.05)$ and the subgroups $\mathrm{SgD}, \mathrm{SgC}$ and $\mathrm{SgF}$ had the lower values than the other subgroups $(\mathrm{p}<0,05)$. For FTIR analysis, there was a decrease amidaIII/phosphate in $\mathrm{SgD}, \mathrm{SgF}$ and SgG and carbonate/phosphate in the SgB. SEM images showed a partial occlusion of the tubules in SgC, SgD and SgF. It is concluded that CPP-ACP combined with Diode laser irradiation increased the dentin resistance to degradation when the dentin was exposed to erosion associated or not with abrasion, and all the treatments were less effective to decrease the dentin degradation when the dentin was exposed to $\mathrm{HCl}$ liquid/abrasion.

Keywords: 1. Prevention. 2. Degradation. 3. Dentin. 4. Erosion. 5. Abrasion. 6. Wear. 
Sumário 


\section{Sumário}

1. Introdução

2. Proposição 


\section{Introdução}




\section{Introdução}

A degradação do substrato dentário vem representando um grande problema na Odontologia atual, pois é um dos principais responsáveis pelo desgaste dental (Shellis; Addy, 2006). Vem afetando uma grande parcela da população principalmente nos pacientes mais velhos, devido a maior tempo de exposição dos dentes na cavidade bucal (Van't Spijker et al., 2009; Kreulen et al., 2010).

A erosão dental é uma lesão provocada pelos efeitos físicos de perda localizada, crônica e patológica de tecido mineral o qual é removido quimicamente da superfície do dente por meio de substância ácida, sem o envolvimento de microrganismos e de caráter irreversível (Cate; Imfeld, 1996; Bartlett, 2009; Almeida e Silva et al. 2011; McCarthy, 2012). Os ácidos que atuam durante o processo erosivo provocam a dissolução dos minerais, este efeito avança por cada camada do esmalte desmineralizado, o que provoca em estágios avançados a exposição da dentina (Lazarchik; Filler, 2000; Lussi et al., 2011; Schlueter et al., 2012a). Uma vez exposta, a suscetibilidade ao processo aumenta em relação ao esmalte (Lazarchik; Filler, 2000; Lussi et al., 2011), expondo e alargando o lúmen dos túbulos (Meurman et al., 1991), podendo gerar sintomatologia dolorosa (Schueter et al., 2012a).

Com relação à origem, a erosão pode ser de origem extrínseca causada pelos ácidos exógenos, como a ingestão de alimentos e bebidas ácidas (Zero, 1996; Bartlett, 2005; Donovan, 2009; Holbrook et al., 2009; Lussi et al., 2011; Lussi et al., 2012; McCarthy, 2012; Stefański; Postek-Stefańska, 2014) ou por o uso de medicamentos (Lussi et al., 2012) como a vitamina C (Lussi et al., 2012; McCarthy, 2012; Bahal; Djemal, 2014). A erosão de origem intrínseca é causada pelos ácidos endógenos principalmente pelo acido gástrico (Bartlett, 2005; Cheung et al., 2005; Donovan, 2009; McCarthy, 2012), sendo mais severa do que dos exógenos (Bartlett; Coward, 2001; Cheung et al., 2005), pois apresentam pH em torno de 1,2 (Ranjitkar et al., 2012), o qual é muito abaixo do nível crítico para a dissolução do esmalte dental (Donovan, 2009; Ranjitkar et al., 2012a) e da dentina (Hoopenbrouwers et al., 1987).

Os ácidos gástricos presentes no suco gástrico alcançam a cavidade bucal a através do vômito ou refluxo (Bartlett et al., 1996; Scheutzel, 1996; Lussi et al., 2011), que é resultado da expulsão do conteúdo gástrico coordenado pelo centro do vômito que 
se encontra no cérebro (Bartlett et al., 1996), sendo comum nas desordens psicossomáticas (Scheutzel, 1996).

Entretanto, o refluxo é uma situação onde o suco gástrico passa ao esôfago, de forma fisiológica ou patológica (Bartlett et al., 1996; Scheutzel, 1996). O refluxo gastroesofágico (GER), considerado fisiológico, se caracteriza por não mostrar sintomas ou danos na mucosa, geralmente se apresenta após refeições (Bartlett et al., 1996; Ranjitkar et al., 2012a). Porém, o refluxo também se pode apresentar na forma da doença do refluxo gastroesofágico (DRGE), sendo uma afecção crônica (Bartlett et al., 1996) caracterizada por produzir danos na mucosa, sintomas de azia como também por causar o refluído do suco gástrico para a cavidade bucal (regurgitação) (Moraes-filho et al., 2002; Ranjitkar et al., 2012a; Dundar; Sengun, 2014).

0 refluxo pode apresentar-se na forma líquida, gasosa ou ambos (mix líquido-gás) tanto em indivíduos saudáveis (GER) ou com DRGE (Sifrim et al., 1999; Tutuian et al., 2008). 0 refluxo na forma de mix líquido-gás apresenta pH menor que 4, também chamado "refluxo ácido tradicional" é observado com maior frequência e tempo de duração nos indivíduos com DRGE comparados com indivíduos saudáveis, observandose neste tipo de refluxo como fator comum o refluxo gasoso prévio ao refluxo líquido (Sifrim et al., 2001). O refluxo gasoso foi relacionado com ausência dos sintomas, conhecendo-se este tipo como "refluxo silencioso" (Ranjitkar et al., 2012a).

Os pacientes com DRGE normalmente apresentam correlação com o desenvolvimento de erosão dental (Schroeder et al., 1995; Lazarchik; Filler, 1997; Gregory-Head et al., 2000; Lazarchik; Filler, 2000; Ali et al., 2002; Barron et al., 2003; Moazzez et al., 2004; Benages et al., 2006; Holbrook et al., 2009; Liberali, 2008; Pace et al., 2008; Milosevic, 2010; Firouzei et al., 2011; Farahmand et al., 2013; Picos et al., 2013; Alavi et al., 2014; Dundar; Sengun, 2014; Roesch-Ramos et al., 2014) provavelmente devido a ação dos ácidos gástricos (Bartlett et al., 1996; Bartlett, 2006; Ranjitkar et al., 2012a; Ranjitkar et al., 2012b). Numa revisão sistemática foi encontrado que os pacientes com DRGE apresentaram a prevalência média de $24 \%$ de erosão dental e os pacientes adultos e pediátricos com DRGE apresentaram a prevalência média de 32,5\% e 17\% de erosão dental respectivamente (Face et al., 2008).

Além disso, parece que a erosão dental pode ser mais severa e intensa com o ácido gástrico gasoso (refluxo gasoso) em comparação com o ácido gástrico líquido (refluxo líquido) (Higo, et al., 2009). Geralmente a erosão pela DRGE esta localizada nas 
superfícies palatinas dos dentes superiores (Gregory-Head et al., 2000; Lazarchik; Filler, 2000; Donovan, 2009; Ranjitkar et al., 2012b), posteriormente em estágios avançados se apresenta nas superfícies linguais e oclusais dos dentes inferiores (Picos et al., 2013), como também são observadas concavidades cervicais (Grippo et al., 2004). Porém a exposição da dentina durante a erosão comumente é nas áreas que apresentam a camada fina de esmalte, o qual acontece nas regiões cervicais perto da margem gengival e a cúspide mesio-vestibular do primeiro molar inferior (Schlueter et al., 2012a).

O processo erosivo na superfície dentária pode ter sua progressão inibida pela ação de proteínas salivares e exógenas (Vukosavljevic et al., 2014). Entre as proteínas exógenas, a caseína (fosfoproteína encontrada no leite bovino) junto ao efeito das enzimas presentes na cavidade bucal forma o fosfopeptídeo de caseína (CPP), o qual tem a característica de se aderir e estabilizar o cálcio fosfato amorfo (ACP), formando reservatório de fosfato e cálcio e promovendo a remineralização (Herod, 1991; Reynolds et al., 1997; Reynolds et al., 1998; Reema et al., 2014; Vukosavljevic et al., 2014).

Considerando o efeito potencial de remineralizarão da caseína, vários estudos vêm sendo realizados e demonstrando algum efeito deste material sobre os tecidos dentais (Rahiotis; Vougiouklakis, 2007; Yamagushi et al., 2007; Barbour et al., 2008; Piekarz et al., 2008; Bartlett, 2009; Donovan, 2009; Cochrane et al., 2010; Gupta; Prakash, 2011; White et al., 2011; Poggio et al., 2013; Stefański; Postek-Stefańska, 2014; Somani et al., 2014). A caseína como proteína tem mostrando capacidade de diminuir a erosão nos tecidos dentais (Barbour et al., 2008; White et al., 2011; Stefański; PostekStefańska, 2014). Somado a isso, a caseína na forma de fosfopeptídeo de caseína-fosfato de cálcio amorfo (CPP-ACP) apresentou características mais promissoras para prevenir a erosão dental (Piekarz et al., 2008; Bartlett, 2009; Donovan, 2009; Lussi et al., 2009; Gupta; Prakash, 2011; Poggio et al., 2013; Somani et al., 2014). Além disso, o CPP-ACP foi observado ser efetivo em inibir a desmineralização (Rahiotis; Vougiouklakis, 2007; Yamagushi et al., 2007; Cochrane et al., 2010), promover remineralização (Rahiotis; Vougiouklakis, 2007; Kumar et al., 2008; Neuhaus; Lussi, 2009), diminuir o desgaste do tecido erodido (Ranjitkar et al., 2009a; Manton et al., 2010;) e erodido/abrasionado (Ranjitkar et al., 2009b).

Também, a irradiação dos tecidos dentais com os lasers Nd:YAG e Diodo tem demostrado promover características favoráveis na superfície dental, podendo ocasionar alterações morfológicas como sinais de fusão e recristalização (Rohanizadeh 
et al., 1999; Lan et al., 2000; Gaspirc ; Skaleric, 2001; Hossain et al., 2001; de Magalhães et al.., 2004; Santos et al., 2005; Naylor et al., 2006; Umana et al., 2013) e oclusão do lúmen dos túbulos (Liu et al., 1997; Schaller et al., 1997; Yonaga et al., 1999; de Magalhães et al.., 2004; Lan et al., 2004; Aranha et al., 2005; Naylor et al., 2006; Gholami et al., 2011; Umana et al., 2013). 0 laser Nd:YAG também demonstrou promover o aumento da resistência do tecido dental aos ácidos (White; Adams, 1996; Schaller et al., 1997; Rohanizadeh et al., 1999; Hossain et al., 2001; Naylor et al., 2006).

Porém, outro fator relacionado à erosão é o processo da abrasão, o qual é definido como o desgaste patológico do esmalte e dentina através de processos mecânicos anormais, envolvendo objetos estranhos ou substâncias introduzidas repetidamente na boca e contatando com os dentes (Imfeld, 1996; Addy; Shellis, 2006). A escovação em condições normais não mostra promover perda de tecido dental de forma patológica (Hunter et al., 2002; Addy e Hunter, 2003; Bartlett; Shah, 2006), mas quando é associada à erosão produz perda de tecido dental de forma patológica (Addy e Hunter, 2003; Addy; Shellis, 2006; Bartlett; Shah, 2006; Schlueter et al., 2012b), sendo a dentina mais susceptível ao desgaste que o esmalte durante o processo erosivo e abrasivo (Ranjitkar et al., 2009b). A perda de tecido através da erosão/abrasão se apresenta comumente quando se realiza a escovação após o refluxo (regurgitação) (Grippo et al., 2012), sendo característico a perda de tecido dental cervical (Grippo et al., 2004; Addy; Shellis, 2006; Grippo et al., 2012), o qual pode expor dentina (Grippo et al., 2004; Grippo et al., 2012) e durante a recessão gengival a dentina e cemento são expostos a este processo (Grippo et al., 2004).

Contudo, há ausência de estudos associados ao processo erosivo e erosivo/abrasivo que sejam correlacionados com a capacidade preventiva dos diferentes métodos. Como também frente à alta susceptibilidade do desenvolvimento de erosão dental nas pessoas com a doença do refluxo gastresofágico (DRGE) é desconhecido o efeito dos tratamentos preventivos frente à ação dos ácidos gástricos na forma líquida e gasosa sobre o substrato dental associados a abrasão. Desta forma tornase necessário conhecer o efeito preventivo do CPP-ACP e desenvolver novos tratamentos que permitam reduzir ou paralisar a progressão da erosão e erosão/abrasão. 


\section{Proposição}




\section{Proposição}

O objetivo do presente estudo foi avaliar a degradação dentinária e os efeitos dos tratamentos com CPP-ACP e pasta experimental (a base de caseína) combinado ou não aos lasers Nd:YAG e Diodo sobre a evolução do processo de degradação da dentina radicular. 


\section{Material e Método}




\section{Material e Método}

\section{Aspectos Éticos}

O presente estudo foi aprovado pelo comitê de Ética em Pesquisa da Faculdade de Odontologia de Ribeirão Preto - FORP-USP, sob o protocolo de n 2011.1.1370.58.0 (Anexo).

\section{Delineamento Experimental}

Este estudo foi fatorial 4 X 7, com as seguintes características:

- Unidade experimental: Fragmentos de dentina radicular $(\mathrm{n}=329)$.

- Delineamento em blocos completos casualizados.

- Fator degradação da dentina em 4 níveis:

* Ácido Clorídrico (HCl) líquido

* Ácido Clorídrico (HCl) líquido/abrasão

* Gás de Ácido Clorídrico (HCl)

* Gás de Ácido Clorídrico (HCl)/abrasão

- Fator tratamento superficial em 7 níveis:

* Ausência de tratamento - controle

* Pasta fosfopeptídeo de caseína-fosfato de cálcio amorfo (CPP-ACP)

* Pasta fosfopeptídeo de caseína-fosfato de cálcio amorfo (CPP-ACP) + laser Nd:YAG

* Pasta fosfopeptídeo de caseína-fosfato de cálcio amorfo (CPP-ACP) + laser Diodo

* Pasta experimental (caseína)

* Pasta experimental (caseína) + laser Nd:YAG

* Pasta experimental (caseína) + laser Diodo

- Variáveis de resposta quantitativa: Perda de volume, degrau, perfil do degaste, rugosidade superficial, número de túbulos, área e perímetro do 
lúmen dos túbulos após tratamentos e degradação com $\mathrm{HCl}$ associado ou não com abrasão.

- Variáveis de resposta qualitativa: Modificações químicas e morfologia superficial após tratamentos superficiais.

- Métodos de análise: Microscopia confocal a laser 3D, espectrometria no infravermelho por transformada de Fourier (FTIR) e microscopia eletrônica de varredura (MEV).

\section{Obtenção dos Espécimes}

Foram selecionados 200 dentes molares humanos erupcionados hígidos, com pequenas facetas oclusais de desgaste e com a raiz totalmente formada, provenientes do Banco de Dentes Humanos da Faculdade de Odontologia de Ribeirão Preto-USP. Após desinfecção (Dominici et al., 2001), os dentes foram armazenados em água deionizada a $4^{\circ} \mathrm{C}$.

Os dentes foram fixados com cera escultura (Asfer Indústria Química Ltda., São Paulo, Brasil) em uma placa de acrílico para ser levados posteriormente a uma maquina de corte de precisão (Isomet 1000, Buehler, Lake Bluff, USA), que por meio do disco diamantado \#7015 (KG Sorensen, São Paulo, Brasil), sob refrigeração a água, foi separada a coroa da raiz com uma secção realizada $2 \mathrm{~mm}$ acima da junção amelocementária; Posteriormente foram obtidos fragmentos de dentina radicular de dimensões de 4x3x2 mm da região cervical da raiz (Figura 1).

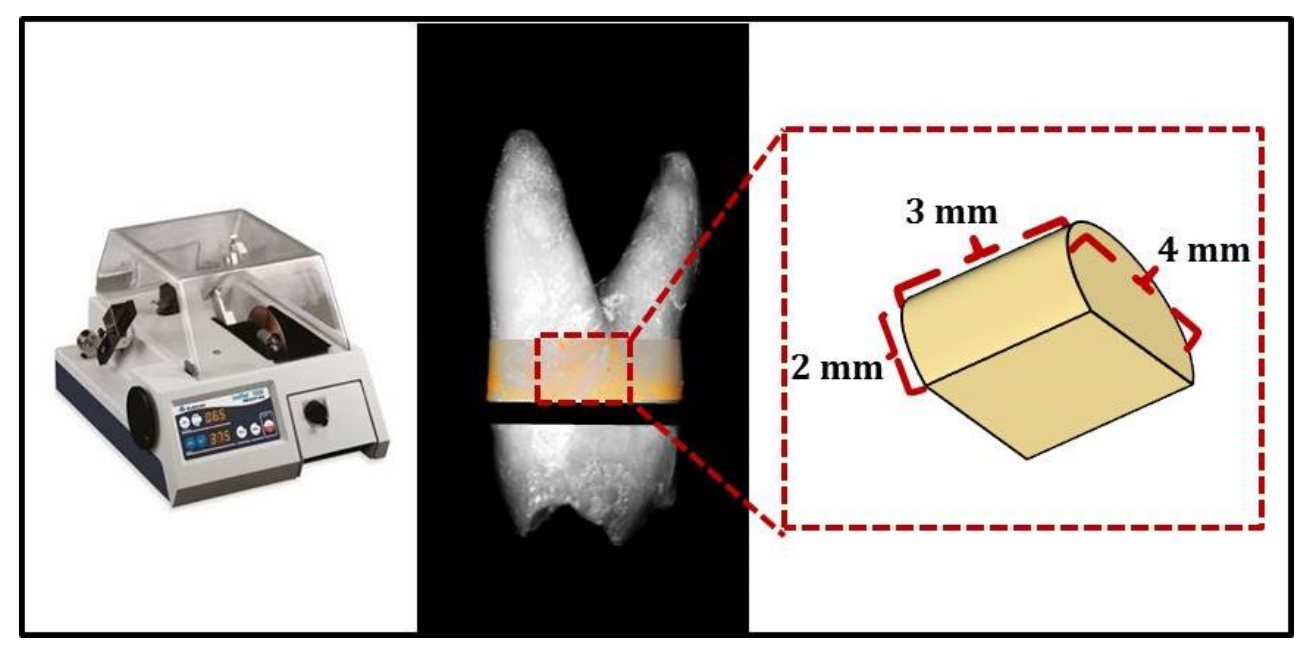

Figura 1. Obtenção dos fragmentos de dentina radicular. 
Em seguida, os fragmentos de dentina foram fixados em cilindros de resina acrílica para a realização da planificação e remoção do cemento radicular com lixa de óxido de alumínio de granulação \#600 e \#1200 (Norton Abrasivos Ltda, São Paulo, Brasil) (Figura 2) com auxilio da politriz (Arotec APL-4, Arotec S/A Ind. e Comercio, São Paulo, Brasil), em seguida foi realizada a limpeza com ultra-som (Ultrasonic Cleaner T 1449 - D, Odontobrás Indústria e Comércio, Ribeirão Preto, Brasil) por 5min.

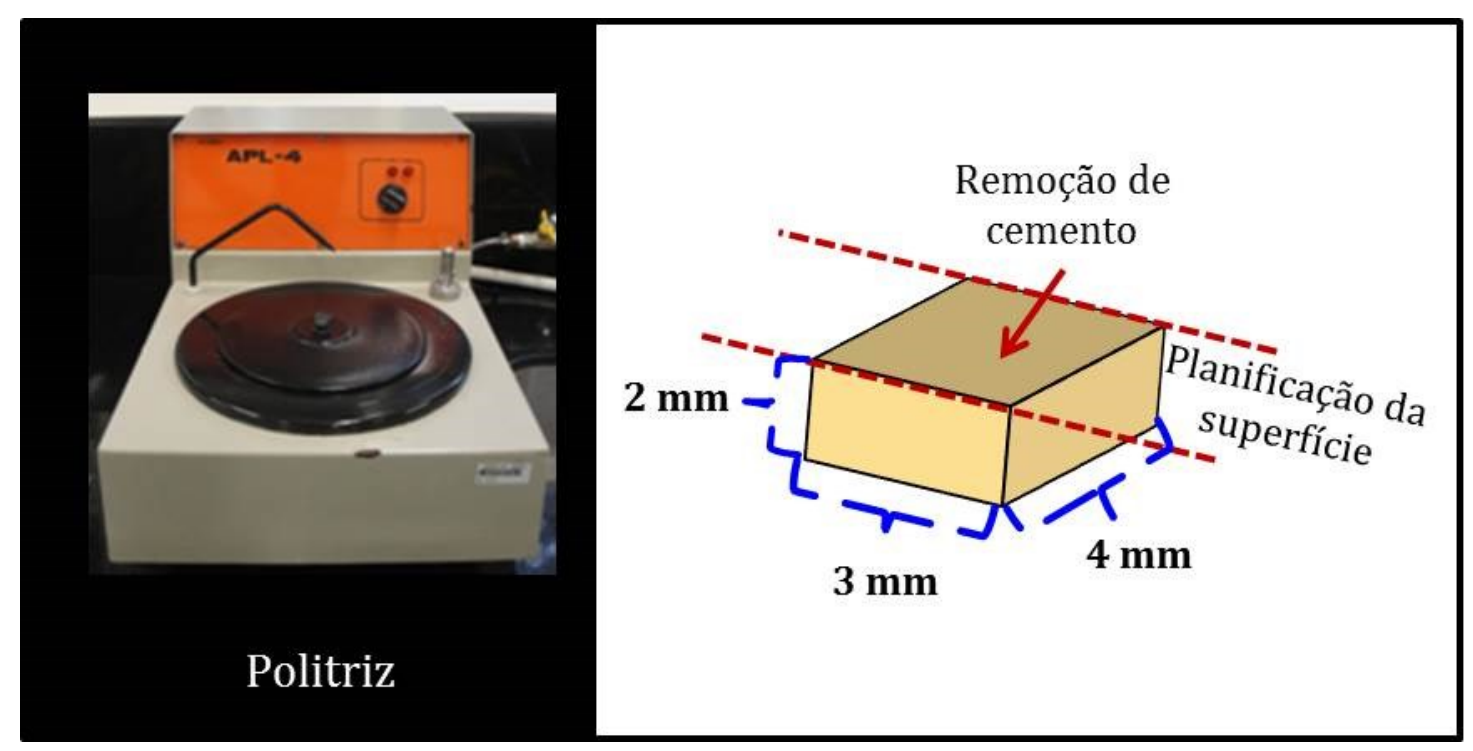

Figura 2. Planificação e remoção do cemento da superfície do fragmento de dentina radicular.

\section{Impermeabilização dos Fragmentos}

Para a impermeabilização dos fragmentos foi utilizada resina composta (Filtek ${ }^{\mathrm{TM} Z 350,3 M}$ ESPE, USA), sem aplicação de sistema adesivo. A resina composta foi cuidadosamente acomodada sobre as faces do fragmento com o auxílio de um dispositivo que permitiu padronizar a forma da resina no fragmento de dentina (Figura 4). A polimerização foi realizada com o fotopolimerizador DB 686 (Dabi Atlante, Ribeirão Preto, Brasil), com $600 \mathrm{~mW} / \mathrm{cm}^{2}$ por 20 segundos.

A impermeabilização dos fragmentos foi realizada com o objetivo de cobrir todas as faces do fragmento com resina composta, exceto a metade da dentina da superfície externa $(2 \times 3 \mathrm{~mm})$ foi deixada sem resina. A outra metade da superfície de dentina 
externa $(2 \mathrm{x} 3 \mathrm{~mm})$ foi coberta com resina composta para ser utilizada posteriormente como referência de dentina hígida (Figura 4).

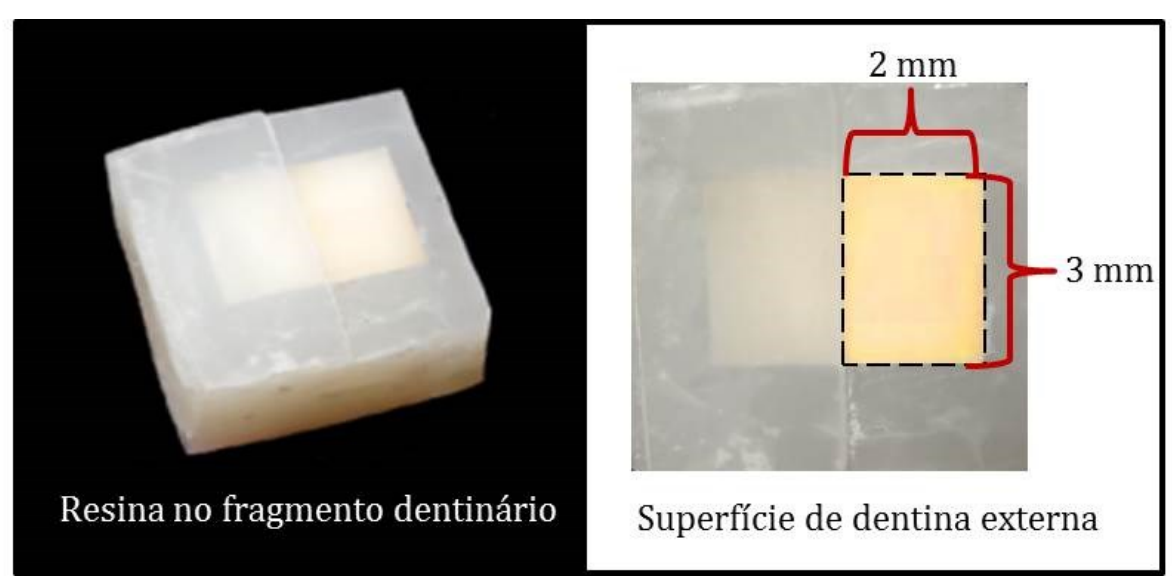

Figura 4. Impermeabilização do fragmento com resina composta

\section{Degradação Inicial e Seleção dos Fragmentos}

Inicialmente os espécimes foram armazenados individualmente em $5 \mathrm{ml}$ de saliva artificial (Amaechi, et al., 1999) por 2 horas a $37^{\circ} \mathrm{C}$ e depois foram imersos individualmente em $5 \mathrm{ml}$ de ácido clorídrico $(\mathrm{HCl})$ líquido $(\mathrm{pH} 1,2,0,1$ Molar) com concentração de $0,3 \%$ a $37^{\circ} \mathrm{C}$ pelo tempo de 20 segundos, sob agitação de $40 \mathrm{rpm}$ em mesa agitadora (Orbital CT-155, Cientec Equipamentos, São Paulo, Brasil) (Figura 5). Foram realizadas 3 exposições e entre cada exposição os espécimes foram armazenados em saliva artificial (Amaechi et al., 1999) a $37^{\circ} \mathrm{C}$ pelo período de 1 hora, utilizando-se 5 $\mathrm{ml}$ de saliva artificial por espécime (protocolo determinado por estudo piloto). 


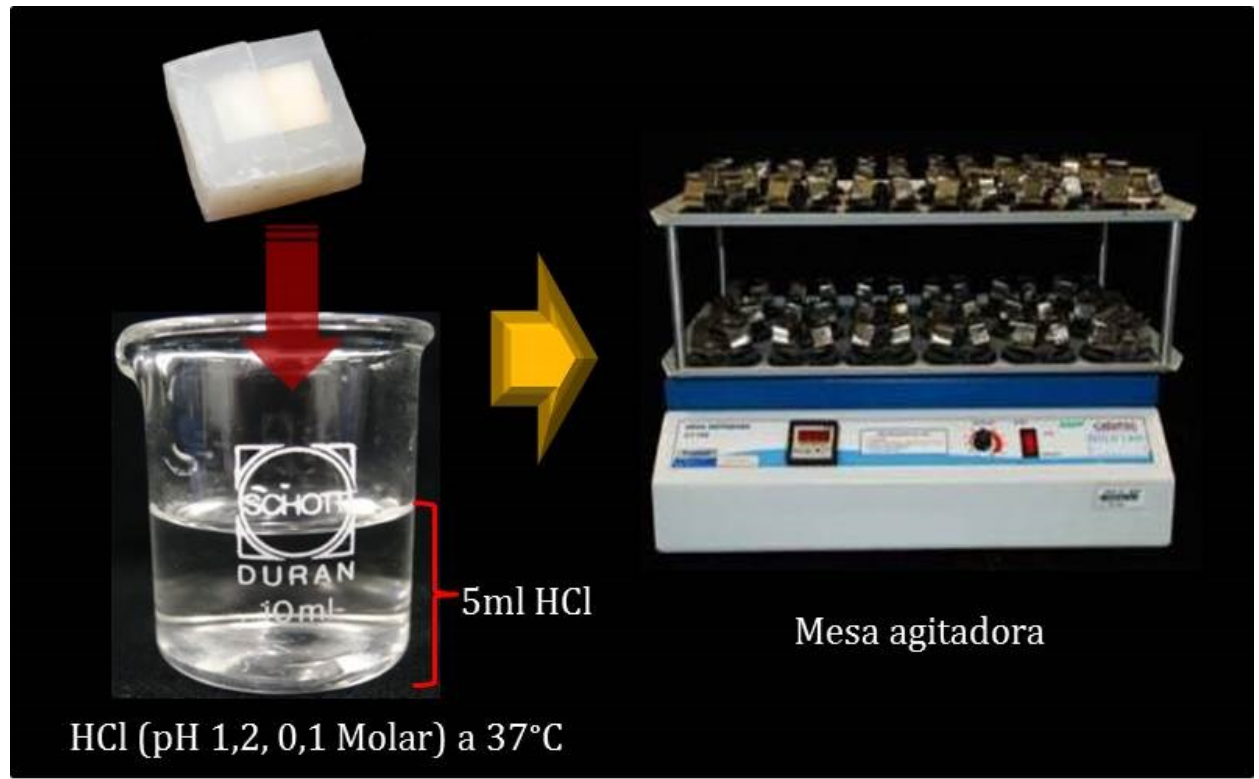

Figura 5. Exposição da dentina ao $\mathrm{HCl}$ para a degradação inicial

Ao finalizar o ciclo de degradação inicial, os espécimes foram armazenados em saliva artificial (Amaechi, et al., 1999) a $37{ }^{\circ} \mathrm{C}$ por 12 horas e posteriormente foram levados para análise morfológica da superfície empregando microscópio confocal a laser 3D (LEXT OLS4000, Olympus, Tóquio, Japão). Para cada espécime foi capturada duas imagens com aumento de 1290x, as imagens foram obtidas em área central padronizada. Os espécimes que apresentaram trincas, malformações na superfície ou os túbulos dentinários ficaram obliterados foram substituídos.

Foram selecionados 280 espécimes e divididos aleatoriamente nos diferentes grupos experimentais:

- $\quad$ Grupo 1:HCl líquido, pH 1,2.

- $\quad$ Grupo 2:HCl líquido+ abrasão.

- $\quad$ Grupo 3:HCl gás, pH 1,2.

- $\quad$ Grupo 4:HCl gás+ abrasão.

Cada grupo foi dividido em 7 subgrupos de acordo com o tratamento superficial realizado: 
- Subgrupo A: Ausência de tratamento - controle.

- Subgrupo B: Pasta CPP-ACP.

- Subgrupo C: Pasta CPP-ACP + laser Nd:YAG.

- Subgrupo D: Pasta CPP-ACP + laser Diodo.

- Subgrupo E: Pasta experimental (caseína).

- Subgrupo F: Pasta experimental (caseína) + laser Nd:YAG.

- Subgrupo G: Pasta experimental (caseína) + laser Diodo.

\section{Tratamentos Preventivos}

\section{Aplicação da Caseína Fosfopeptídea - Fosfato de Cálcio (CPP-ACP)}

A pasta CPP-ACP (GC Tooth Mousse, Tóquio, Japão) foi aplicada na superfície da dentina com auxílio de aplicador descartável, permanecendo em contato com a superfície dentinária por um período de 5 minutos (Figura 6), a superfície foi friccionada nos primeiros 20 segundos e o excesso da pasta foi removido após 3 minutos. Ao finalizar os 5 minutos de tratamento, o espécime foi lavado com água deionizada e posteriormente armazenado em umidade relativa por 30 minutos a $37^{\circ} \mathrm{C}$ (protocolo sugerido pelo fabricante da pasta).

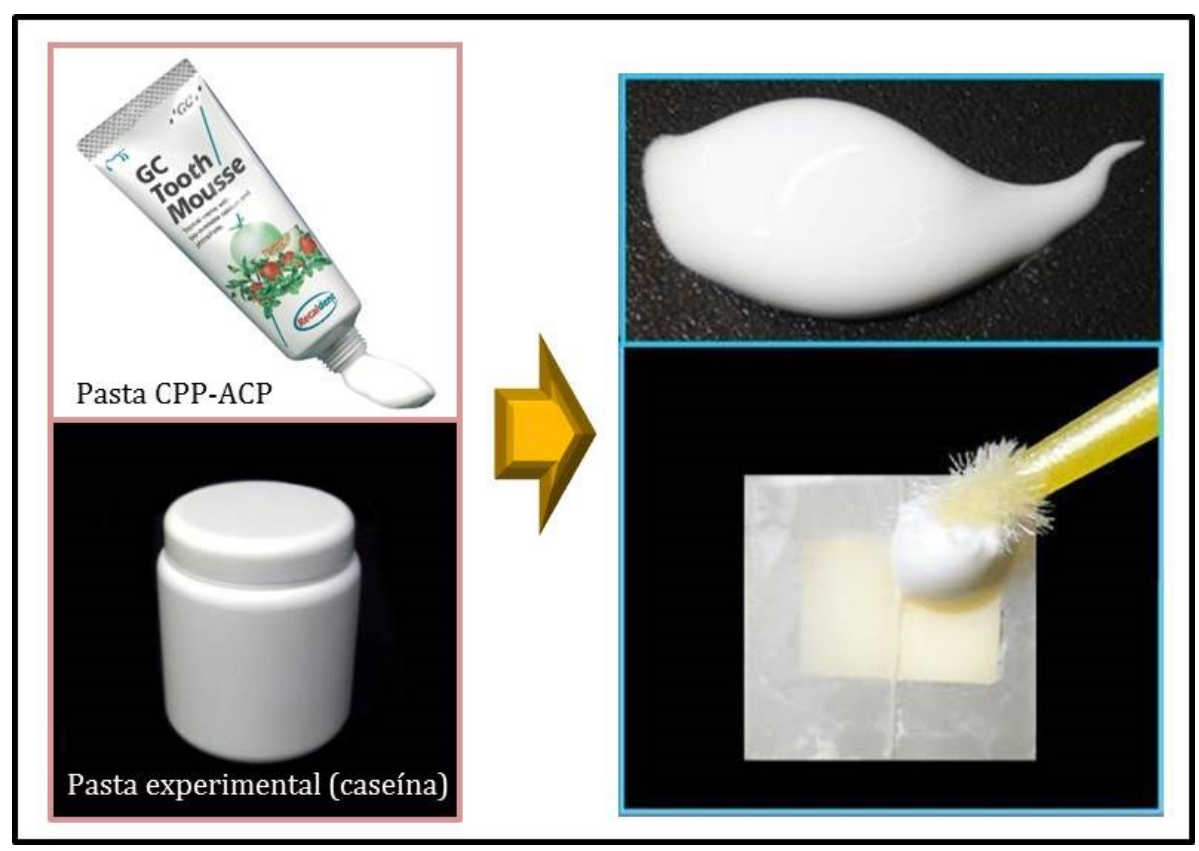

Figura 6. Aplicação das pastas CPP-ACP e experimental. 


\section{Aplicação da Pasta Experimental (Caseína)}

A pasta experimental foi aplicada na superfície da dentina com auxílio de aplicador descartável, permanecendo em contato com a superfície dentinária por um período de 5 minutos (Figura 6), a superfície foi friccionada nos primeiros 20 segundos e o excesso da pasta foi removido após 3 minutos. Ao finalizar os 5 min de tratamento o espécime foi lavado com água deionizada (protocolo determinado por estudo piloto).

\section{Laser Nd:YAG}

Para a irradiação com laser Nd:YAG foi empregado o equipamento SmartFile (Deka, Calezando, Itália), que possui comprimento de onda de 1,064 $\mu \mathrm{m}$. Em função disso, foi misturado carvão vegetal em pó na proporção padronizada de 1:30 nas pastas empregadas (CPP-ACP e pasta experimental) para melhorar a interação da irradiação do laser e posteriormente foi aplicada na superfície da dentina com auxílio de um aplicador descartável. A pasta foi mantida pelo período de 5 minutos. Após o primeiro minuto $20 \mathrm{~s}$ sob fricção) a superfície foi irradiada com o laser em movimento de varredura (pulso longo, energia de $40 \mathrm{~mJ}$, frequência de $10 \mathrm{~Hz}$, totalizando $0,4 \mathrm{~W}$ de potência) com fibra de quartzo de 0,3 $\mathrm{mm}$ de espessura posicionada perpendicularmente à amostra em uma distância de $1 \mathrm{~mm}$ durante 15 segundos (Derceli, 2014) (Figura 7). Depois de ter completado 3 minutos da aplicação o excesso foi cuidadosamente removido com auxílio de uma gaze. Ao finalizar os 5 min de tratamento, o espécime foi lavado com agua deionizada. Após a aplicação da pasta CPP-ACP os espécimes foram mantidos em umidade relativa por $30 \mathrm{~min}$ (segundo instruções do fabricante).

\section{Laser Diodo}

Para a irradiação com laser Diodo foi empregado o equipamento Einstein DL (DC International, Wellington, USA) de comprimento de onda de $980 \mathrm{~nm}$. Para melhorar a interação do laser foi misturada na pasta (CPP-ACP e pasta experimental) carvão vegetal em pó em uma proporção padronizada de 1:30 e posteriormente foi aplicada na superfície da dentina com auxílio de um aplicador descartável. A pasta foi mantida pelo período de 5 minutos. Após o primeiro minuto (20s sob fricção) a superfície foi irradiada 
com o laser em movimento de varredura (energia de $0,5 \mathrm{~W}$ e pulso $200 \mu \mathrm{s}$ ) com fibra de acrílico de 0,4 mm de espessura posicionada perpendicularmente à amostra a uma distância de $1 \mathrm{~mm}$ por 15 segundos (protocolo determinado por estudo piloto) (Figura 7). Depois de ter completado 3 minutos da aplicação da pasta o excesso foi cuidadosamente removido com auxílio de uma gaze. Ao finalizar os 5 minutos de tratamento, o espécime foi lavado com agua deionizada (protocolo determinado por estudo piloto). Após a aplicação da pasta CPP-ACP os espécimes foram mantidos em umidade relativa por 30min (segundo instruções do fabricante).

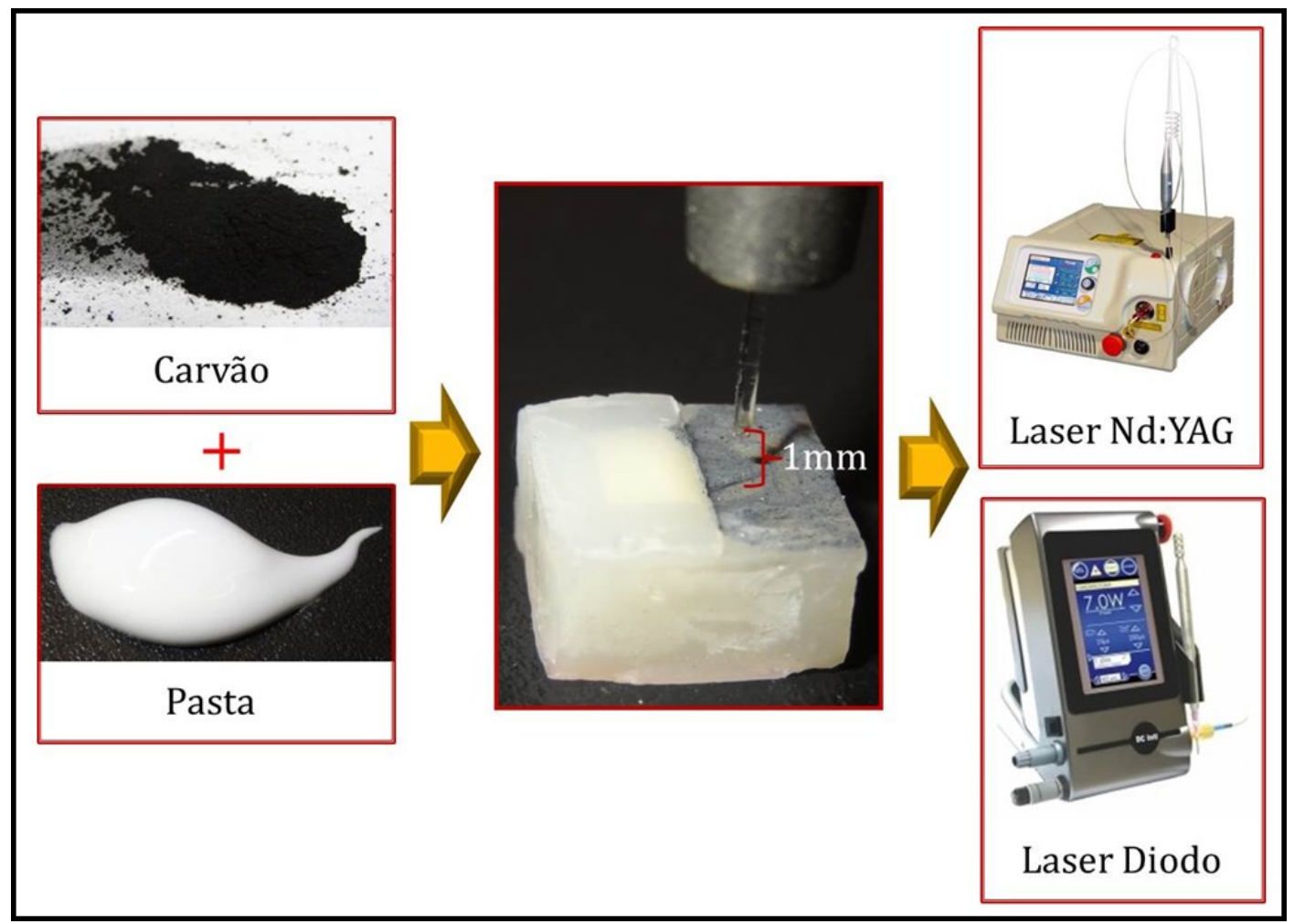

Figura 7. Aplicação das pastas CPP-ACP e experimental (Caseína) associada ao laser Nd:YAG ou Diodo. 


\section{Degradação da dentina}

Os espécimes foram individualmente armazenados em $5 \mathrm{ml}$ de saliva artificial (Amaechi et al., 1999) a $37{ }^{\circ} \mathrm{C}$ por 2 horas e depois cada grupo foi exposto à erosão associada ou não à abrasão:

\section{* Erosão:}

\section{- HCl líquido}

Para a erosão da dentina através do ácido clorídrico ( $\mathrm{HCl}$ ) líquido os espécimes foram individualmente expostos em $5 \mathrm{ml}$ de solução de ácido clorídrico (pH 1,2, 0,1 Molar, concentração de 0,3\%) a $37^{\circ} \mathrm{C}$ por 20 segundos sob agitação de 40 rpm em mesa agitadora (Orbital CT-155, Cientec Equipamentos, São Paulo, Brasil). A exposição ao $\mathrm{HCl}$ foi realizada 6 vezes ao dia, durante 5 dias, sendo trocada a solução de $\mathrm{HCl}$ em cada exposição (Figura 8). Entre cada exposição ao ácido os espécimes foram lavados com água deionizada e individualmente armazenados em $5 \mathrm{ml}$ de saliva artificial (Amaechi et al., 1999) a $37^{\circ} \mathrm{C}$ pelo intervalo de 1 hora entre cada exposição e de um dia a outro ao final de cada ciclo de degradação, sendo a saliva artificial trocada diariamente.

\section{- Gás de HCl}

Para a erosão da dentina com o gás de ácido clorídrico $(\mathrm{HCl})$, os espécimes foram expostos ao gás de $\mathrm{HCl}(\mathrm{pH} 1,2)$ a $37^{\circ} \mathrm{C}$ por $20 \mathrm{~s}$ a 1 ATM pressão atmosférica. A exposição foi realizada 6 vezes ao dia, durante 5 dias. Para a exposição ao gás de $\mathrm{HCl}$ foi utilizado um dispositivo que permitiu manter o gás de HCl. Para produzir o gás, foi aquecido $500 \mathrm{ml}$ de solução de $\mathrm{HCl}$ com concentração de 15,84\% (Derceli, 2014). A solução foi aquecida e o pH foi controlado com auxílio de uma fita de papel indicador pH Acilit® (Merck, KGaA, Darmstadt, Alemanha). A solução de $\mathrm{HCl}$ foi trocada diariamente para garantir as condições ideais do gás. Após exposição ao ácido os espécimes foram lavados com água 
deionizada e armazenados individualmente em $5 \mathrm{ml}$ saliva artificial (Amaechi et al., 1999) a $37^{\circ} \mathrm{C}$ pelo intervalo de 1 hora entre cada exposição e de um dia a outro ao final de cada ciclo de degradação, sendo a saliva trocada diariamente.

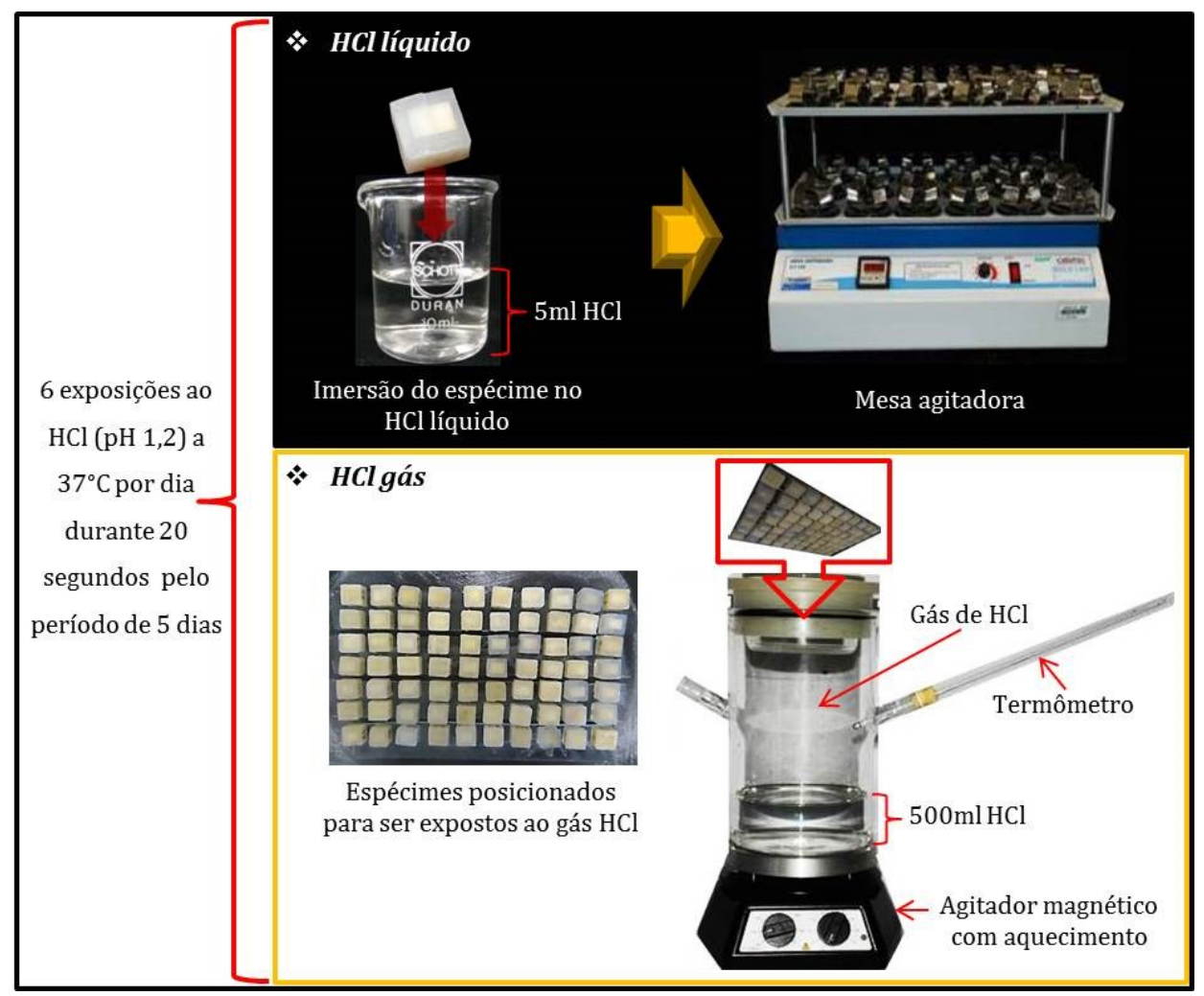

Figura 8. Erosão da dentina com $\mathrm{HCl}$.

\section{Erosão associada à abrasão:}

A abrasão foi realizada com escovas elétricas (Oral-B, São Paulo, Brasil) de cabeça pequena e cerdas macias, as quais simulam a técnica rotacional de escovação. As escovas foram colocadas em um dispositivo para padronizar a posição e altura da escova no fragmento. Após posicionar os espécimes perpendicularmente às cerdas da escova dental, foi colocado 0,5 ml de gel dental (Sanifill, fase 2, São Paulo, Brasil) (sem flúor e com sílica abrasiva) para cada espécime entre o fragmento e a escova dental (previamente umedecida com água deionizada). Durante a escovação foi aplicada uma força de 200 gf com peso colocado na cabeça da escova (Figura 9). Foram realizadas 2 escovações por dia, durante 10 segundos, sendo escovados os espécimes a cada 3 exposições ao ácido $\mathrm{HCl}$. Após escovação os espécimes foram lavados com água 
deionizada e armazenados individualmente em $5 \mathrm{ml}$ de saliva artificial (Amaechi et al., 1999) a $37^{\circ} \mathrm{C}$ pelo intervalo de 1 hora após a primeira escovação e de uma dia a outro após a segunda escovação, sendo a saliva trocada diariamente.

A escovação foi realizada entre a $3^{\circ}$ e $4^{\circ}$ exposição ao $\mathrm{HCl}$, com intervalo de 1 hora entre os desafios e após a $6^{\circ}$ exposição ao HCl. Para os grupos sem escovação foi esperado duas horas entre a $3^{\circ}$ e $4^{\circ}$ exposição ao $\mathrm{HCl}$ para manter o mesmo tempo de intervalo.

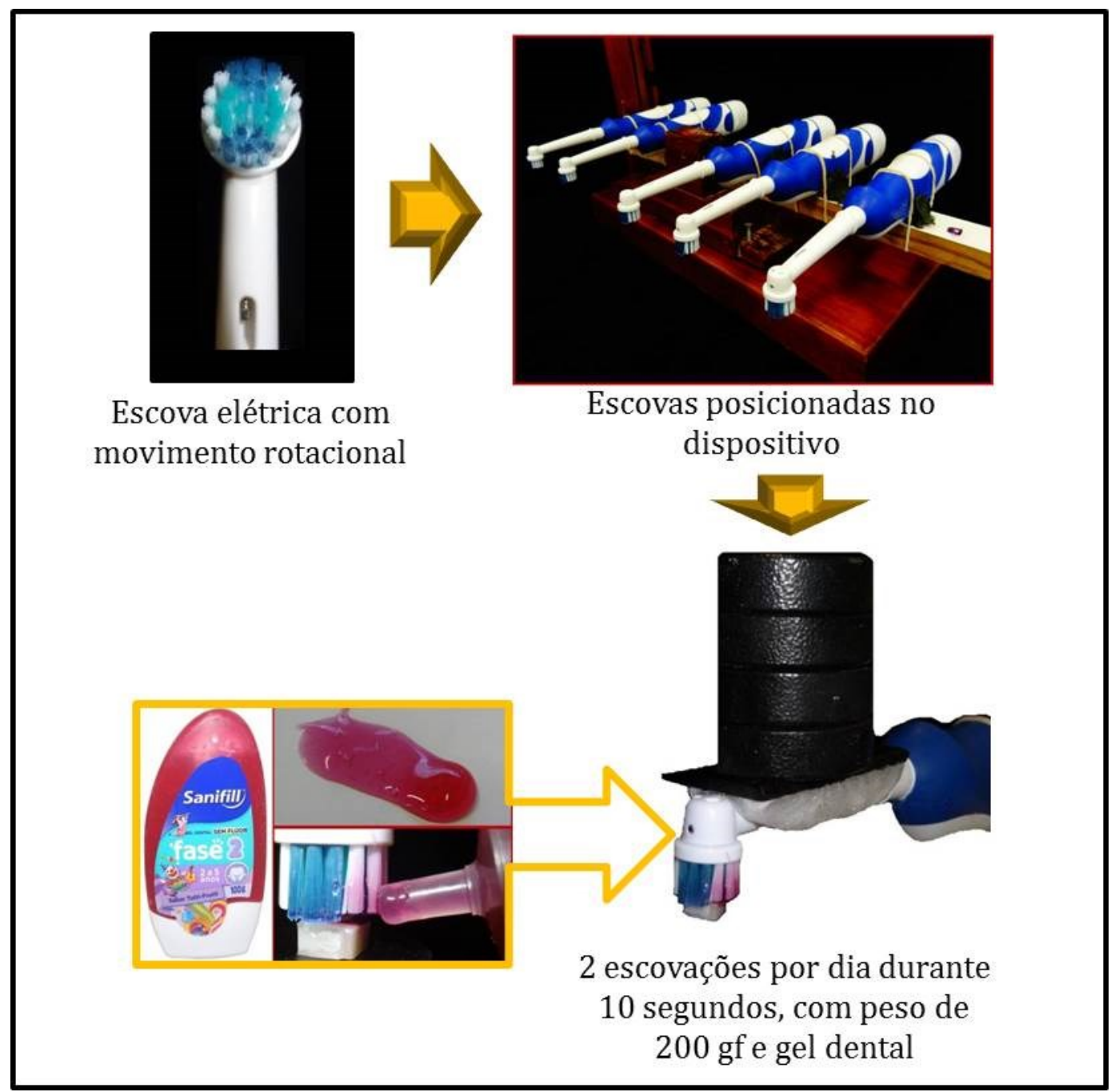

Figura 9. Metodologia de abrasão realizada no estudo.

Para realizar as análises, a resina composta sobre a dentina hígida (referência) foi removida delicadamente. Depois, foi realizada a limpeza dos espécimes com ultra-som (UltrasonicCleaner T - 1449 - D, Odontobrás Indústria e Comércio, Ribeirão Preto - SP, Brasil) por 5 minutos, e então os espécimes foram lavados com água deionizada. 
Posteriormente os fragmentos foram posicionados na mesa do microscópio confocal a laser 3D (LEXT OLS4000, Olympus, Tokyo, Japão) e foram capturadas imagens através do laser semicondutor $(\lambda=405 \mathrm{~nm})$ do microscópio. As imagens foram analisadas por meio do software OLS 4000 (Figura 10).

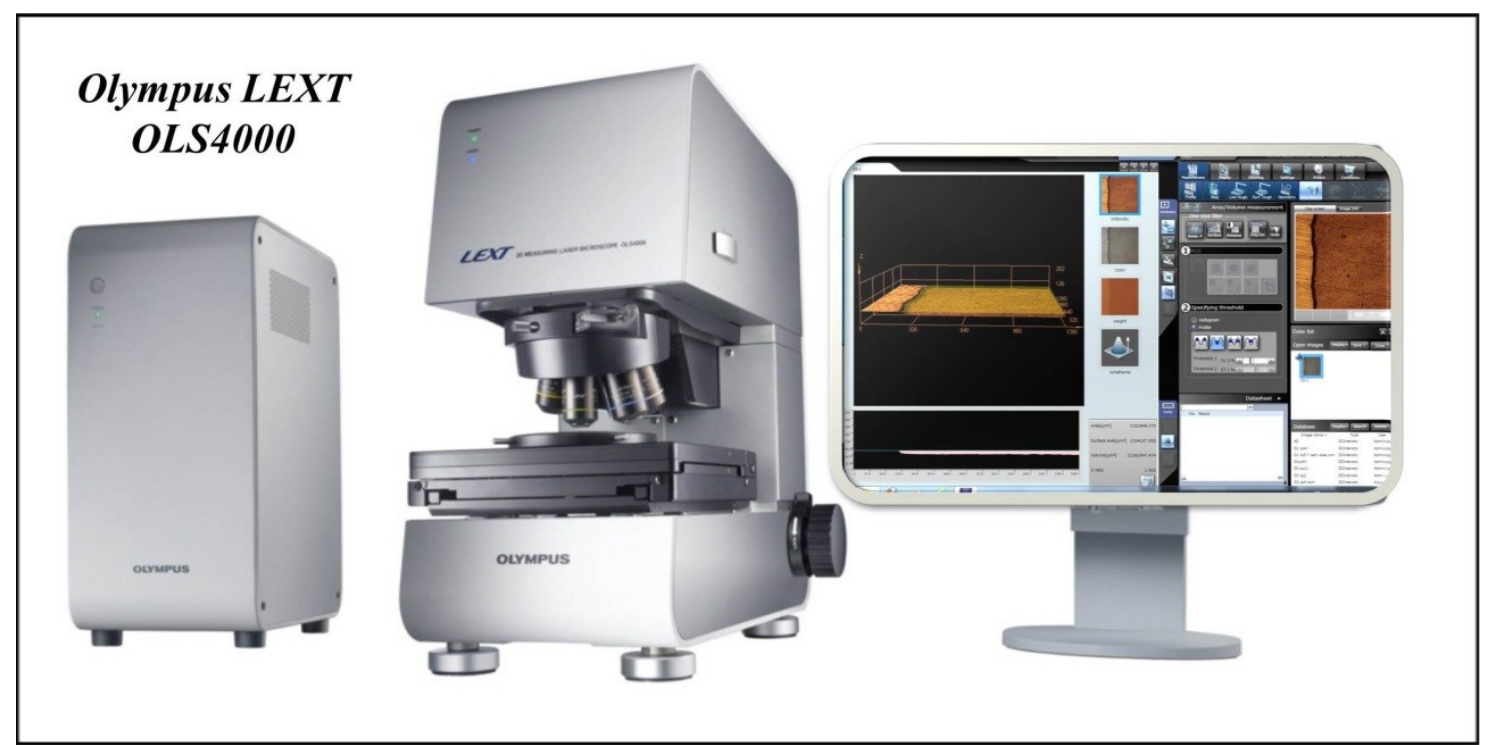

Figura 10. Microscopio confocal a laser 3D e análise da imagem.

\section{- Volume, degrau e perfil de desgaste}

Para estas análises foi utilizada uma imagem de 216x de aumento por espécime, a qual foi obtida da em uma região central padronizada. A imagem abrangeu a dentina hígida (referência) e dentina degradada (com tratamento superficial e exposta ao $\mathrm{HCl}$ com ou sem abrasão)(Figura 11).

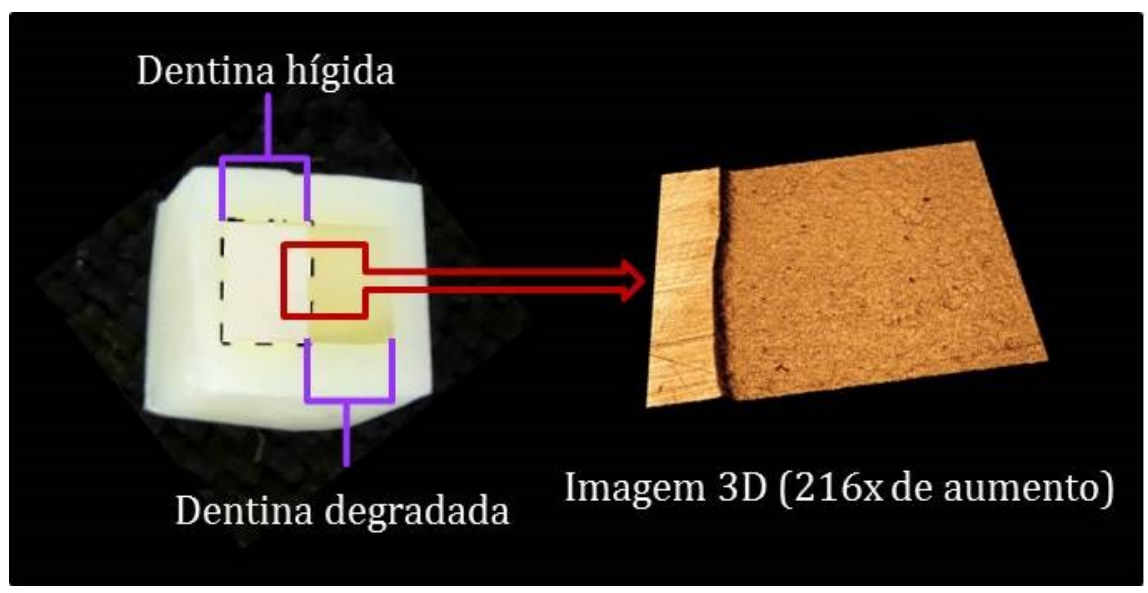

Figura 11. Imagem para análise de volume, degrau e perfil de desgaste. 
O volume perdido foi analisado para determinar quanto de tecido mineralizado foi perdido durante os processos erosivos ou erosivos/abrasivos. Para realização da medição do volume perdido traçou-se um plano baseado na área de referencia e toda a estrutura perdida abaixo desse plano foi calculada em $\mu \mathrm{m}^{3}$. Contudo, apesar de padronizar todas as medidas, existem variações de dimensões da área protegida englobada na imagem e então para manter a mesma proporção para todos os espécimes empregou-se a razão do volume de estrutura perdida $\left(\mu \mathrm{m}^{3}\right)$ pela área $\left(\mu \mathrm{m}^{2}\right)$ da dentina degradada (Figura 12), para empregar na análise dos dados.

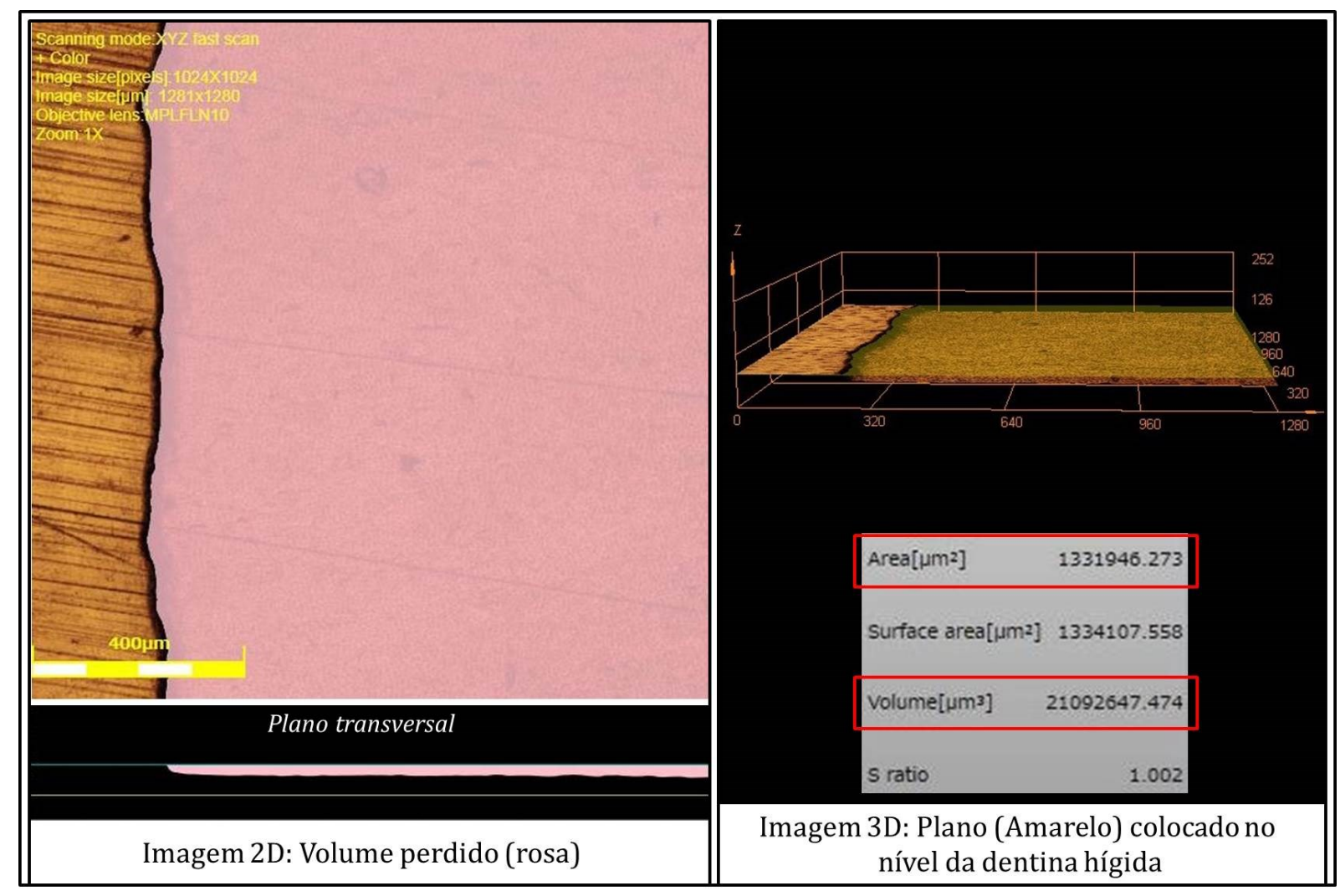

Imagem 12. Análise do volume.

Para a análise do degrau se realizou a medição da altura $(\mu \mathrm{m})$ do degrau, tendo como referência a área controle. Essa mensuração teve objetivo de determinar o degrau formado pelo substrato dentinário e como informação complementar do volume perdido. Para isso traçou-se uma reta que abrangeu a dentina hígida e a dentina degradada (com tratamento superficial e exposta ao $\mathrm{HCl}$ com ou sem abrasão), o 
tamanho da reta foi padronizado e em cada imagem foram realizadas 10 leituras (Figura 13) e então, empregou-se a média delas para analise dos dados.

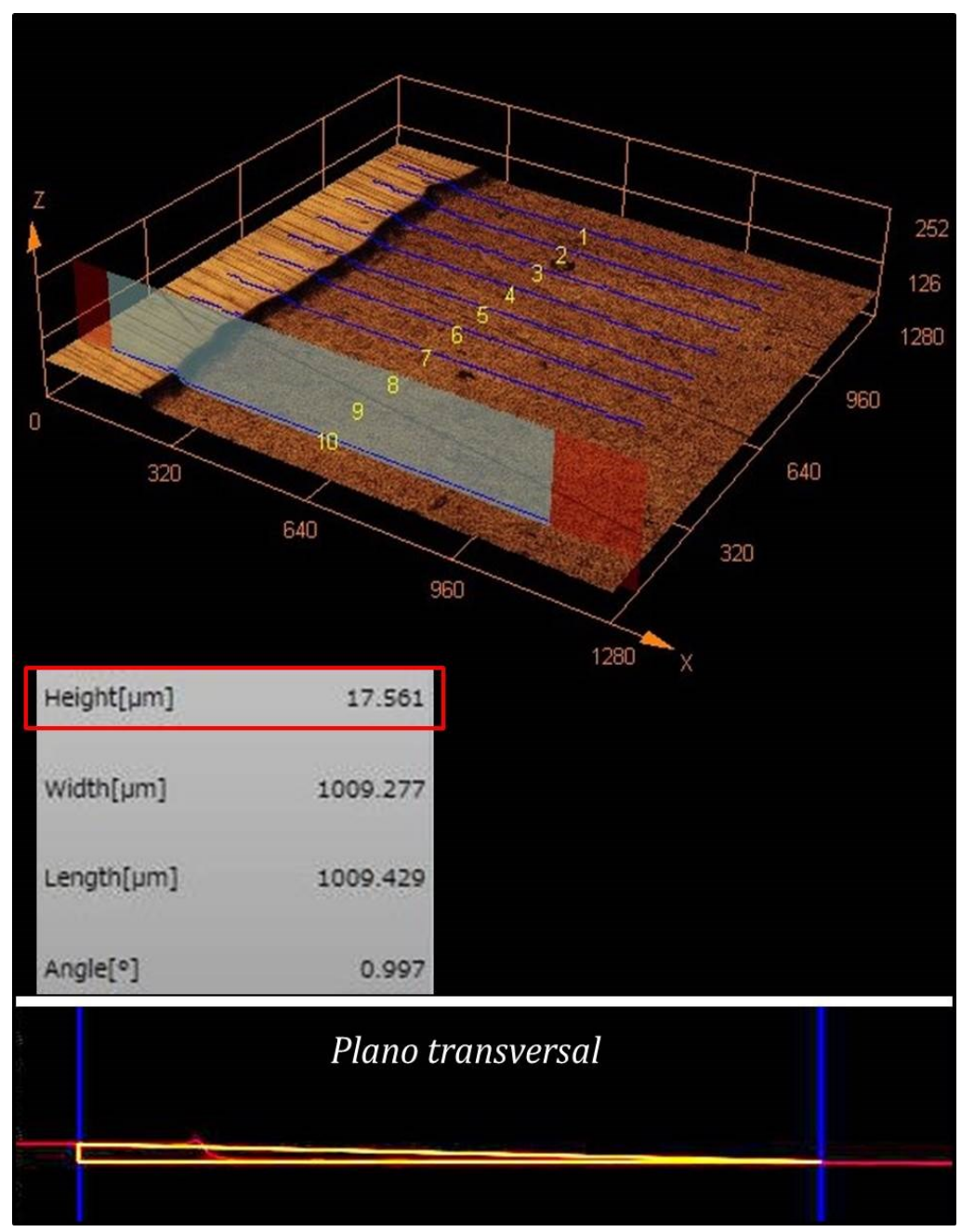

Figura 13. Imagem 3D para a medição do degrau através de reta (azul).

A perfilometria foi empregada para verificar o padrão de desgaste em relação a área controle. A medição do padrão $\mathrm{Rv}(\mu \mathrm{m})$ foi realizada através de uma reta que abrangeu a dentina hígida e a dentina degradada (com tratamento superficial e exposta ao $\mathrm{HCl}$ com ou sem abrasão). Em cada imagem foram realizadas 10 leituras do $\mathrm{Rv}$ (Figura 14). 


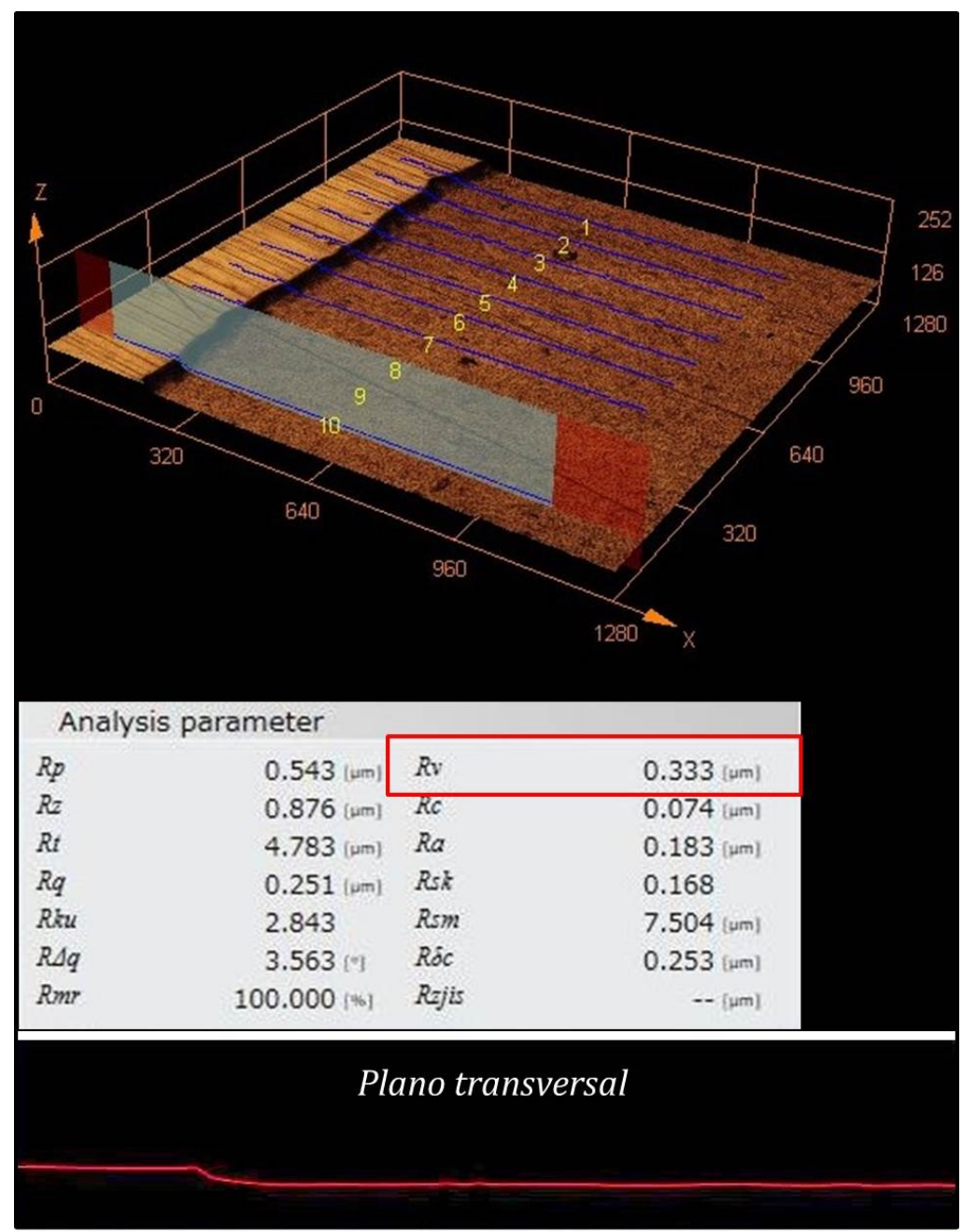

Figura 14. Imagem 3D para a medição da perfilometria.

Realizou a analise da rugosidade foi determinada para verificar se os tratamentos promoveram distintos padrões de texturas na superfície, para tanto realizou a leitura da rugosidade de ambas as áreas (referência e experimental). Para a avaliação da rugosidade foi baseada na diferença da rugosidade da dentina hígida (referência) e da dentina degradada (com tratamento superficial e exposta ao $\mathrm{HCl}$ com ou sem abrasão). Para esta análise foi obtida imagem com 216x de aumento em uma região central padronizada, na dentina hígida (referência) e na dentina degradada (com tratamento superficial e exposta ao $\mathrm{HCl}$ com ou sem abrasão). Em cada imagem foi calculada a rugosidade de superficial Sa $(\mu \mathrm{m})$ (Figura 15). 


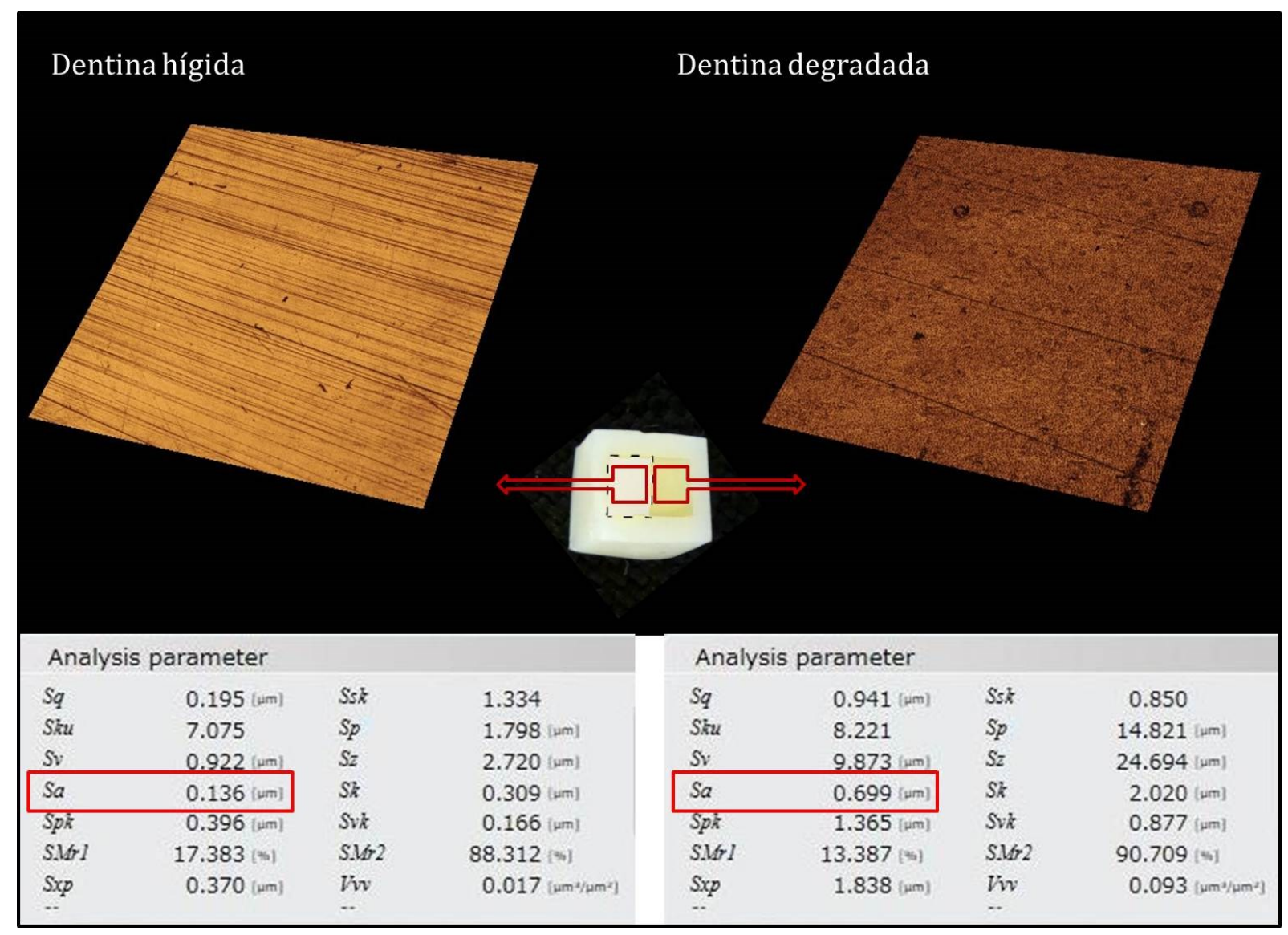

Figura 15. Imagem 3D para análise da rugosidade.

\section{- $\quad$ Número de túbulos, área e perímetro do lúmen dos túbulos}

Foi analisada a numero de túbulos para determinar se o tratamento promoveu a obliteração dos túbulos e que poderiam influenciar na ação dos ácidos. 0 perímetro e a área foram avaliados para que determinar se a ação dos ácidos na ampliação das embocaduras dos túbulos foi afetada pelos agentes empregados. As análises foram baseadas na diferença do número, área e perímetro do lúmen dos túbulos da dentina degradada inicialmente e a dentina degradada com posterior tratamento superficial e exposta ao $\mathrm{HCl}$ com ou sem abrasão. Para isso foram obtidas duas imagens de 1290x de aumento em uma região central padronizada, na dentina exposta à degradação inicial e na dentina após tratamento superficial e ciclos de degradação. Por meio do software OLS 4000 foram localizados os túbulos em cada imagem e uma vez localizados os túbulos o software calculou o número de túbulos, área $\left(\mu \mathrm{m}^{2}\right)$ e perímetro $(\mu \mathrm{m})$ do lúmen dos 
túbulos (Figura 16). Para análise dos dados realizou-se o percentual da cada medida, pela seguinte formula: $\% \mathrm{E}=($ valor final $* 100) /$ valor inicial.

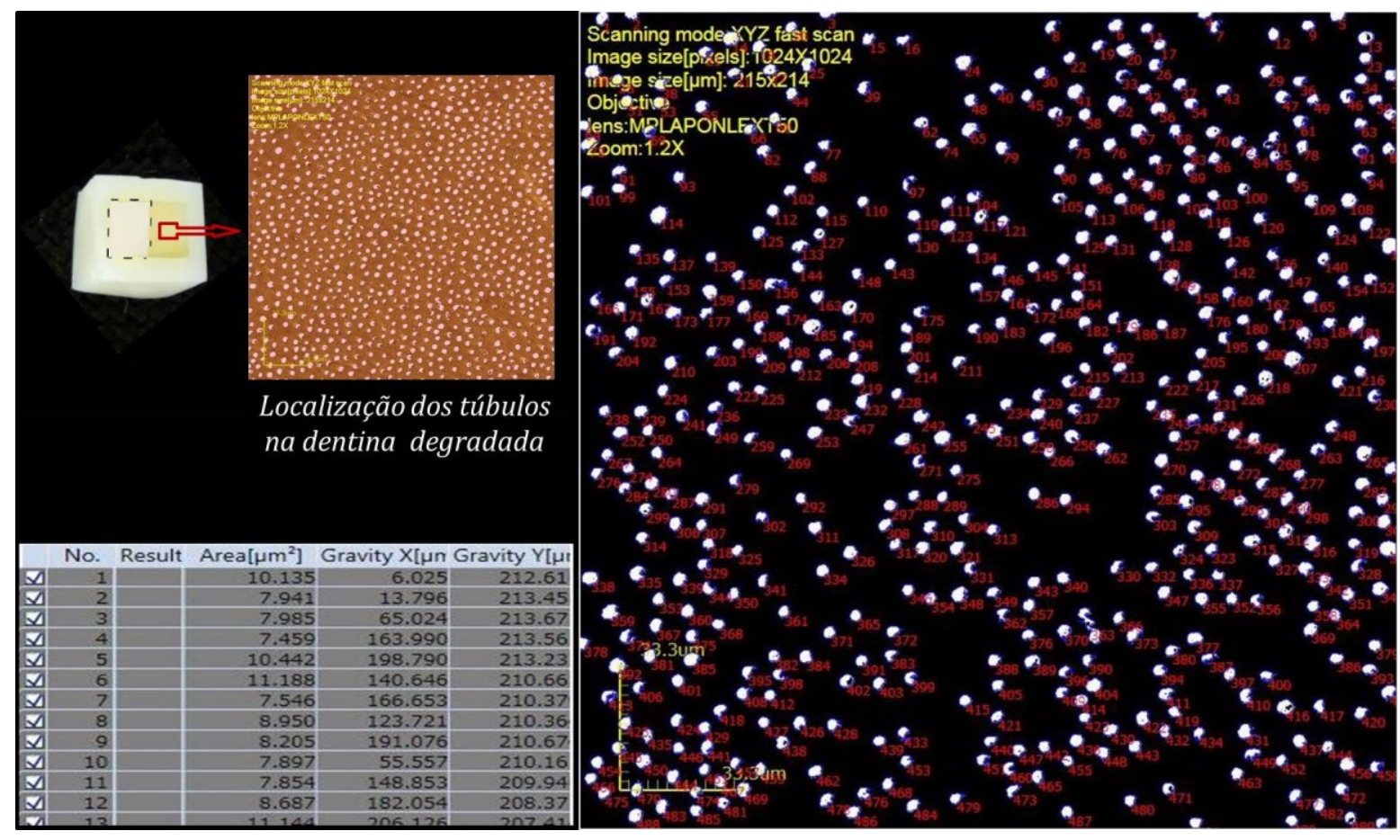

Figura 16. Imagem 2D da análise dos túbulos

\section{- $\quad$ Alterações químicas}

Para a análise química foi utilizado o espectrômetro de infravermelho por transformada de Fourier (Nicolet 380, Thermo Electron Corporation, Massachusetts, USA) o qual permitiu realizar as análises químicas com relação à AmidaIII/ $/ \mathrm{PO}_{4}$ e $\mathrm{CO}_{3} / \mathrm{PO}_{4}$ (Figura 17). A razão da porção orgânica e inorgânica permite avaliar como os tratamentos afetaram as estruturas do substrato dentinário. Sendo que a amida III representa a parte orgânica e o carbonato é a parte inorgânica, em que a diminuição da razão significa tecido mais mineralizado e aumento determina um tecido mais desminerzalido. Neste espectrômetro foi empregado um acessório de reflexão totalmente atenuada Start DuraScope (Thermo Electron Corporation, Massachusetts, USA) o qual está equipado com um cristal de diamante e permite realizar espectros de absorção na faixa espectral entre $4000-700 \mathrm{~cm}^{-1}$. A área da banda de cada composto 
químico foi delimitada, o fundo foi subtraído e a área sob cada banda foi integrada. Cada área foi normalizada pela banda de fosfato (1190- 702 centímetros (-1)).

Foram preparados 28 espécimes $(3 \times 4 \times 2)$ e isolados da mesma forma previamente mencionada, com a exceção que foi mantida exposta toda a superfície da dentina externa $(3 \times 4 \mathrm{~mm})$. Os espécimes foram polidos com disco feltro e suspensão de alumina 0,3 e 0,05 $\mu \mathrm{m}$ (Arotec S/A Ind. e Comércio, São Paulo, Brasil). Depois foi realizada a limpeza através do ultra-som (Ultrasonic Cleaner T - 1449 - D, Odontobrás Indústria e Comércio, Ribeirão Preto - SP, Brasil) em 2 ciclos de 5 minutos, sendo os espécimes lavados em água deionizada entre os dois ciclos.

Posteriormente os espécimes foram levados ao espectrômetro de infravermelho por transformada de Fourier (Nicolet 380, Thermo Electron Corporation, Massachusetts, USA) para realizar as análises químicas. Depois os espécimes foram armazenados em saliva artificial (Amaechi, et al., 1999) por 2 horas a $37^{\circ} \mathrm{C}$ e a continuação foi realizada a degradação inicial da mesma forma previamente mencionada. Ao finalizar o ciclo de degradação inicial, os espécimes foram armazenados em saliva artificial (Amaechi, et al., 1999) por 12 horas a $37^{\circ} \mathrm{C}$, sendo posteriormente levados ao espectrômetro de infravermelho por transformada de Fourier (Nicolet 380, Thermo Electron Corporation, Massachusetts, USA) para as análises químicas. Posteriormente foram aleatoriamente divididos segundo os tratamentos superficiais $(n=4)$ :

\footnotetext{
$\checkmark$ Ausência de tratamento - controle.

$\checkmark$ Pasta CPP-ACP.

$\checkmark$ Pasta CPP-ACP + laser Nd:YAG.

$\checkmark$ Pasta CPP-ACP + laser Diodo.

$\checkmark$ Pasta experimental (caseína).

$\checkmark$ Pasta experimental (caseína) + laser Nd:YAG.

$\checkmark$ Pasta experimental (caseína) + laser Diodo.
}

Após os tratamentos superficiais foram realizadas as análises químicas no espectrômetro de infravermelho por transformada de Fourier (Nicolet 380, Thermo Electron Corporation, Massachusetts, USA). 
Os dados das análises químicas realizadas foram comparados e foi obtida a evolução quantidade de ions dos espécimes previamente à degradação até depois dos tratamentos superficiais na dentina degradada.

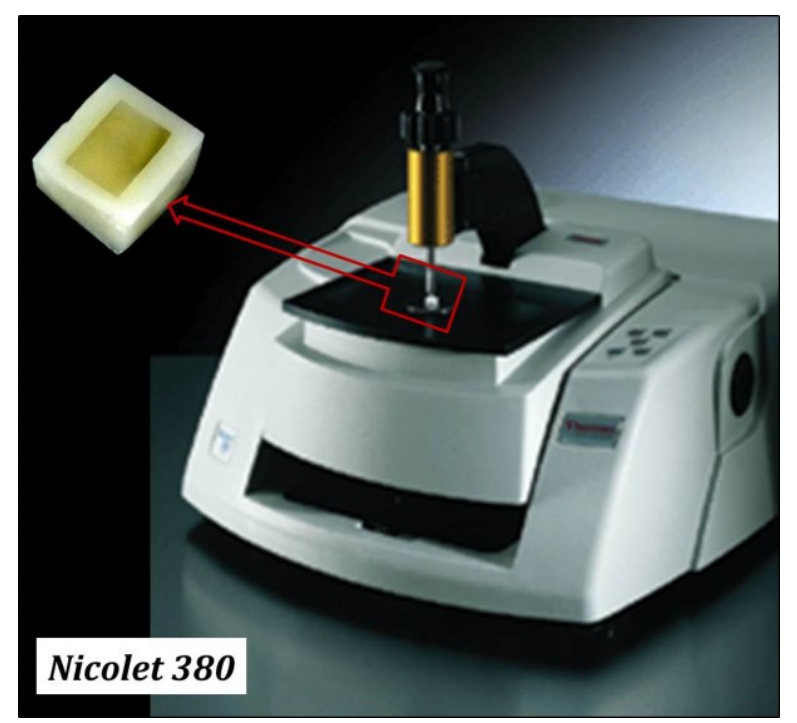

Figura 17. FTIR para análises químicas com relação à AmidaIII/ $\mathrm{PO}_{4} \mathrm{e} \mathrm{CO}_{3} / \mathrm{PO}_{4}$

\section{- $\quad$ Alterações morfológicas}

Esta análise foi realizada por meio da microscopia eletrônica de varredura (MEV) (Philips XL30 FEG, Eindhoven, Holanda). Foram preparados 21 espécimes $(3 \times 4 \times 2)$ e isolados da mesma forma previamente mencionada, com a exceção que foi mantida exposta toda a superfície da dentina externa $(3 \times 4 \mathrm{~mm})$.

Depois os espécimes foram armazenados em saliva artificial (Amaechi, et al., 1999) por 2 horas a $37^{\circ} \mathrm{C}$ e a continuação foi realizada a degradação inicial na mesma forma previamente mencionada. Ao finalizar o ciclo de degradação inicial os espécimes foram armazenados em saliva artificial (Amaechi, et al., 1999) por 12 horas a $37^{\circ} \mathrm{C}$. Posteriormente foram aleatoriamente divididos segundo os tratamentos superficiais $(n=3)$ propostos.

Após os tratamentos superficiais, os espécimes foram preparados para a análise da MEV. As amostras foram imersas em solução de glutaraldeido a 2,5\% tamponado com solução de cacodilato de sódio por 12 horas a 0,1M com pH 7,4 (Merck KGaA, Darmstadt, 
D-64293, Alemanha) em temperatura de 4ํㅡ, seguido de lavagem com água deionizada, por 1 hora. Desidratação dos espécimes foi realizada com diferentes concentrações de etanol (Labsynth Ltda., Diadema, SP, Brasil) por um período pré-determinado (25\% por 20 minutos, $50 \%$ por 20 minutos, $75 \%$ por 20 minutos, $90 \%$ por 30 minutos e $100 \%$ por 1hora). Para fixar e estabilizar a estrutura orgânica os espécimes foram imersos em solução de HMDS (Merck KGaA, Darmstadt, D-64293, Alemanha) por 10 minutos. Após o preparo as amostras foram secas com papel absorvente, fixados em stubs através de fita adesiva de carbono dupla-face (Electron Microscopy Sciences, Washington, EUA) e então realizada a cobertura com ouro em aparelho de metalização a vácuo (SDC 050, Bal-Tec AG, FL9496, Balzers, Liechtenstein)

Os espécimes foram levados ao microscópio eletrônico de varredura (Philips XL30 FEG, Eindhoven, Holanda) pertencente ao Laboratório Multi-Usuários do Departamento de Engenharia de Materiais da Universidade Federal de São Carlos (Figura 18). Foi realizada a varredura de toda a superfície do espécime e, em seguida, foi fotografada a área mais representativa de cada grupo em diferentes aumentos (2000x, 10000x e 30000x).

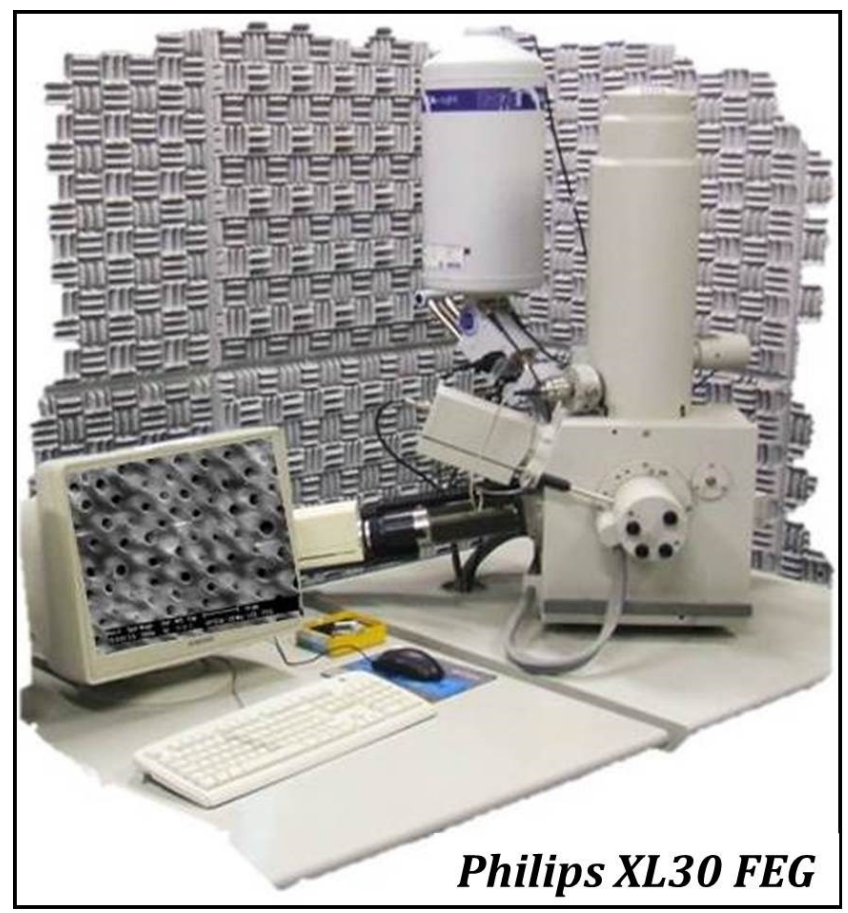

Figura 18. MEV para análise de morfologia dentinária 


\section{Análise dos dados}

Para a análise dos dados obtidos foi utilizado o software SigmaStat (Windows version 3.5, Systat Software Inc.). A distribuição dos dados foi normal e homogênea, sendo submetidos à análise de variância (ANOVA) a dois critérios e teste de Tukey $(\mathrm{p}<0,05)$. Os dados do FTIR foram avaliados de forma descritiva e as imagens de MEV foram avaliadas qualitativamente. 


\section{Resultados}




\section{Resultados}

\section{Perda de volume}

Na análise dos dados da perda de volume pode-se observar que no fator erosão ocorreu diferença estatisticamente significante entre os grupos $(p<0,05)$, sendo o G2 apresentado a maior perda de volume estatisticamente significante $(\mathrm{p}<0,05)$, seguido do G1. Por sua vez, os grupos G3 e G4 tiveram os menores valores e foram semelhantes entre si $(p>0,05)$ (Figura 19). No fator tratamento superficial, observou-se que o $\mathrm{SgD}$ apresentou o menor valor para a perda de volume, o qual foi semelhante ao SgB e diferente dos outros subgrupos $(\mathrm{p}<0,05)$ (Figura 20).

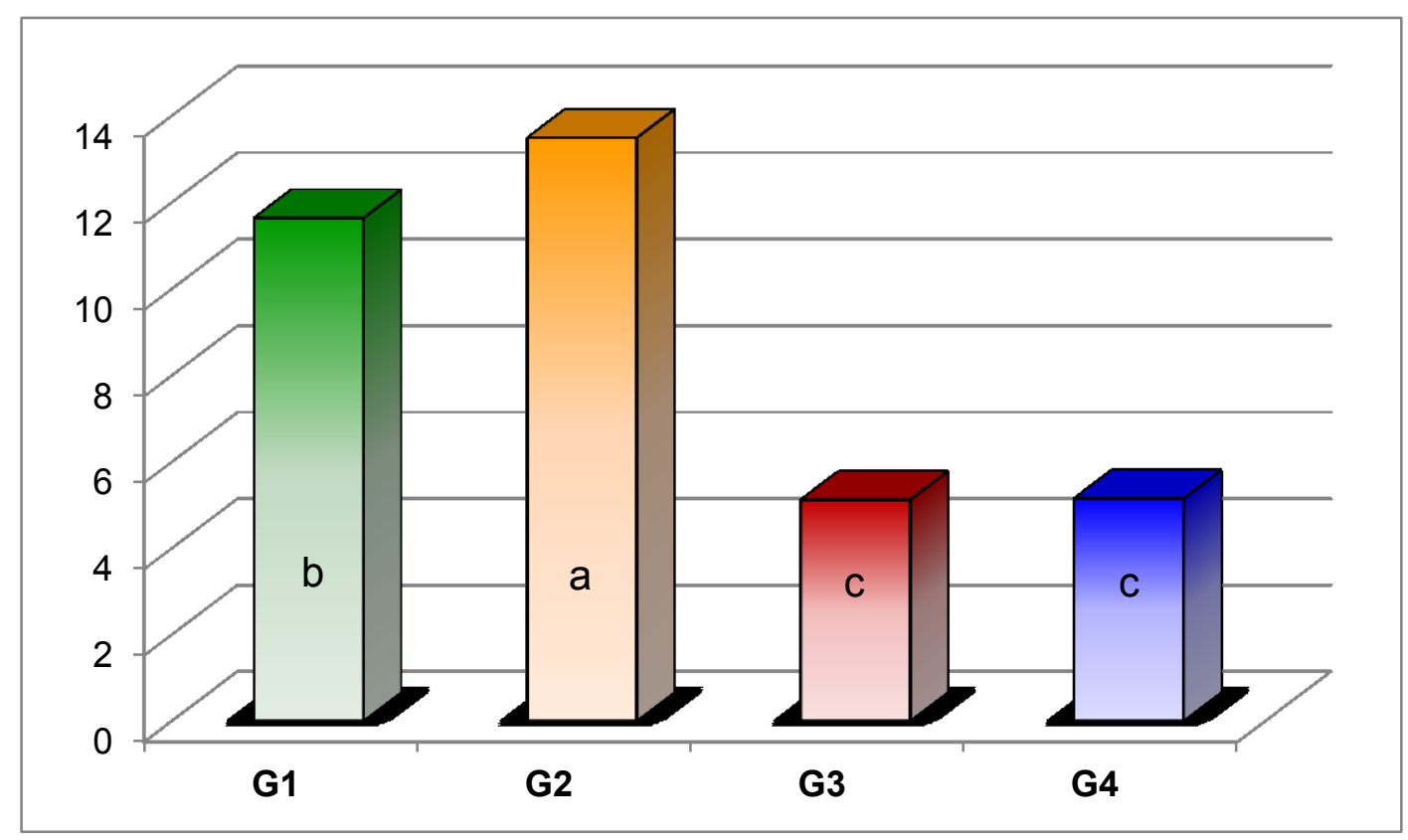

Figura 19. Perda de volume (em $\mu \mathrm{m})$ de acordo com o tipo de erosão (letra diferente indica diferença estatística significante- p<0,05) (G1-HCl líquido; G2-HCl líquido+abrasão; G3-HCl gasoso; G4-HCl gasoso+abrasão). 


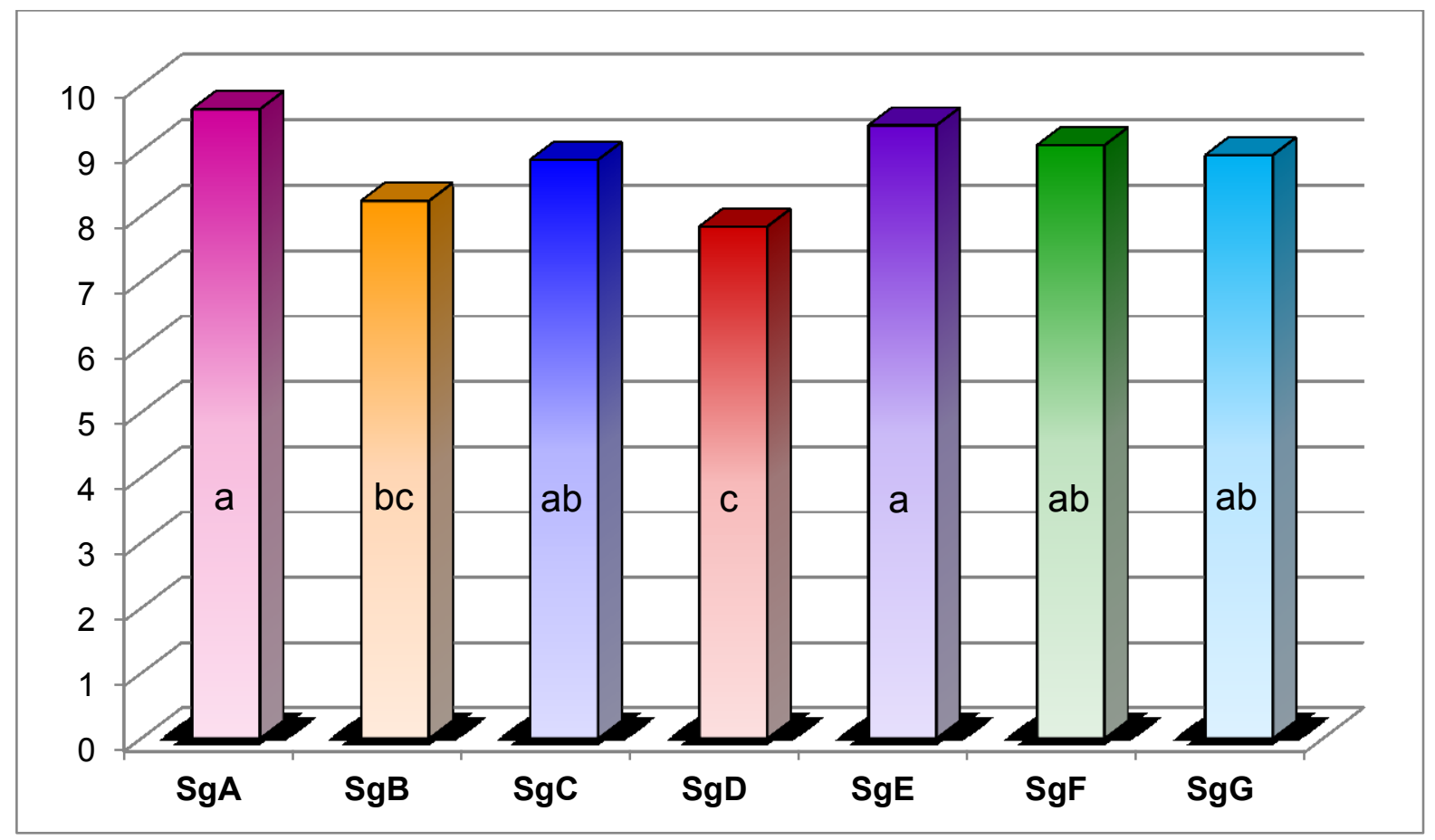

Figura 20. Perda de volume $(\mu \mathrm{m})$ de acordo ao tipo de tratamento superficial (letra diferente indica diferença estatística significante - p<0,05) (SgA - Controle; SgB - CPP-ACP; SgC - CPP-ACP + Nd:YAG; SgD - CPP-ACP + Diodo; SgE - Pasta experimental; SgF - Pasta experimental + Nd:YAG; SgG - Pasta experimental + Diodo).

A interação dos fatores pelo comportamento dos diferentes grupos e subgrupos pode-se observar na Tabela 1. Pode-se observar que os G1 e G2 apresentaram comportamento distinto do G3 e G4, ou seja, nos G1 e no G2, o SgD apresentou os menores valores $(p<0,05)$, e nos G3 e G4 todos os subgrupos foram semelhante entre si $(\mathrm{p}>0,05)$. 
Tabela 1. Média $\left(\mu \mathrm{m}^{3} / \mu \mathrm{m}^{2}\right)$ e desvio padrão dos grupos e subgrupos estudados para análise do volume perdido em razão da área.

\begin{tabular}{|c|c|c|c|c|}
\hline & G1 & G2 & G3 & G4 \\
\hline Sg A & $12,86 \pm 0,63 \mathrm{~A} \mathrm{a}$ & $14,42 \pm 1,24 \mathrm{~A} \mathrm{a}$ & $5,55 \pm 0,92 \mathrm{~A} \mathrm{~b}$ & $5,69 \pm 1,46 \mathrm{~A} \mathrm{~b}$ \\
\hline Sg B & $10,77 \pm 1,66 \mathrm{BC} \mathrm{b}$ & $13,08 \pm 2,03 \mathrm{AB} \mathrm{a}$ & $4,45 \pm 1,69 \mathrm{~A} \mathrm{c}$ & $4,62 \pm 1,65 \mathrm{~A} \mathrm{c}$ \\
\hline Sg C & $11,48 \pm 0,70 \mathrm{ABC} \mathrm{b}$ & $13,62 \pm 1,28 \mathrm{AB} \mathrm{a}$ & $5,35 \pm 1,41 \mathrm{~A} \mathrm{c}$ & $4,98 \pm 1,70 \mathrm{~A} \mathrm{c}$ \\
\hline Sg D & $9,98 \pm 0,89 \mathrm{C} \mathrm{b}$ & $12,41 \pm 1,08 \mathrm{~B} \mathrm{a}$ & $4,46 \pm 2,00 \mathrm{~A} \mathrm{c}$ & $4,49 \pm 1,62 \mathrm{~A} \mathrm{c}$ \\
\hline Sg E & $12,63 \pm 1,86 \mathrm{AB} \mathrm{a}$ & $13,83 \pm 2,03 \mathrm{AB} \mathrm{a}$ & $5,52 \pm 1,41 \mathrm{~A} \mathrm{~b}$ & $5,55 \pm 1,94 \mathrm{~A} \mathrm{~b}$ \\
\hline Sg F & $12,06 \pm 1,08 \mathrm{AB} \mathrm{a}$ & $13,55 \pm 1,81 \mathrm{AB} \mathrm{a}$ & $5,29 \pm 1,50 \mathrm{~A} \mathrm{~b}$ & $5,41 \pm 1,20 \mathrm{~A} \mathrm{~b}$ \\
\hline Sg G & $11,65 \pm 2,07 \mathrm{ABC} \mathrm{b}$ & $13,50 \pm 1,11 \mathrm{AB} \mathrm{a}$ & $5,22 \pm 1,34 \mathrm{~A} \mathrm{c}$ & $5,34 \pm 1,74 \mathrm{~A} \mathrm{c}$ \\
\hline
\end{tabular}

Letra maiúscula comparação em coluna - letra minúscula comparação na linha; mesma letra indica similaridade estatística $(\mathrm{p}>0,05)$.

\section{Degrau}

$\mathrm{Na}$ análise dos dados pode-se observar o padrão do degrau foi similar à análise do volume perdido (Figuras 21 e 22), ou seja, o G2 apresentou o maior degrau e estatisticamente diferente dos outros grupos $(\mathrm{p}<0,05)$, seguido do G1 que também foi diferente $(p<0,05)$ e tendo o G3 e G4 os menores valores e estatisticamente semelhantes entre si $(p>0,05)$. Para o tratamento observou-se que o SgD apresentou o menor degrau semelhante ao SgB e estatisticamente diferente aos demais subgrupos $(p<0,05)$. 


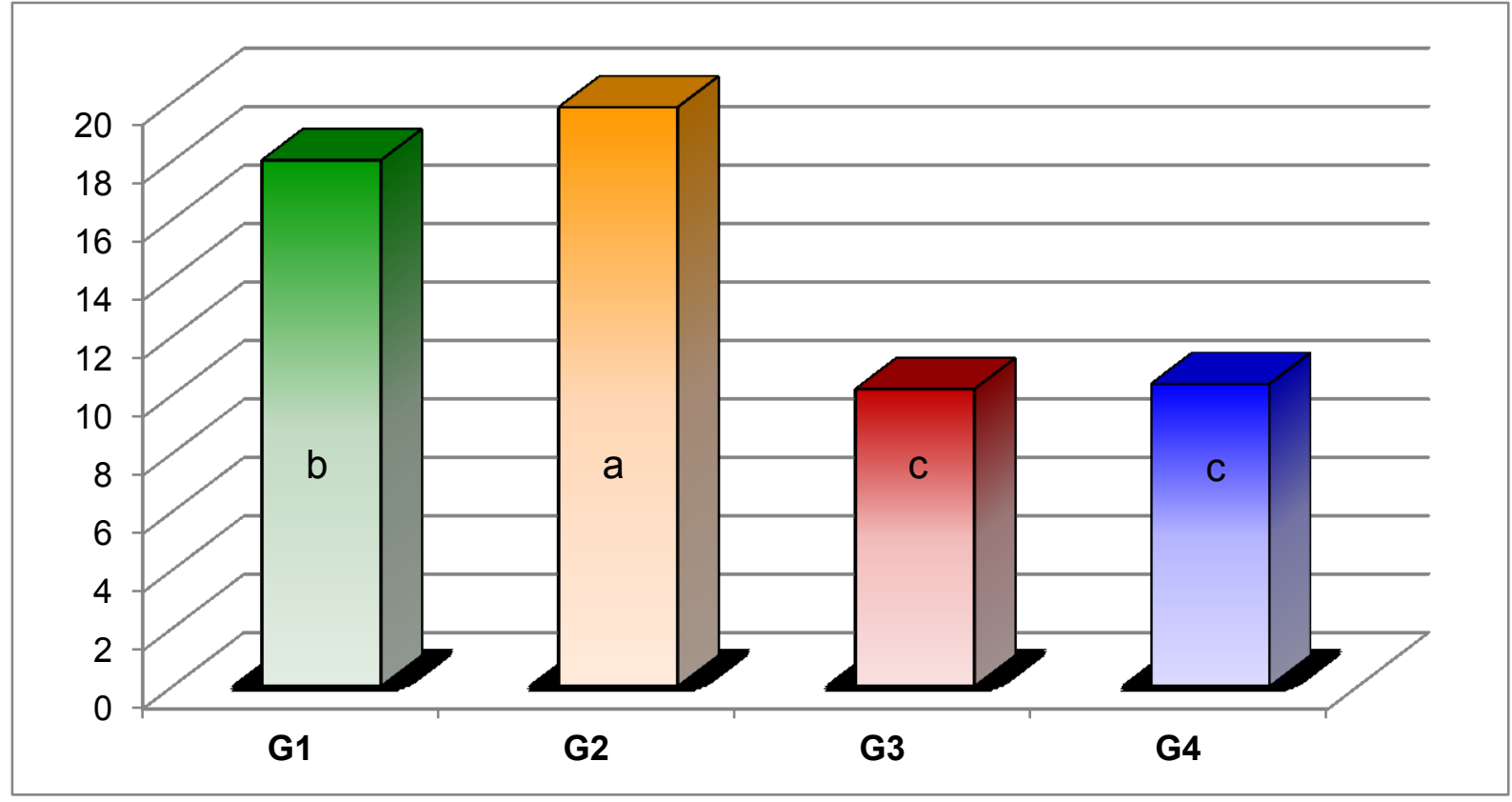

Figura 21. Degrau (em $\mu \mathrm{m}$ ) de acordo ao tipo de erosão (letra diferente indica diferença estatística significante- p<0,05) (G1-HCl líquido; G2-HCl líquido+abrasão; G3-HCl gasoso; G4-HCl (gasoso+abrasão).

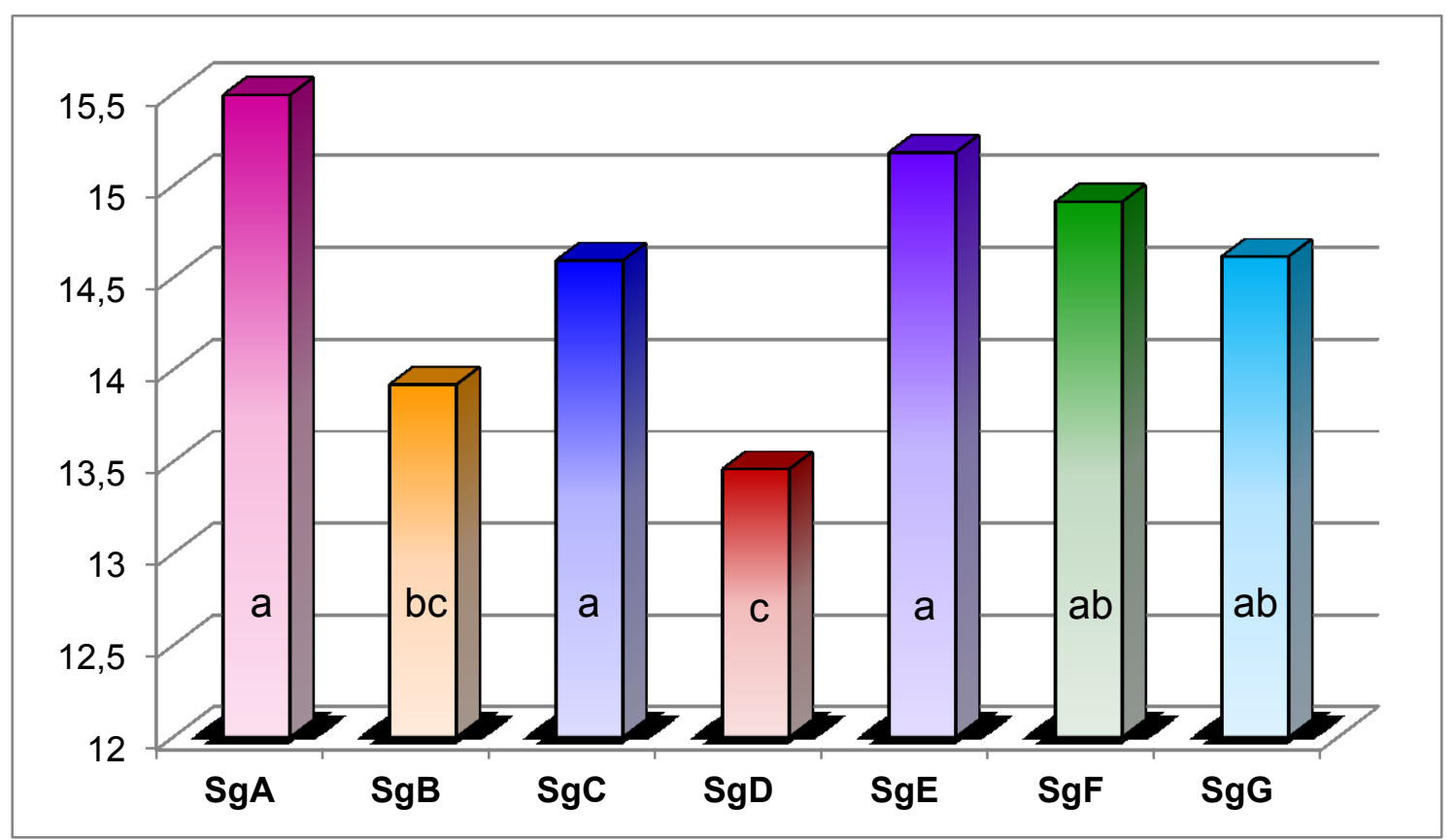

Figura 22. Degrau $(\mathrm{em} \mu \mathrm{m})$ de acordo ao tipo de tratamento superficial realizado (letra diferente indica diferença estatística significante- $\mathrm{p}<0,05)$ (SgA - Controle; SgB - CPP-ACP; SgC CPP-ACP + Nd:YAG; SgD - CPP-ACP + Diodo; SgE - Pasta experimental; SgF - Pasta experimental + Nd:YAG; SgG - Pasta experimental + Diodo). 
A interação dos fatores pelo comportamento dos diferentes grupos e subgrupos pode-se observar na Tabela 2. Pode-se observar que apenas no G1 houve diferença entre os subgrupos em que o SgD apresentou o menor valor e estatisticamente diferente $(\mathrm{p}<0,05)$ dos SgA e SgE.

Tabela 2. Média (em $\mu \mathrm{m}$ ) e desvio padrão dos grupos e subgrupos para análise do degrau.

\begin{tabular}{|c|c|c|c|c|}
\hline & G1 & G2 & G3 & G4 \\
\hline SgA & $19,08 \pm 0,39 \mathrm{~A} \mathrm{a}$ & $20,88 \pm 1,54 \mathrm{~A} \mathrm{a}$ & $10,91 \pm 0,63 \mathrm{~A} \mathrm{~b}$ & $11,09 \pm 1,06 \mathrm{~A} \mathrm{~b}$ \\
\hline $\mathbf{S g B}$ & $17,16 \pm 2,12 \mathrm{AB} \mathrm{b}$ & $19,31 \pm 2,79 \mathrm{~A} \mathrm{a}$ & $9,31 \pm 2,19 \mathrm{~A} \mathrm{c}$ & $9,89 \pm 1,93 \mathrm{~A} \mathrm{c}$ \\
\hline $\mathbf{S g C}$ & $18,03 \pm 0,35 \mathrm{AB}$ a & $19,80 \pm 1,14 \mathrm{~A} \mathrm{a}$ & $10,32 \pm 1,30 \mathrm{~A} \mathrm{~b}$ & $10,23 \pm 2,19 \mathrm{~A} \mathrm{~b}$ \\
\hline SgD & $16,35 \pm 1,43 \mathrm{~B} \mathrm{~b}$ & $18,77 \pm 0,73 \mathrm{~A} \mathrm{a}$ & $9,16 \pm 2,50 \mathrm{~A} \mathrm{c}$ & $9,55 \pm 2,08 \mathrm{~A} \mathrm{c}$ \\
\hline $\mathbf{S g E}$ & $18,89 \pm 2,22 \mathrm{~A} \mathrm{a}$ & $20,46 \pm 2,43 \mathrm{~A} \mathrm{a}$ & $10,61 \pm 1,58 \mathrm{~A} \mathrm{~b}$ & $10,75 \pm 1,89 \mathrm{~A} \mathrm{~b}$ \\
\hline SgF & $18,51 \pm 0,64 \mathrm{AB} \mathrm{a}$ & $19,88 \pm 1,86 \mathrm{~A} \mathrm{a}$ & $10,50 \pm 1,58 \mathrm{~A} \mathrm{~b}$ & $10,74 \pm 0,79 \mathrm{~A} \mathrm{~b}$ \\
\hline SgG & $18,04 \pm 2,05 \mathrm{AB} \mathrm{a}$ & $19,61 \pm 1,34 \mathrm{~A} \mathrm{a}$ & $10,47 \pm 1,49 \mathrm{~A} \mathrm{~b}$ & $10,33 \pm 2,10 \mathrm{~A} \mathrm{~b}$ \\
\hline
\end{tabular}

Letra maiúscula comparação em coluna - letra minúscula comparação na linha; mesma letra indica similaridade estatística $(\mathrm{p}>0,05)$.

\section{Perfilometria}

$\mathrm{Na}$ perfilometria pode-se observar que no fator erosão todos os grupos apresentaram comportamento semelhante entre si (Figura 23). No fator do tratamento superficial observou-se que o SgB e SgD apresentaram os menores valores, os quais foram similares ao SgC, SgF e SgG e diferentes estatisticamente significante do SgA e SgE $(\mathrm{p}<0,05)$ (Figura 24). 


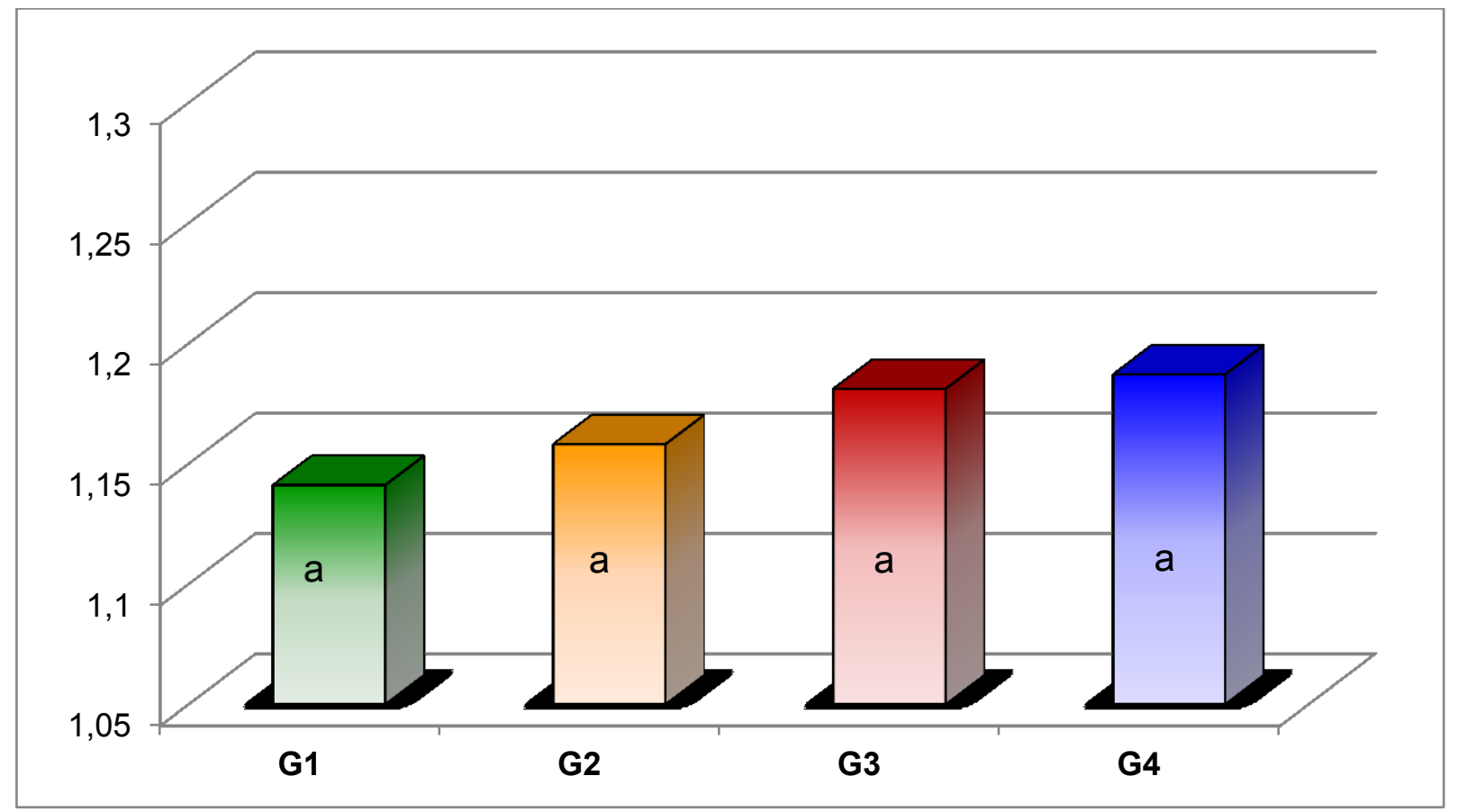

Figura 23. Perfil de desgaste $(\mathrm{em} \mu \mathrm{m})$ em de acordo ao tipo de erosão (letra diferente indica diferença estatística significante- p<0,05) (G1-HCl líquido; G2-HCl líquido+abrasão; G3-HCl gasoso; G4-HCl gasoso+abrasão).

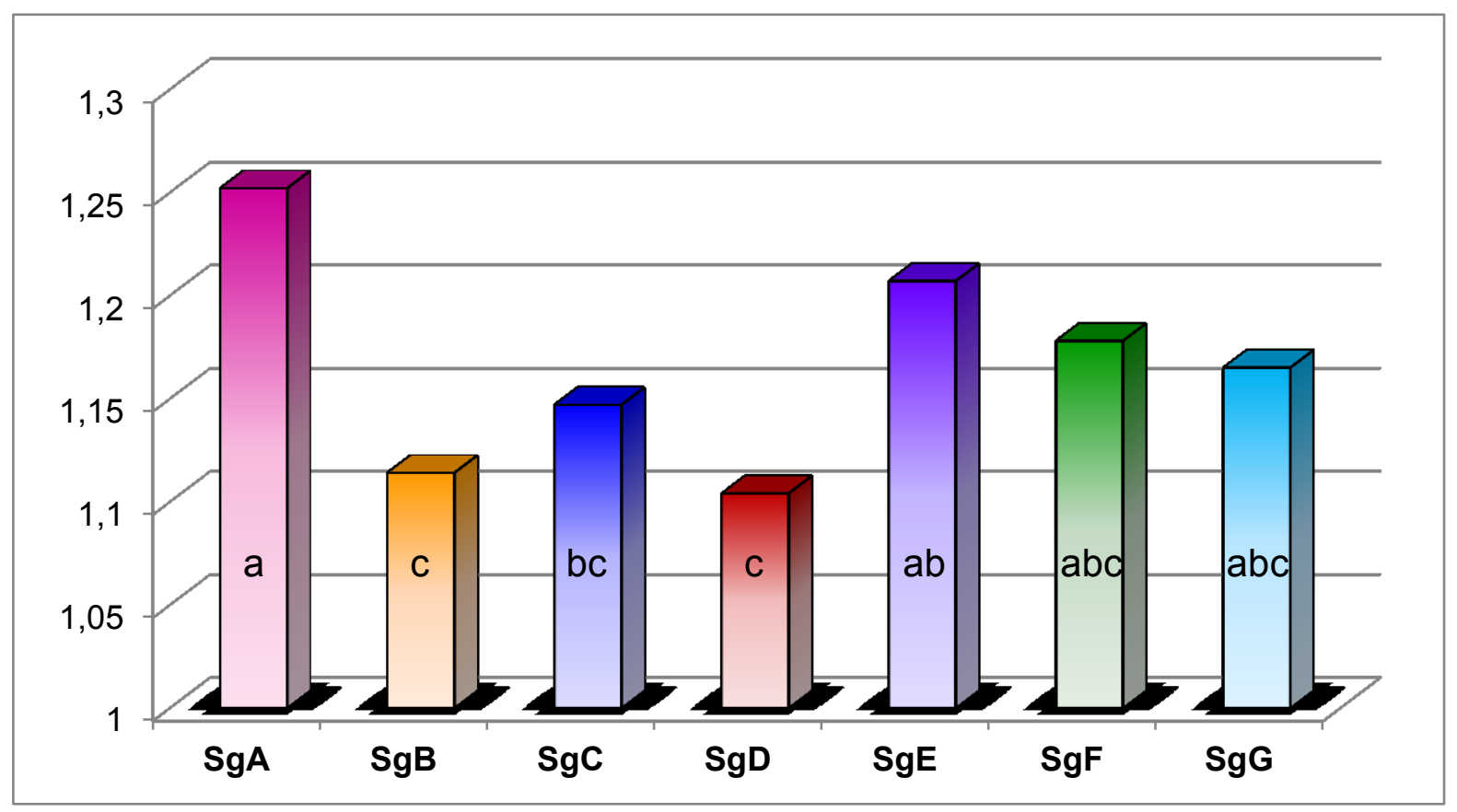

Figura 24. Perfil de desgaste $(\mathrm{em} \mu \mathrm{m})$ de acordo ao tipo de tratamento superficial realizado (letra diferente indica diferença estatística significante- $\mathrm{p}<0,05$ ) (SgA - Controle; SgB - CPP-ACP; SgC - CPP-ACP + Nd:YAG; SgD - CPP-ACP + Diodo; SgE - Pasta experimental; SgF - Pasta experimental + Nd:YAG; SgG - Pasta experimental + Diodo). 
A interação dos fatores pelo comportamento dos diferentes grupos e subgrupos pode-se observar na Tabela 3. Pode-se observar que apenas no G2 houve diferença significante entre os subgrupos, tendo SgD apresentado o menor valor e estatisticamente diferente do SgA $(p<0,05)$.

Tabela 3. Média (em $\mu \mathrm{m}$ ) e desvio padrão dos grupos e subgrupos na análise do perfil de desgaste.

\begin{tabular}{|c|c|c|c|c|}
\hline & G1 & G2 & G3 & G4 \\
\hline SgA & $1,20 \pm 0,17 \mathrm{~A} \mathrm{a}$ & $1,29 \pm 0,10 \mathrm{~A}$ a & $1,26 \pm 0,13 \mathrm{~A} \mathrm{a}$ & $1,26 \pm 0,17 \mathrm{~A} \mathrm{a}$ \\
\hline $\mathbf{S g B}$ & $1,07 \pm 0,08 \mathrm{~A} \mathrm{a}$ & $1,12 \pm 0,08 \mathrm{AB}$ a & $1,13 \pm 0,10 \mathrm{~A} \mathrm{a}$ & $1,14 \pm 0,08 \mathrm{~A} \mathrm{a}$ \\
\hline SgC & $1,14 \pm 0,13 \mathrm{~A} \mathrm{a}$ & $1,16 \pm 0,15 \mathrm{AB}$ a & $1,14 \pm 0,11 \mathrm{~A} \mathrm{a}$ & $1,15 \pm 0,09 \mathrm{~A} \mathrm{a}$ \\
\hline SgD & $1,06 \pm 0,16 \mathrm{~A} \mathrm{a}$ & $1,10 \pm 0,12 \mathrm{~B} \mathrm{a}$ & $1,12 \pm 0,10 \mathrm{~A} \mathrm{a}$ & $1,13 \pm 0,08 \mathrm{~A} \mathrm{a}$ \\
\hline SgE & $1,19 \pm 0,07 \mathrm{~A} \mathrm{a}$ & $1,17 \pm 0,16 \mathrm{AB}$ a & $1,23 \pm 0,14 \mathrm{~A} \mathrm{a}$ & $1,24 \pm 0,12 \mathrm{~A} \mathrm{a}$ \\
\hline SgF & $1,16 \pm 0,12 \mathrm{~A} \mathrm{a}$ & $1,14 \pm 0,24 \mathrm{AB}$ a & $1,20 \pm 0,15 \mathrm{~A} \mathrm{a}$ & $1,21 \pm 0,07 \mathrm{~A} \mathrm{a}$ \\
\hline SgG & $1,16 \pm 0,17 \mathrm{~A} \mathrm{a}$ & $1,13 \pm 0,16 \mathrm{AB}$ a & $1,18 \pm 0,15 \mathrm{~A} \mathrm{a}$ & $1,19 \pm 0,21 \mathrm{~A} \mathrm{a}$ \\
\hline
\end{tabular}

Letra maiúscula comparação em coluna - letra minúscula comparação na linha; mesma letra indica similaridade estatística $(\mathrm{p}>0,05)$. 


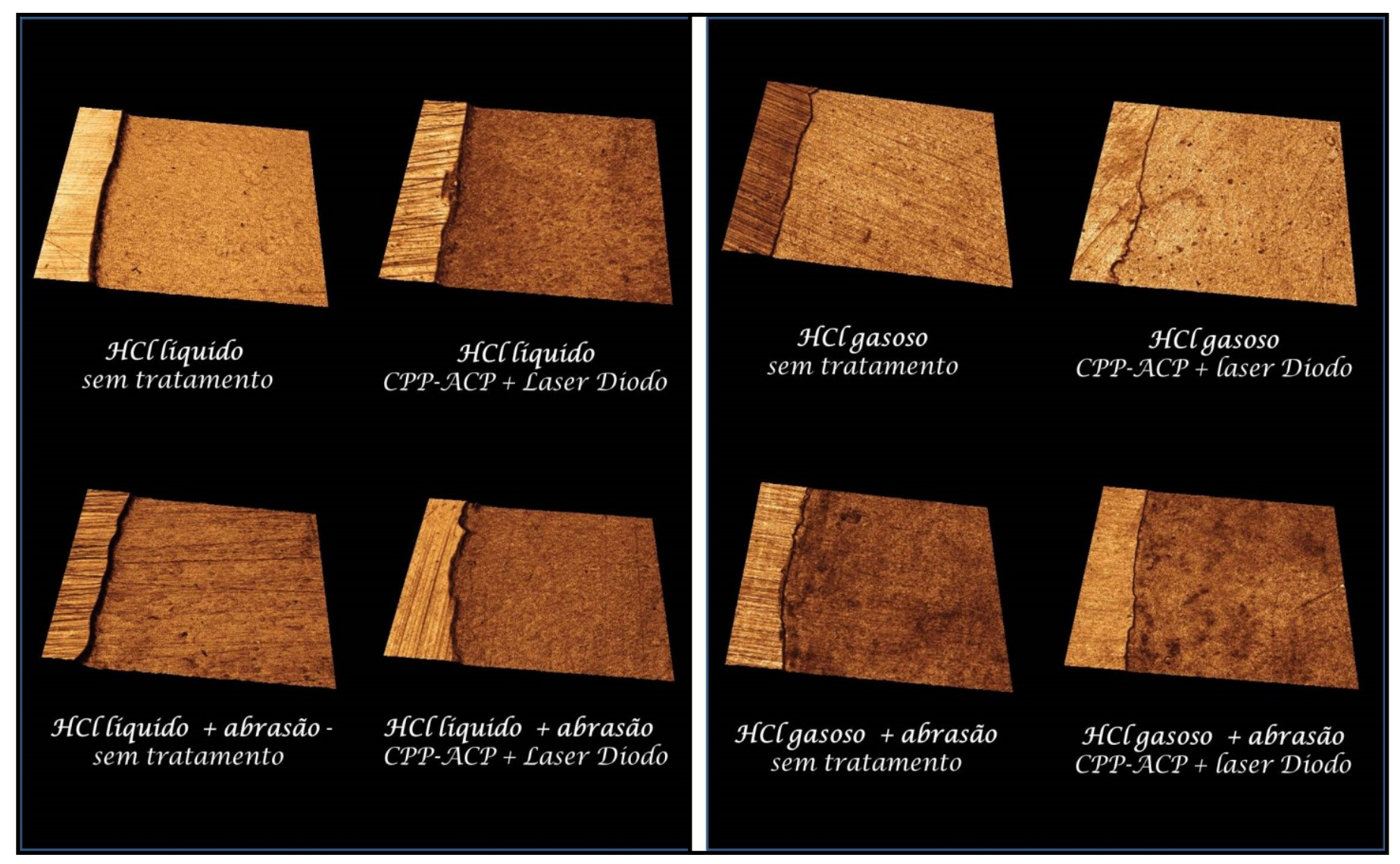

Figura 25. Imagens em 3D comparando o $\mathrm{HCl}$ líquido e $\mathrm{HCl}$ gasoso com e sem abrasão na dentina sem tratamento preventivo e a tratada com CPP-ACP + laser Diodo.

Pode-se observar na Figura 25 que o processo de degradação foi mais intenso nos grupos no qual foi empregado o $\mathrm{HCl}$ na forma líquida do que gasosa em que observa-se um padrão de desgaste mais perceptível. 


\section{Rugosidade}

Na rugosidade pode-se observar que no fator erosão o G3 apresentou maior rugosidade sendo estatisticamente diferente que os outros grupos $(\mathrm{p}<0,05)$, por sua vez os grupos G1, G2 e G4 foram semelhantes entre si ( $>00,05)$ (Figura 26). No fator de tratamento superficial o SgE apresentou maior rugosidade e estatisticamente diferente que os outros subgrupos $(\mathrm{p}<0,05)$, os subgrupos $\mathrm{SgA}, \operatorname{SgB}, \operatorname{SgC}, \operatorname{SgF}$ e $\operatorname{SgG}$ foram similares entre si $(p>0,05)$ (Figura 27).

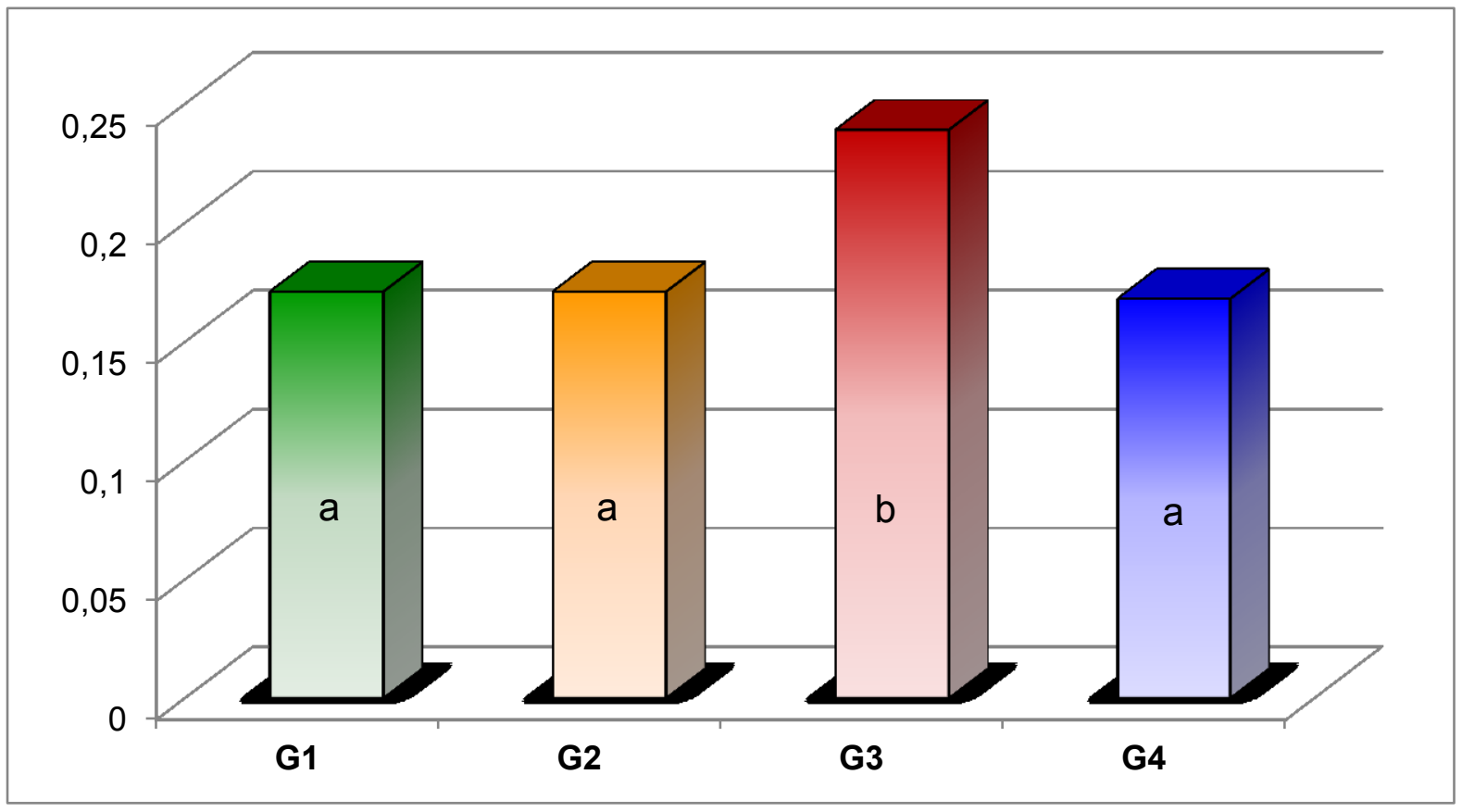

Figura 26. Rugosidade $(\mathrm{em} \mu \mathrm{m})$ da superfície dos espécimes de acordo ao tipo de erosão (diferente letra indica diferença estatística significante - $\mathrm{p}<0,05)$ (G1-HCl líquido; G2-HCl líquido+abrasão; G3-HCl gasoso; G4-HCl gasoso+abrasão). 


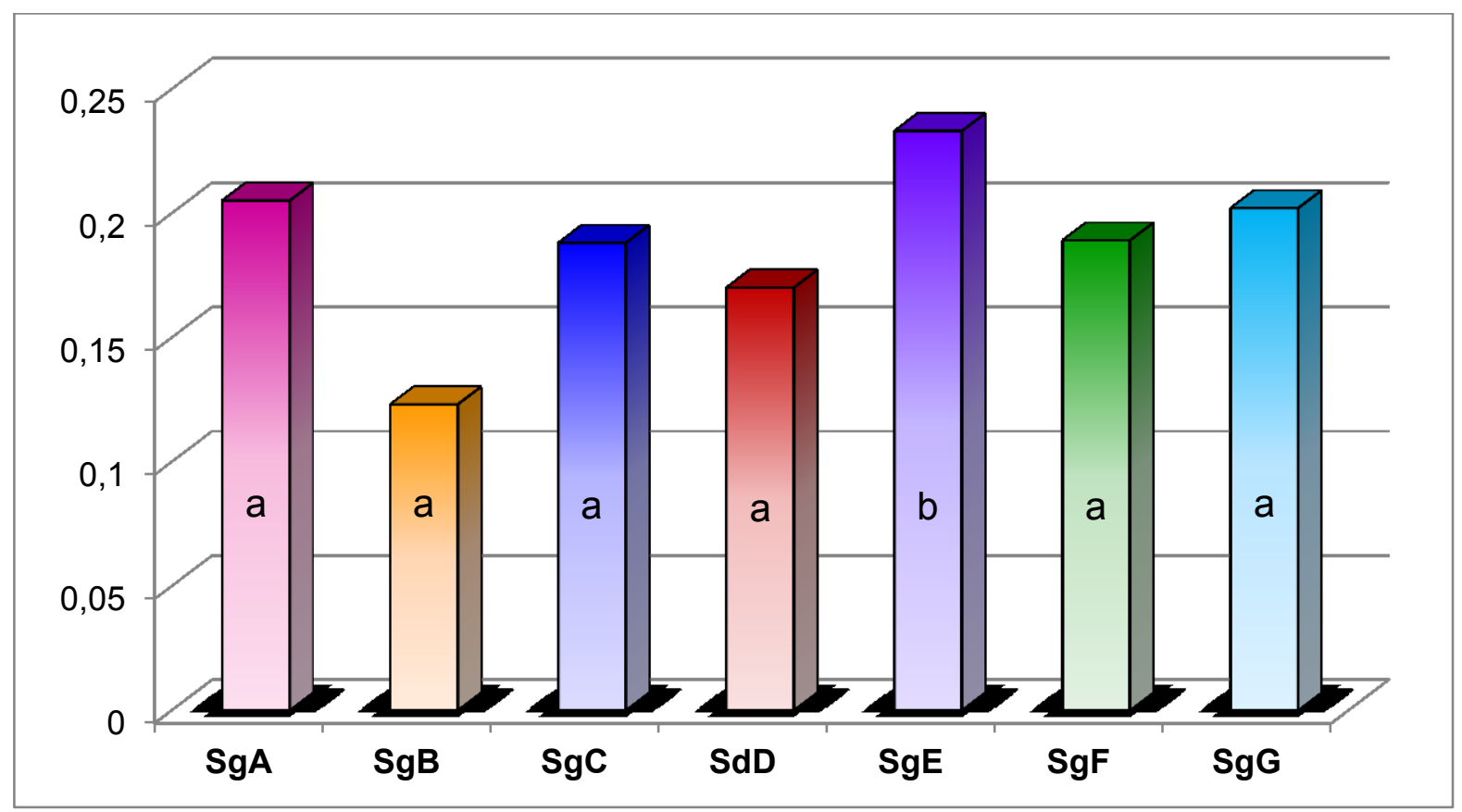

Figura 27. Rugosidade (em $\mu \mathrm{m})$ da superfície dos espécimes de acordo ao tipo de tratamento superficial (diferente letra indica diferença estatística significante - $\mathrm{p}<0,05)$ ( $\mathrm{SgA}$ - Controle; SgB - CPP-ACP; SgC - CPP-ACP + Nd:YAG; SgD - CPP-ACP + Diodo; SgE - Pasta experimental; SgF Pasta experimental + Nd:YAG; SgG - Pasta experimental + Diodo).

A interação dos fatores pelo comportamento dos diferentes grupos e subgrupos pode-se observar na Tabela 4. Pode-se observar que apenas o G1 apresentou diferente estatisticamente significante entre os subgrupos, tendo SgB apresentou o menor valor e diferente dos SbA, SgE, SgF e SgG $(p<0,05)$. 
Tabela 4. Média (em $\mu \mathrm{m})$ e desvio padrão dos grupos e subgrupos na análise da rugosidade superficial

\begin{tabular}{|c|c|c|c|c|}
\hline & G1 & G2 & G3 & G4 \\
\hline SgA & $0,20 \pm 0,14 \mathrm{~B} \mathrm{a}$ & $0,24 \pm 0,19 \mathrm{~A} \mathrm{a}$ & $0,22 \pm 0,13 \mathrm{~A} \mathrm{a}$ & $0,16 \pm 0,11 \mathrm{~A} \mathrm{a}$ \\
\hline SgB & $-0,01 \pm 0,18 \mathrm{~A} \mathrm{a}$ & $0,18 \pm 0,15 \mathrm{~A} \mathrm{~b}$ & $0,16 \pm 0,10 \mathrm{~A} \mathrm{~b}$ & $0,17 \pm 0,11 \mathrm{~A} \mathrm{~b}$ \\
\hline SgC & $0,18 \pm 0,19 \mathrm{AB}$ ab & $0,10 \pm 0,09 \mathrm{~A} \mathrm{a}$ & $0,32 \pm 0,18 \mathrm{~A} \mathrm{~b}$ & $0,16 \pm 0,11 \mathrm{~A} \mathrm{ab}$ \\
\hline SgD & $0,13 \pm 0,17 \mathrm{AB}$ a & $0,15 \pm 0,12 \mathrm{~A} \mathrm{a}$ & $0,25 \pm 0,15 \mathrm{~A} \mathrm{a}$ & $0,15 \pm 0,09 \mathrm{~A} \mathrm{a}$ \\
\hline SgE & $0,25 \pm 0,20 \mathrm{~B} \mathrm{a}$ & $0,22 \pm 0,22 \mathrm{~A} \mathrm{a}$ & $0,27 \pm 0,15 \mathrm{~A} \mathrm{a}$ & $0,18 \pm 0,14 \mathrm{~A} \mathrm{a}$ \\
\hline SgF & $0,19 \pm 0,17 \mathrm{~B} \mathrm{a}$ & $0,16 \pm 0,15 \mathrm{~A} \mathrm{a}$ & $0,24 \pm 0,11 \mathrm{~A} \mathrm{a}$ & $0,17 \pm 0,07 \mathrm{~A} \mathrm{a}$ \\
\hline SgG & $0,26 \pm 0,21 \mathrm{~B} \mathrm{a}$ & $0,15 \pm 0,14 \mathrm{~A} \mathrm{a}$ & $0,21 \pm 0,13 \mathrm{~A} \mathrm{a}$ & $0,19 \pm 0,07 \mathrm{~A} \mathrm{a}$ \\
\hline
\end{tabular}

Letras maiúscula comparação em coluna - letra minúscula comparação na linha; mesma letra indica similaridade estatística $(\mathrm{p}>0,05)$.

\section{Número - Túbulos}

No número de túbulos expostos pode observar que no fator erosão houve uma maior exposição de túbulos no G1 em comparação aos outros grupos sendo esta diferença estatisticamente significante $(p<0,05)$, por sua vez, para os grupos G2,G3 e G4 foram similares entre si $(\mathrm{p}>0,05)$ (Figura 28). Para o fator tratamento superficial pode-se observar que o SgD e SgF apresentaram menores valores de exposição de túbulos, os quais foram similares ao $\mathrm{SgB}, \operatorname{SgC}$ e $\operatorname{SgE}(\mathrm{p}>0,05)$ e diferentes estatisticamente significante que SgA e SgG ( $p<0,05)$ (Figura 29). 


\section{Resultados}

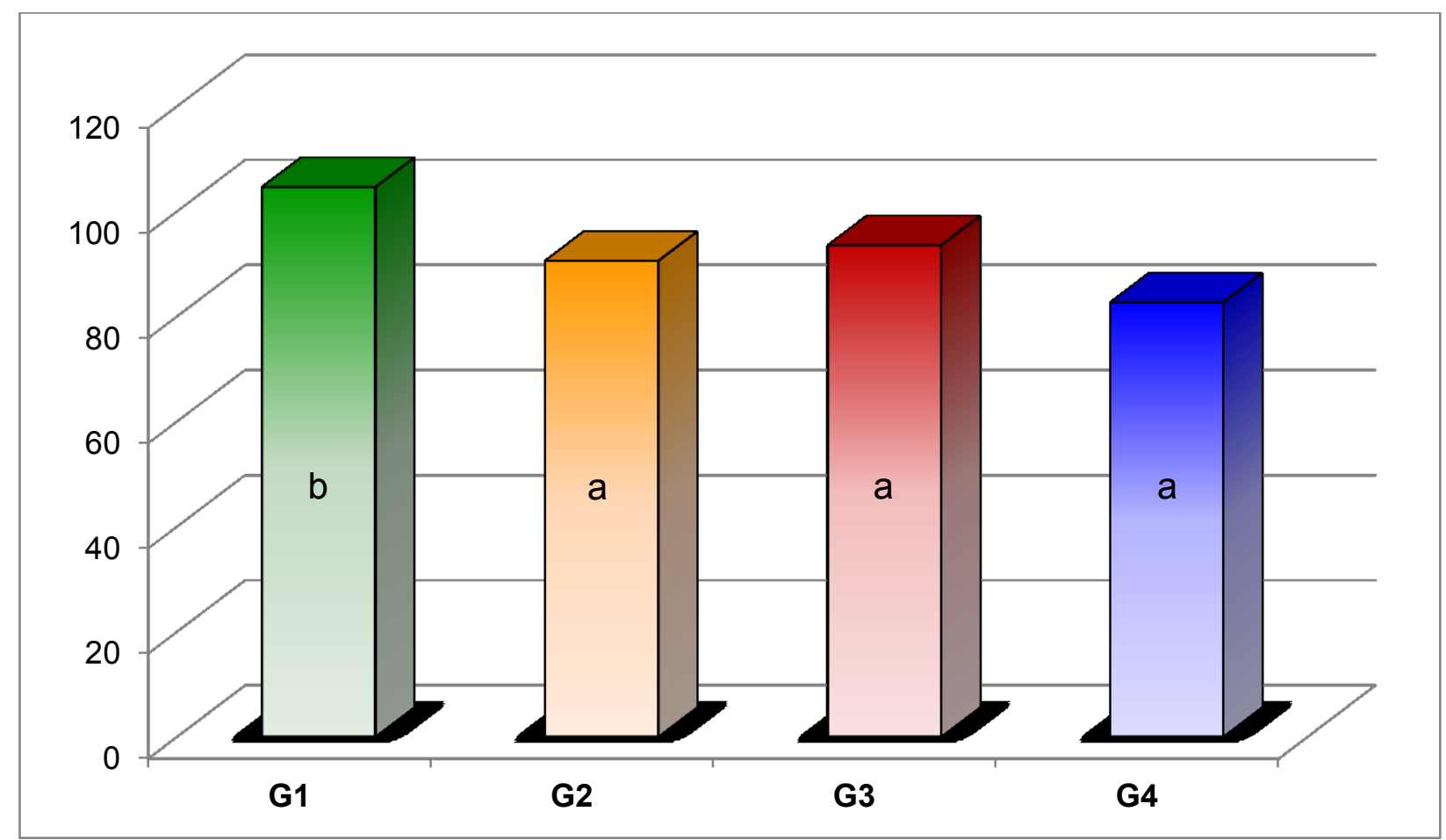

Figura 28. Porcentagem de número de túbulos expostos de acordo ao tipo de erosão (diferente letra indica diferença estatística significante- p<0,05) (G1-HCl líquido; G2-HCl líquido+abrasão; G3-HCl gasoso; G4- $\mathrm{HCl}$ gasoso+abrasão).

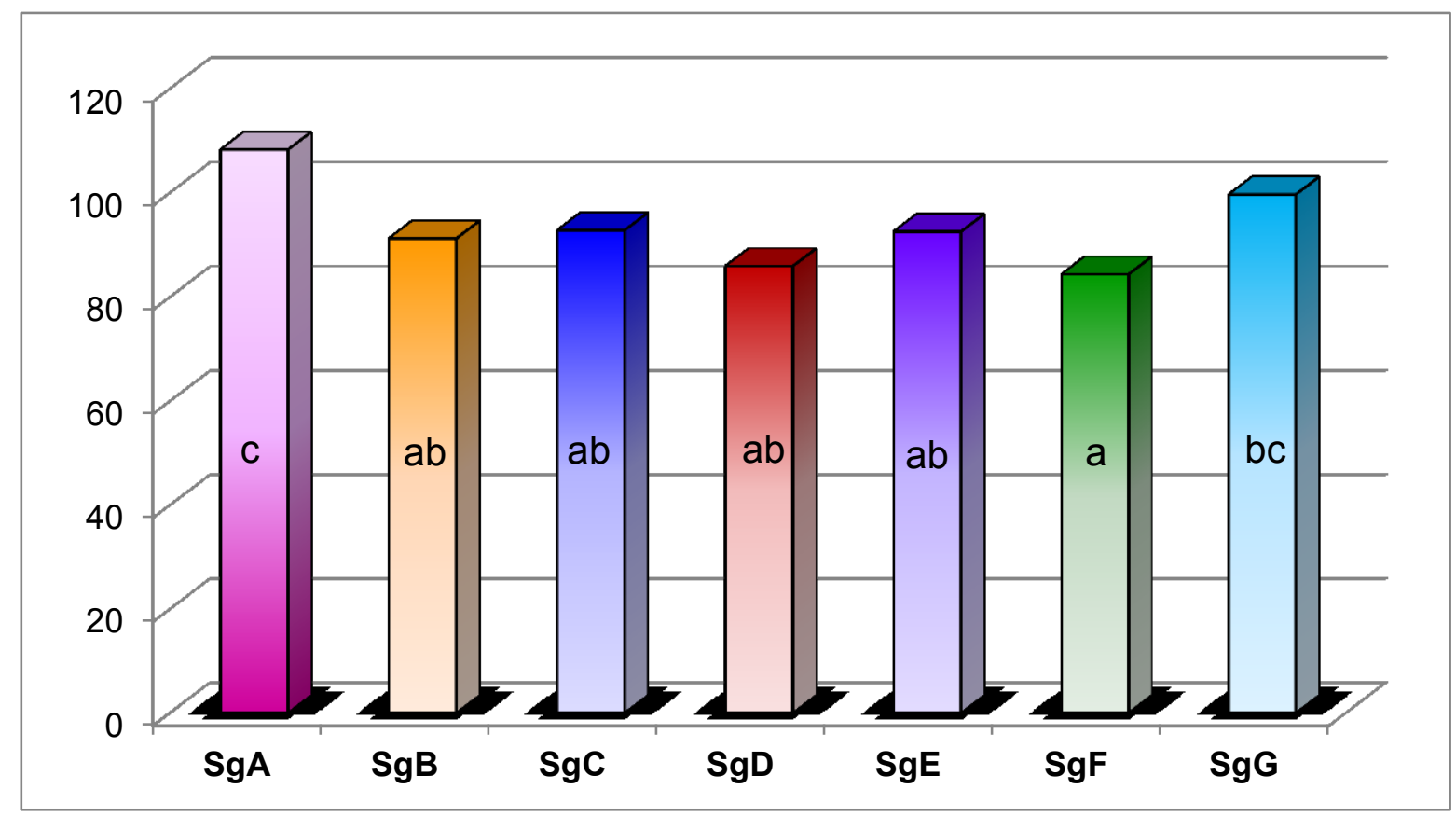

Figura 29. Número de túbulos (\%) expostos de acordo ao tipo de tratamento superficial (diferente letra indica diferença estatística significante - p<0,05) (SgA - Controle; SgB - CPP-ACP; SgC - CPP-ACP + Nd:YAG; SgD - CPP-ACP + Diodo; SgE - Pasta experimental; SgF - Pasta experimental + Nd:YAG; SgG - Pasta experimental + Diodo). 
A interação dos fatores pelo comportamento dos diferentes grupos e subgrupos pode-se observar na Tabela 5. Pode observar que apenas o G4 apresentou diferenteça estatística significante entre os subgrupos, tendo o SgF apresentaram diferença significante $(\mathrm{p}<0,05)$ com o SgA.

Tabela 5. Média (\%) e desvio padrão dos grupos e subgrupos na análise do número de túbulos.

\begin{tabular}{|c|c|c|c|c|}
\hline & G1 & G2 & G3 & G4 \\
\hline SGA & $123,95 \pm 37,86 \mathrm{~A} \mathrm{~b}$ & $92,21 \pm 17,59 \mathrm{~A} \mathrm{a}$ & $106,74 \pm 15,64 \mathrm{~A} \mathrm{ab}$ & $110,12 \pm 32,36 \mathrm{~A} \mathrm{ab}$ \\
\hline SGB & $97,55 \pm 10,24 \mathrm{~A} \mathrm{a}$ & $92,59 \pm 13,28 \mathrm{~A} \mathrm{a}$ & $91,17 \pm 18,63 \mathrm{~A} \mathrm{a}$ & $92,68 \pm 14,47 \mathrm{AB} \mathrm{a}$ \\
\hline SGC & $99,93 \pm 17,93 \mathrm{~A} \mathrm{a}$ & $86,05 \pm 16,63 \mathrm{~A} \mathrm{a}$ & $94,85 \pm 29,88 \mathrm{~A} \mathrm{a}$ & $90,17 \pm 37,02 \mathrm{AB}$ a \\
\hline SGD & $103,40 \pm 17,59 \mathrm{~A} \mathrm{~b}$ & $85,73 \pm 15,96 \mathrm{~A} \mathrm{ab}$ & $83,37 \pm 17,70 \mathrm{~A}$ ab & $71,00 \pm 28,18 \mathrm{~B} \mathrm{a}$ \\
\hline SGE & $101,06 \pm 26,01 \mathrm{~A} \mathrm{a}$ & $89,41 \pm 9,35 \mathrm{~A} \mathrm{a}$ & $86,02 \pm 16,28 \mathrm{~A} \mathrm{a}$ & $93,54 \pm 29,81 \mathrm{AB}$ a \\
\hline SGF & $98,35 \pm 3,66 \mathrm{~A} \mathrm{~b}$ & $94,10 \pm 7,05 \mathrm{~A} \mathrm{~b}$ & $84,81 \pm 26,22 \mathrm{~A} \mathrm{ab}$ & $59,95 \pm 23,07 \mathrm{~B} \mathrm{a}$ \\
\hline SGG & $107,89 \pm 16,95 \mathrm{~A} \mathrm{a}$ & $93,84 \pm 14,19 \mathrm{~A} \mathrm{a}$ & $107,71 \pm 22,78 \mathrm{~A} \mathrm{a}$ & $89,03 \pm 29,68 \mathrm{AB}$ a \\
\hline
\end{tabular}

Letra maiúscula comparação em coluna - letra minúscula comparação na linha; mesma letra indica similaridade estatística $(\mathrm{p}>0,05)$.

\section{Área - Túbulos}

A área dos túbulos no fator erosão o G2 teve menor área que os outros grupos e estatisticamente significante $(p<0,05)$, tendo os grupos G1, G3 e G4 foram semelhantes entre si $(p>0,05)$ (Figura 30). Para o fator tratamento superficial pode-se observar que o SgD teve o menor valor de área de túbulos, o qual foi similar ao SgC e SF (p>0,05) e diferente estatisticamente significante do SgA, SgB, SgE e SgG (p<0,05) (Figura 31), ou seja foram menos afetados pelo desafio. 


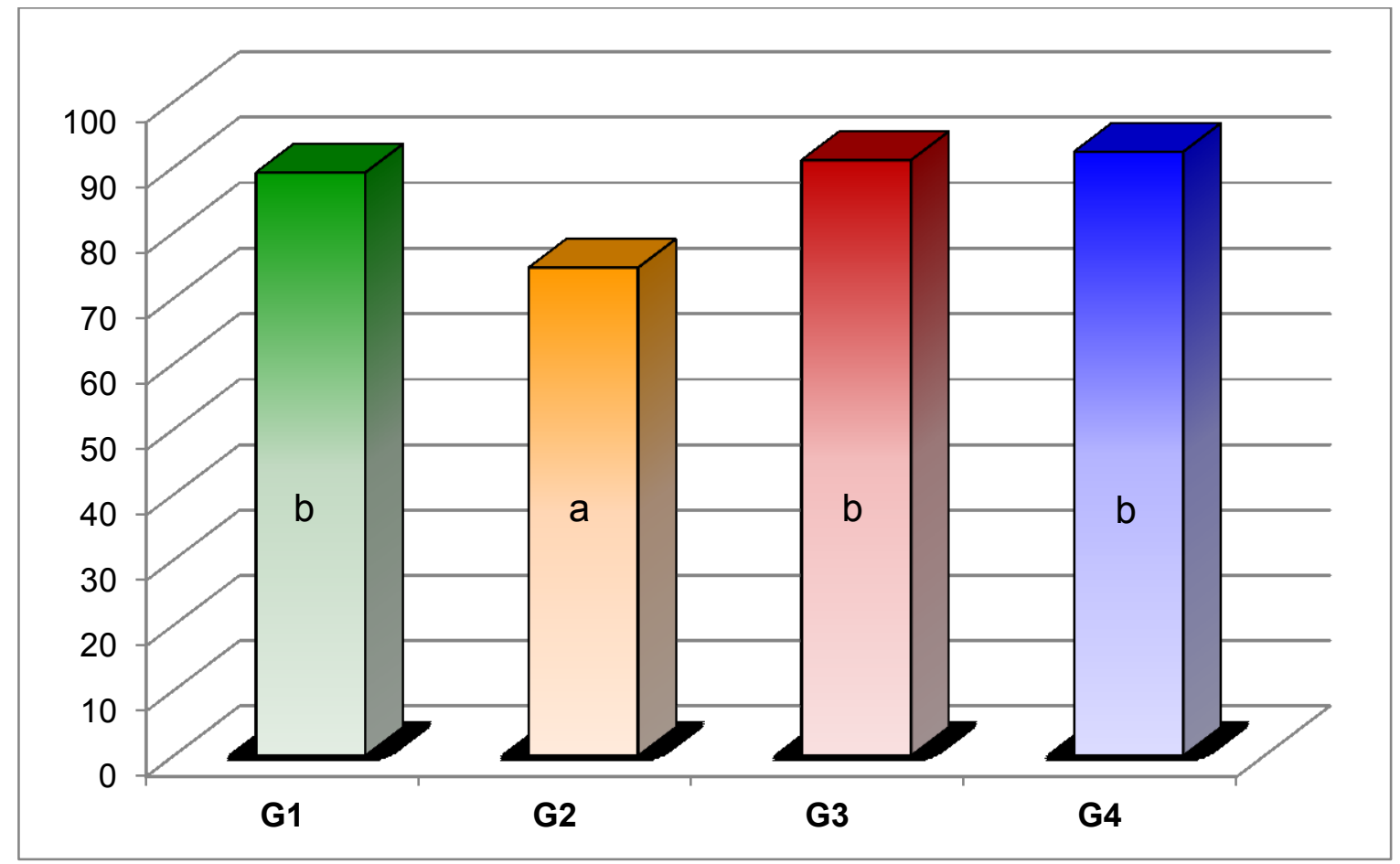

Figura 30. Porcentagem da área dos túbulos expostos de acordo ao tipo de degradação estudada (diferente letra indica diferença estatística significante - p<0,05) (G1-HCl líquido; G2-HCl líquido+abrasão; G3-HCl gasoso; G4-HCl gasoso+abrasão).

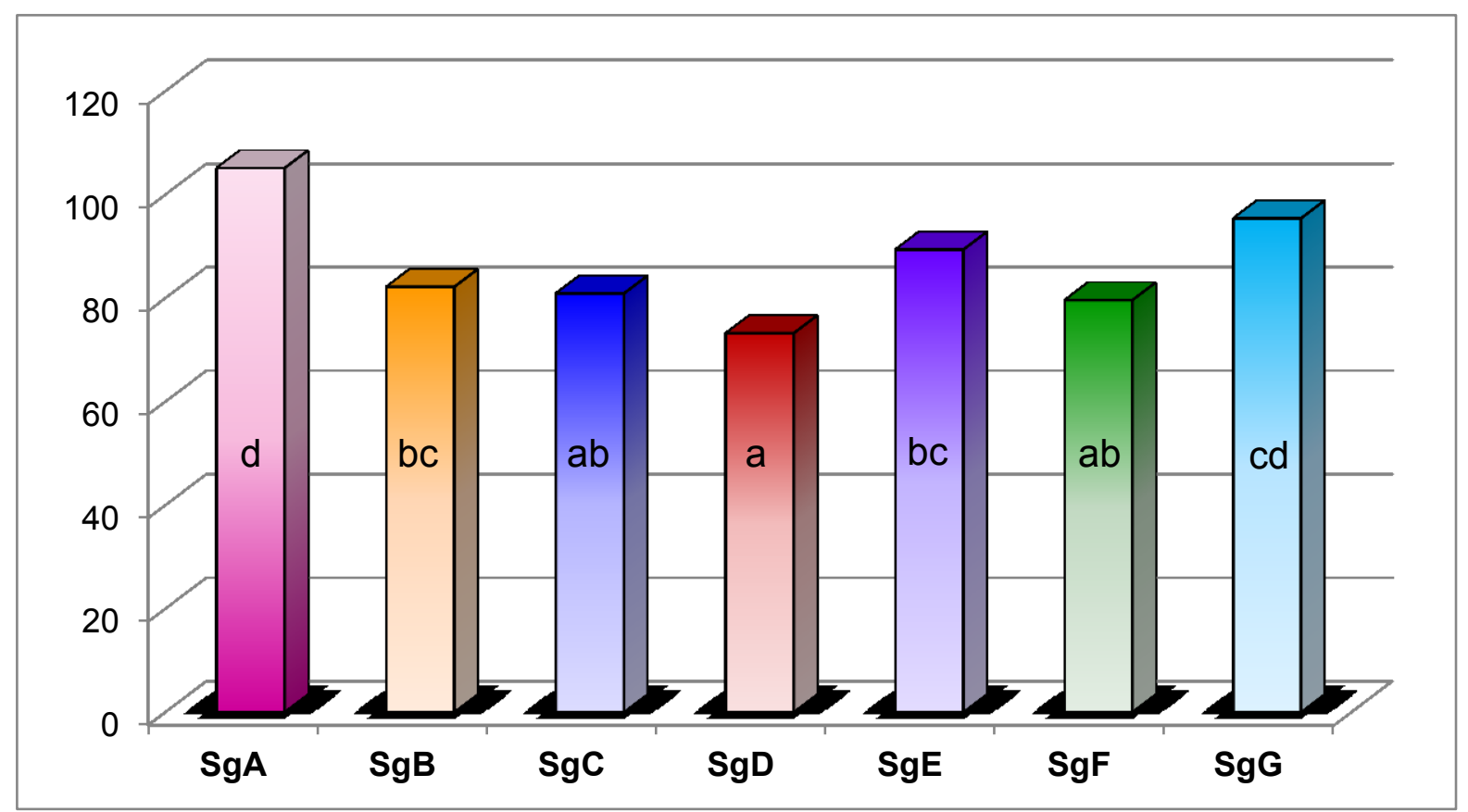

Figura 31. Área dos túbulos (\%) expostos de acordo ao tipo de tratamento superficial (diferente letra indica diferença estatística significante - p<0,05) (SgA - Controle; SgB - CPP-ACP; SgC - CPPACP + Nd:YAG; SgD - CPP-ACP + Diodo; SgE - Pasta experimental; SgF - Pasta experimental + Nd:YAG; SgG - Pasta experimental + Diodo). 
A interação dos fatores pelo comportamento dos diferentes grupos e subgrupos pode-se observar na Tabela 6. Pode-se observar que no G1 os SgC, o SgD e o SgF apresentaram os menores valores e estatisticamente diferente do SgG $(p<0,05)$. No G4, o SgD apresentou o menor valor e estatisticamente diferente de todos os subgrupos a exceção $\operatorname{SgB}(\mathrm{p}<0,05)$.

Tabela 6. Média (\%) e desvio padrão dos grupos e subgrupos na análise da área dos túbulos.

\begin{tabular}{|c|c|c|c|c|}
\hline & G1 & G2 & G3 & G4 \\
\hline SgA & $102,72 \pm 21,71 \mathrm{AB} \mathrm{b}$ & $74,52 \pm 13,97 \mathrm{~A} \mathrm{a}$ & $120,67 \pm 14,38 \mathrm{~B} \mathrm{~b}$ & $122,39 \pm 48,55 \mathrm{C} \mathrm{b}$ \\
\hline SgB & $85,79 \pm 19,34 \mathrm{AB}$ a & $74,75 \pm 15,05 \mathrm{~A} \mathrm{a}$ & $87,63 \pm 6,35 \mathrm{~A} \mathrm{a}$ & $87,79 \pm 13,70 \mathrm{AB}$ a \\
\hline SgC & $76,73 \pm 18,62 \mathrm{~A} \mathrm{a}$ & $72,97 \pm 18,02 \mathrm{~A} \mathrm{a}$ & $79,13 \pm 15,51 \mathrm{~A} \mathrm{a}$ & $94,56 \pm 16,47 \mathrm{BC}$ a \\
\hline SgD & $79,11 \pm 11,53 \mathrm{~A} \mathrm{~b}$ & $62,41 \pm 25,46 \mathrm{~A} \mathrm{a}$ & $80,63 \pm 13,15 \mathrm{~A} \mathrm{~b}$ & $70,53 \pm 10,80 \mathrm{~A}$ ab \\
\hline SgE & $87,14 \pm 23,46 \mathrm{AB}$ a & $81,00 \pm 13,71 \mathrm{~A} \mathrm{a}$ & $91,22 \pm 7,26 \mathrm{~A} \mathrm{a}$ & $98,00 \pm 13,29 \mathrm{BC}$ a \\
\hline SgF & $81,41 \pm 8,29 \mathrm{~A} \mathrm{a}$ & $73,83 \pm 18,82 \mathrm{~A} \mathrm{a}$ & $84,24 \pm 17,38 \mathrm{~A} \mathrm{a}$ & $78,71 \pm 18,42 \mathrm{~B} \mathrm{a}$ \\
\hline SgG & $110,90 \pm 34,73 \mathrm{~B} \mathrm{a}$ & $82,83 \pm 13,77 \mathrm{~A} \mathrm{a}$ & $93,64 \pm 8,69 \mathrm{~A} \mathrm{a}$ & $94,09 \pm 15,76 \mathrm{~B} \mathrm{a}$ \\
\hline
\end{tabular}

Letras maiúscula comparação em coluna - letra minúscula comparação na linha; mesma letra indica similaridade estatística $(\mathrm{p}>0,05)$.

\section{Perímetro - Túbulos}

$\mathrm{Na}$ análise dos dados pode-se observar o perímetro dos túbulos foi similar à análise da área (Figuras 32 e 33). No fator erosão pode-se observar que o grupo G2 apresentou uma diminuição no perímetro dos túbulos e estatisticamente diferente dos outros grupos $(p<0,05)$, sendo os outros grupos G1, G3 e G4 foram similares entre si $(p>0,05)$. Para o fator tratamento superficial pode-se observar que o SgD teve o menor perímetro de túbulos, o qual foi similar ao $\operatorname{SgC}$ e $\operatorname{SgF}(p>0,05)$ e diferente estatisticamente significante do SgA, SgB, SgE e $\operatorname{SgG}(\mathrm{p}<0,05)$ 


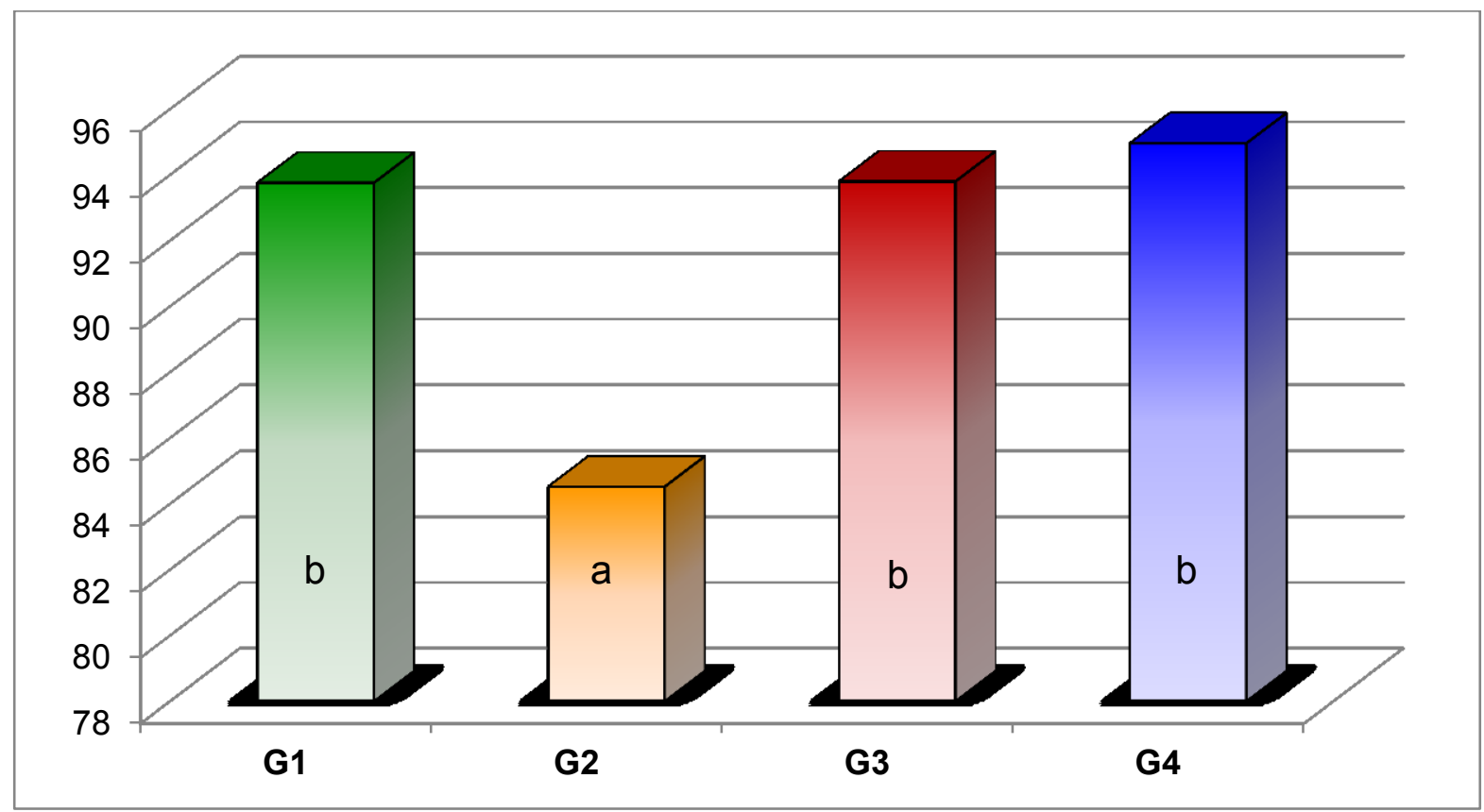

Figura 32. Perímetro dos túbulos expostos de acordo ao tipo de erosão (diferente letra indica diferença estatística significante - p<0,05) (G1-HCl líquido; G2-HCl líquido+abrasão; G3-HCl gasoso; G4-HCl gasoso+abrasão).

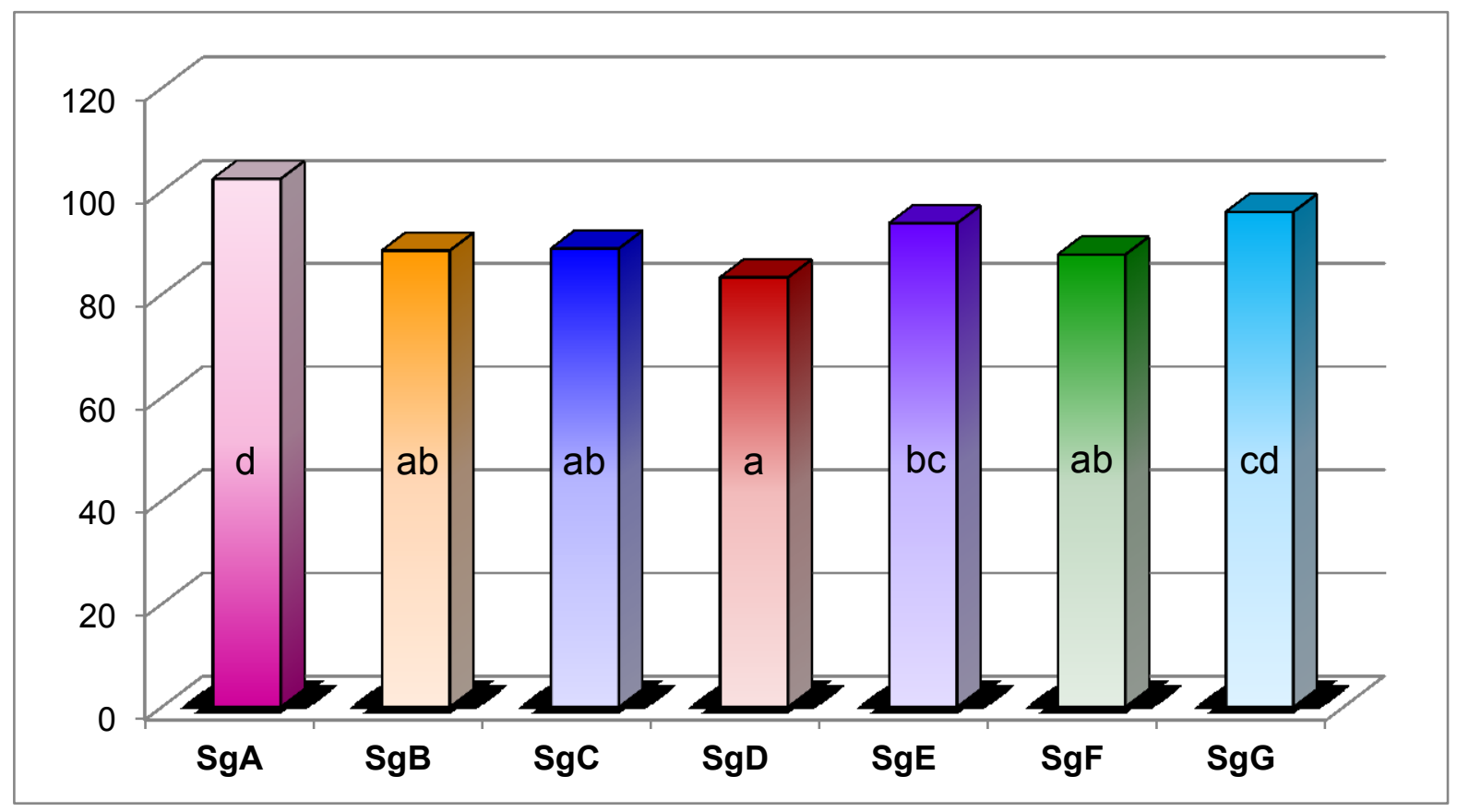

Figura 33. Perímetro dos túbulos (\%) expostos de acordo ao tipo de tratamento superficial (diferente letra indica diferença estatística significante - p<0,05) (SgA - Controle; SgB - CPP-ACP; SgC - CPP-ACP + Nd:YAG; SgD - CPP-ACP + Diodo; SgE - Pasta experimental; SgF - Pasta experimental + Nd:YAG; SgG - Pasta experimental + Diodo). 
A interação dos fatores pelo comportamento dos diferentes grupos e subgrupos pode-se observar na Tabela 7. No G1, o SgC e SgD apresentaram os menores valores e estatisticamente diferente do SgG $(\mathrm{p}<0,05)$. No G2 e G4, o SgD mostrou os menores valores e estatisticamente diferente dos SgE e SgG $(p<0,05)$. No G3 observou-se que o SgA foi estatisticamente diferente dos demais subgrupos $(\mathrm{p}<0,05)$ e no G4 o SgD apresentou inferior e semelhante apenas aos Sg B e SgF (p>0,05) e diferente dos demais $(\mathrm{p}>0,05)$.

Tabela 7. Média (\%) e desvio padrão dos grupos e subgrupos na análise do perímetro dos túbulos.

\begin{tabular}{|c|c|c|c|c|}
\hline & G1 & G2 & G3 & G4 \\
\hline SgA & $101,57 \pm 11,72 \mathrm{AB} \mathrm{b}$ & $84,17 \pm 9,41 \mathrm{AB}$ a & $111,41 \pm 7,34 \mathrm{~B} \mathrm{~b}$ & $112,24 \pm 25,05 \mathrm{C} \mathrm{b}$ \\
\hline SgB & $90,98 \pm 11,75 \mathrm{AB} \mathrm{a}$ & $85,16 \pm 9,27 \mathrm{AB}$ a & $93,05 \pm 4,24 \mathrm{~A} \mathrm{a}$ & $93,13 \pm 8,45 \mathrm{AB}$ a \\
\hline SgC & $86,95 \pm 12,03 \mathrm{~A} \mathrm{ab}$ & $83,51 \pm 11,98 \mathrm{AB}$ a & $88,20 \pm 10,29 \mathrm{~A} \mathrm{ab}$ & $96,66 \pm 10,30 \mathrm{BC} \mathrm{b}$ \\
\hline SgD & $88,12 \pm 6,99 \mathrm{~A} \mathrm{~b}$ & $75,57 \pm 16,78 \mathrm{~A} \mathrm{a}$ & $87,62 \pm 8,32 \mathrm{~A} \mathrm{~b}$ & $81,61 \pm 6,94 \mathrm{~A} \mathrm{ab}$ \\
\hline SgE & $92,14 \pm 13,80 \mathrm{AB}$ a & $89,63 \pm 7,76 \mathrm{~B} \mathrm{a}$ & $94,64 \pm 4,04 \mathrm{~A} \mathrm{a}$ & $98,51 \pm 7,40 \mathrm{BC}$ a \\
\hline SgF & $90,47 \pm 6,14 \mathrm{AB} \mathrm{a}$ & $83,69 \pm 11,68 \mathrm{AB}$ a & $89,83 \pm 10,19 \mathrm{~A} \mathrm{a}$ & $86,57 \pm 12,69 \mathrm{AB} \mathrm{a}$ \\
\hline SgG & $106,05 \pm 17,48 \mathrm{~B} \mathrm{~b}$ & $9,94 \pm 9,23 \mathrm{~B} \mathrm{a}$ & $91,77 \pm 17,15 \mathrm{~A}$ ab & $95,92 \pm 8,88 \mathrm{BC} \mathrm{ab}$ \\
\hline
\end{tabular}

Letras maiúscula comparação em coluna - letra minúscula comparação na linha; mesma letra indica similaridade estatística $(\mathrm{p}>0,05)$.

Na figura 34 pode-se observar o comportamento dos diferentes grupos estudados em que verifica-se nas figuras B, C, D e H ocorreu uma diminuição no número de túbulos, além de observar tubulos obliterados. 


\section{Resultados}

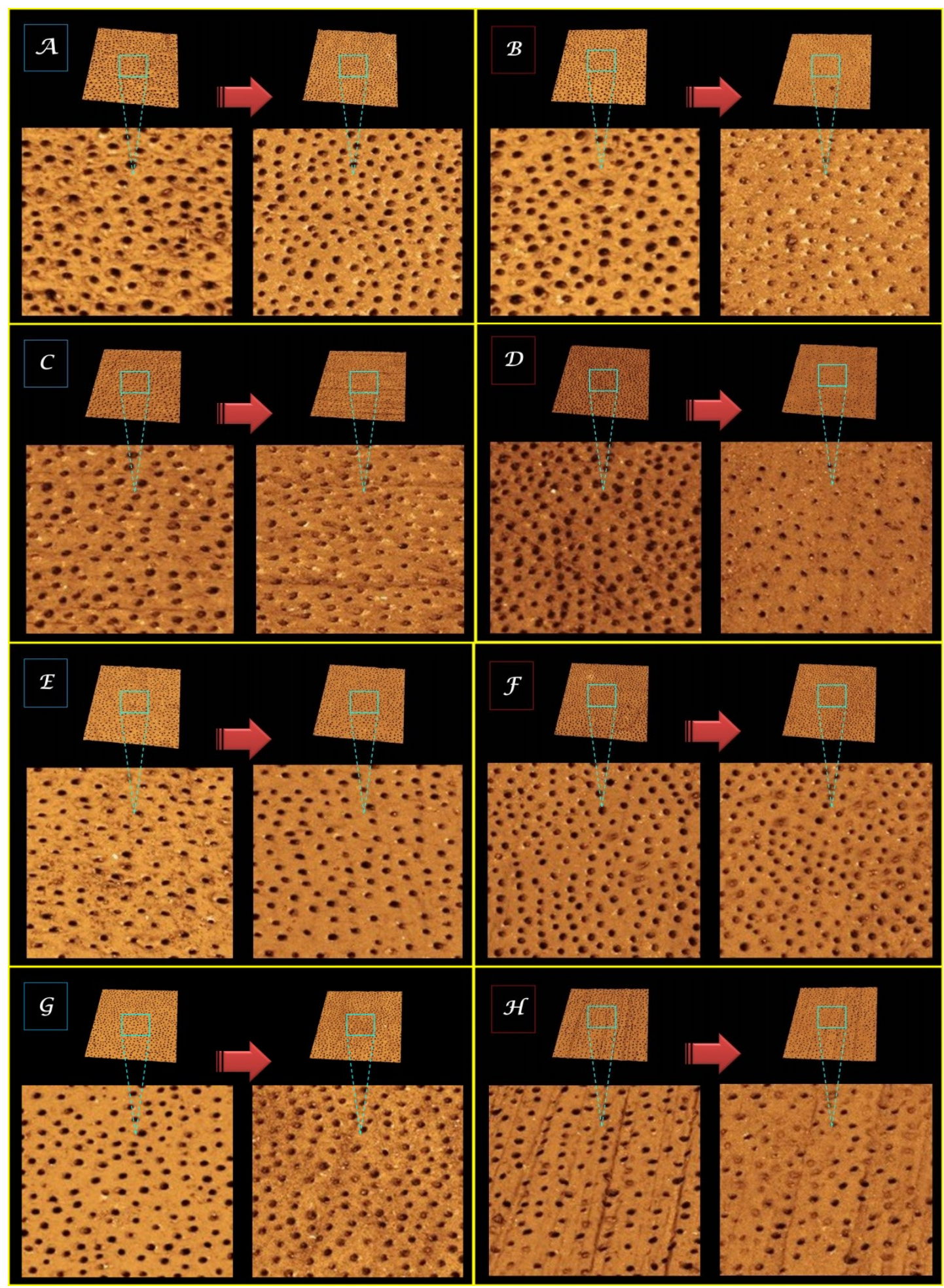

Figura 34. A) SgA (Degradação inicial e após HCl líquido), pode-se observar os túbulos abertos; B) SgD (Degradação inicial e após HCl líquido), se observam vários túbulos ocluídos. C) SgA (Degradação inicial e após HCl líquido + abrasão), pode-se ver alguns túbulos ocluídos; D) SgD (Degradação inicial e após HCl líquido + abrasão), os túbulos se mostram obliterados; E) SgA (Degradação inicial e após HCl gasoso), os túbulos se mostram abertos; F) SgD (Degradação inicial e após HCl gasoso), alguns túbulos se apresentam ocluídos; G) SgA (Degradação inicial e após HCl gasoso + abrasão), os túbulos se observam abertos; H) SgD (Degradação inicial e após gasoso + abrasão), alguns túbulos se mostram ocluídos. 


\section{FTIR}

$\mathrm{Na}$ figura 35, pode-se observar que SgD, SgF e SgG apresentaram notável diminuição da presença de amida III/fosfato em comparação aos outros subgrupos, o que demonstra que apresentaram menor quantidade de estrutura orgânica da dentina.

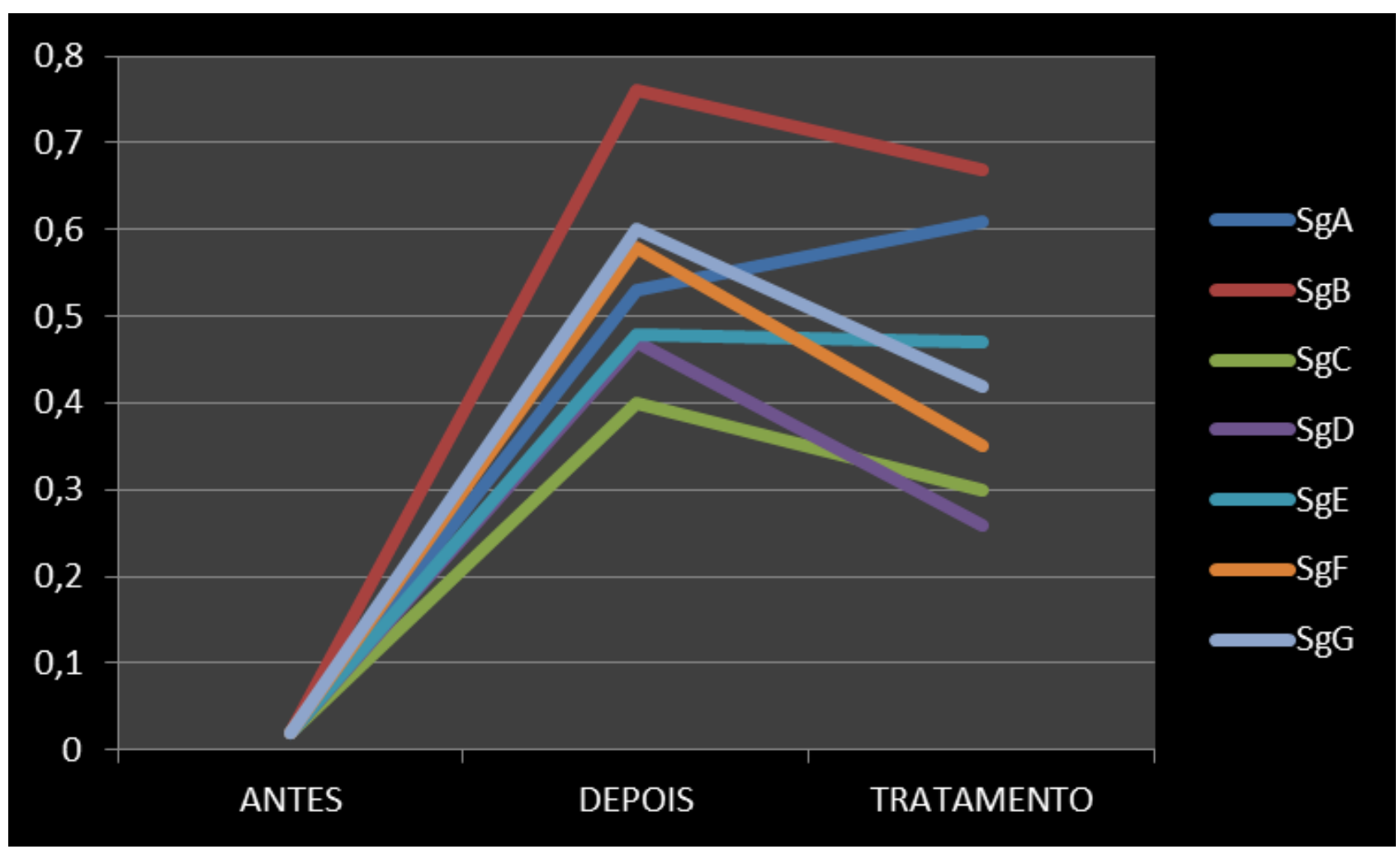

Figura 35. Razão amidaIII/fosfato antes e depois da exposição ao $\mathrm{HCl}$ e depois do tratamento para os subgrupos estudados. 
Na figura 36, o SgB observou maior diminuição da presença de carbonato/fosfato em comparação com os outros subgrupos, ou seja o tecido apresentou-se mais mineralizado em relação aos outros grupos.

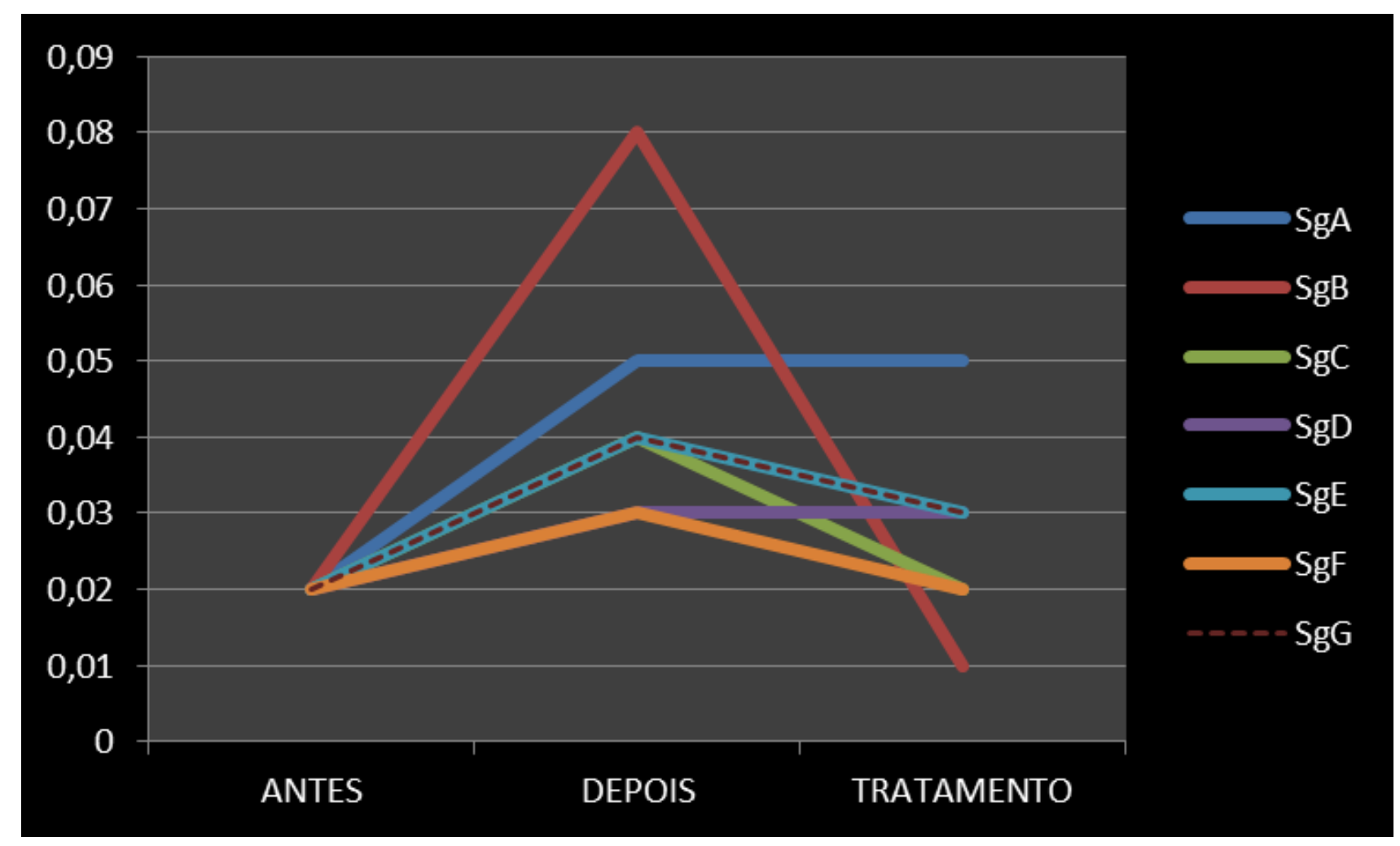

Figura 36. Razão carbonato/fosfato antes e depois da exposição ao $\mathrm{HCl}$ e depois do tratamento para os subgrupos estudados. 


\section{Microscopia Eletrônica de Varredura (MEV)}

No SgA (Figura $37 \mathrm{AB}$ ) os túbulos dentinários apresentam-se abertos, observa-se a superfície intertubular desmineralizada e porosa. O SgB (Figura $38 \mathrm{AB}$ ) apresenta os túbulos dentinários com o lúmen aberto e algumas porosidades na dentina intertubular. O SgC e SgD apresentam o lúmen dos túbulos parcialmente fechados e a dentina intertubular mostra sinais de fusão com poucas porosidades (Fig 38 CD-EF). O SgE e SgG (Figura 39 AB-EF) observam-se os túbulos dentinários abertos e a superfície da dentina intertubular com algumas porosidades e partículas. SgF (Fig39 CD) verificou-se os fechamento parcial dos túbulos dentinários e uma superfície intertubular homogênea.

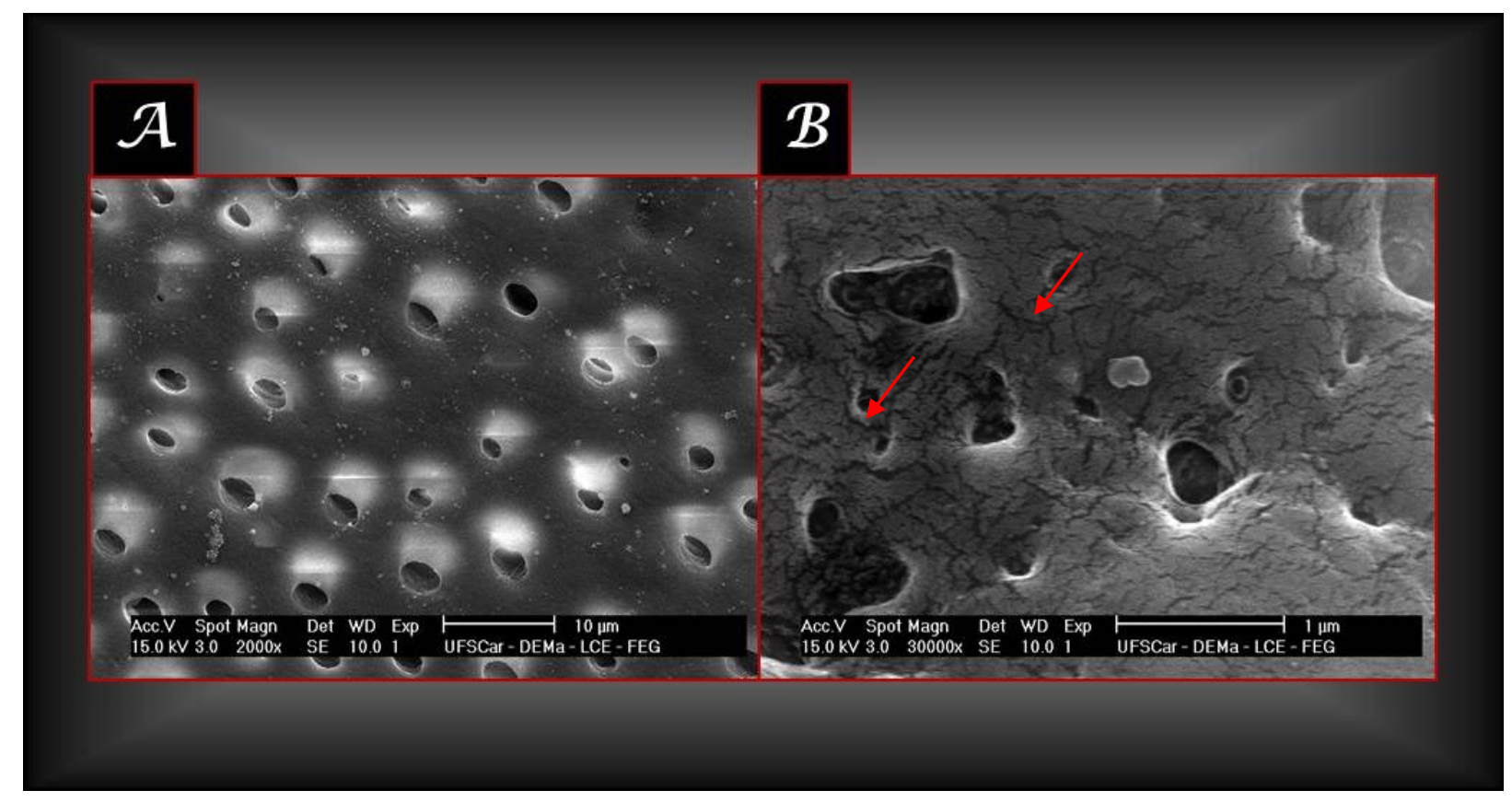

Figura 37. SgA (A e B) observa-se túbulos dentinários abertos e a presença de porosidades (setas vermelhas). 


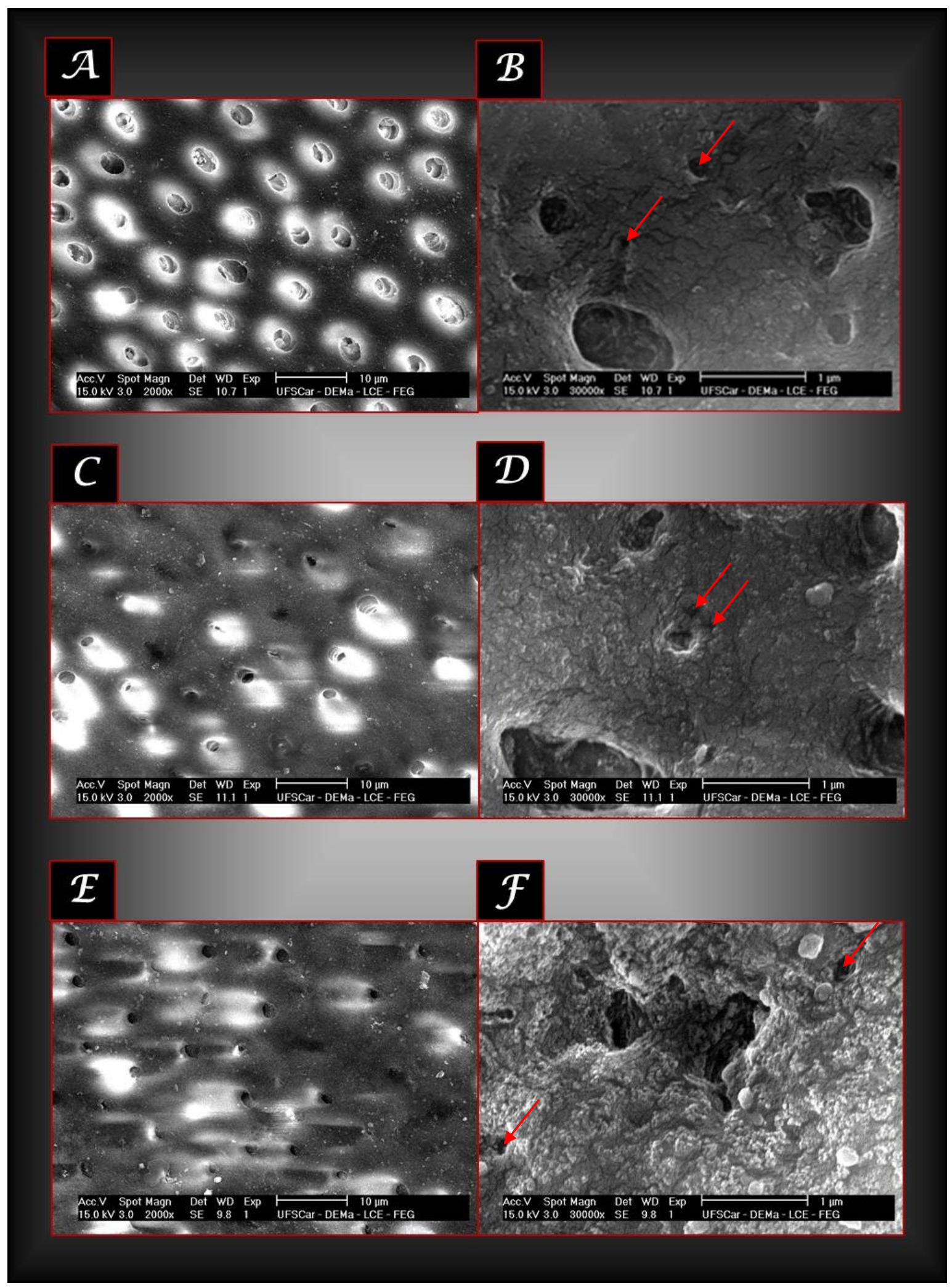

Figura 38. SgB (A e B): A - Observa-se túbulos dentinarios abertos; B - Presença de porosidades (setas vermelhas). SgC (C e D) - Observa-se os túbulos dentinários parcialmente fechados; D São observadas sinais de fusão e algumas porosidades (setas vermelhas). SgD (E e F): E Observam-se os túbulos dentinários parcialmente fechados; F - São observadas sinais de fusão e algumas porosidades (setas vermelhas). 


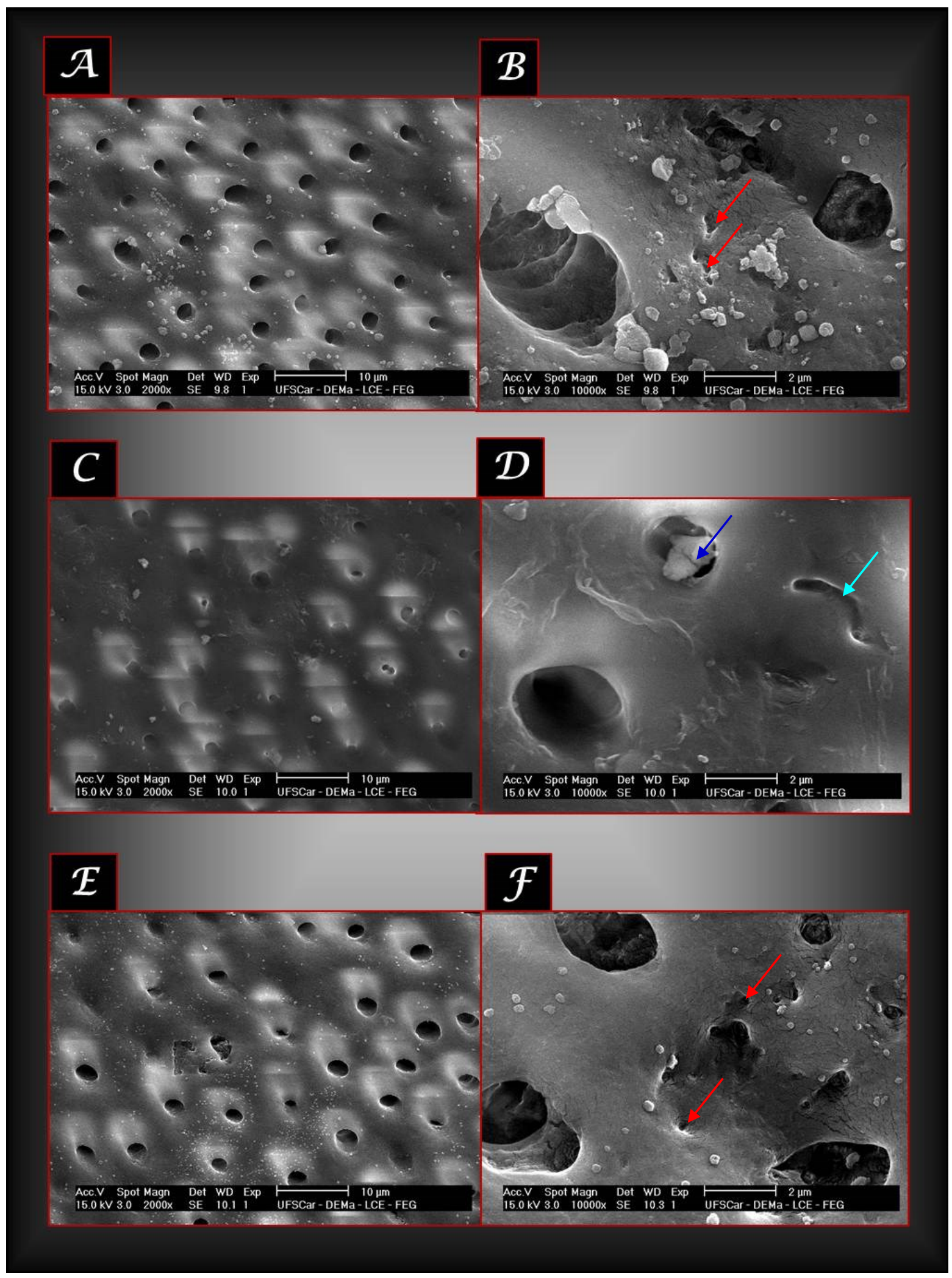

Figura 39. SgE (A e B): A - Observa-se túbulos dentinarios abertos; B - Presença de porosidades (setas vermelhas). SgF (C e D): C - Observa-se túbulos dentinários parcialmente fechados; D túbulo obstruído (seta azul escuro) e túbulo fechado (seta azul claro). SgG (E e F): E - Observa-se túbulos dentinarios abertos; F - Presença de porosidades (setas vermelhas). 


\section{Discussão}




\section{Discussão}

A erosão dental vem apresentando alta incidência e muitas vezes está correlacionada principalmente a pacientes com DRGE (Schroeder et al., 1995; Lazarchik; Filler, 1997; Gregory-Head et al., 2000; Lazarchik; Filler, 2000; Ali et al., 2002; Barron et al., 2003; Moazzez et al., 2004; Benages et al., 2006; Liberali, 2008; Pace et al., 2008; Holbrook et al., 2009; Milosevic, 2010; Firouzei et al., 2011; Farahmand et al., 2013; Picos et al., 2013; Alavi et al., 2014; Roesch-Ramos et al., 2014), tendo o refluxo do ácido gástrico como a causa deste tipo de lesão (Bartlett et al., 1996; Bartlett, 2006; Ranjitkar et al., 2012a; Ranjitkar et al., 2012b). 0 principal componente do ácido gástrico é o ácido clorídrico, sendo este fator o responsável da escolha do ácido empregado no presente estudo.

Além disso, a DRGE causa o refluído do ácido gástrico (presente no refluxo) à cavidade bucal (regurgitação) (Moraes-filho et al., 2002; Ranjitkar et al., 2012a; Dundar; Sengun, 2014), podendo-se apresentar na forma líquida, gasosa ou ambos (mix líquidogás), tendo o refluxo mix líquido-gás como fator comum o refluxo gasoso prévio ao refluxo líquido (Sifrim et al., 2001). Por esta razão no presente estudo foi obtido $\mathrm{HCl}$ na forma líquida e gasosa, tentando simular as condições que ocorrem na cavidade bucal, visto que ambas formas atuam de maneira distintas no esmalte dental (Derceli, 2014).

Por outro lado, a presença da escovação dental é um fator importante devido a sua característica de promover abrasão, a qual em associação com a erosão é potencializada a perda do tecido dental (Addy; Hunter, 2003; Addy; Shellis, 2006; Schlueter et al., 2012b). Este fato é agravado quando da realização da higienização (Grippo et al., 2012), assim neste estudo foi realizada a escovação em parte dos espécimes entre os episódios para avaliar o efeito da associação do processo erosivo com abrasivo.

Normalmente a região mais susceptível para a formação de lesões não cariosas ocasionadas por um processo de degradação de tecido é na região cervical junto à junção amelocementária (Walter et al., 2014; Bartlett; Shah, 2006), devido à presença de uma camada mais fina de esmalte e de cemento, favorecendo a exposição de dentina à degradação (Walter et al., 2014). Esta por sua vez é mais susceptível a processos de desmineralização (Wood et al., 2008), a tensões devido à carga oclusal (Rees, 1998; 
Osborne-Smith et al., 1999; Wood et al., 2008), à falta de rigidez real do esmalte devido à orientação prisma (Spears, 1997; Wood et al., 2008) e também ao efeito piezoeléctrico (Wood et al., 2008). Clinicamente na erosão e abrasão ocorre a perda de tecido dental cervical (Grippo et al., 2004; Addy; Shellis, 2006; Grippo et al., 2012), promovendo a recessão gengival expondo o cemento ao meio bucal (Grippo et al., 2004)e consequente por processo de degradação dos tecidos ocorre a exposição da dentina (Grippo et al., 2004; Grippo et al., 2012). Por esse motivo, foi escolhida a dentina radicular do terço cervical para a realização deste estudo.

Diversos métodos vêm sendo utilizados para avaliar os processos de degradação das estruturas dentarias, dentre os mais atuais tem-se microscópio confocal a laser 3D (MCL) que tem a capacidade de capturar imagens em 3D da superfície permitindo avaliar a topografia e morfologia da superfície sem preparo prévio, podendo inclusive realizar avaliações longitudinais. A literatura mostra as análises de volume (Ranjitkar et al., 2008; Austin et al., 2014), degrau (Austin et al., 2010; Maia et al., 2014;), perfilometria (Hughes et al., 2000; West et al., 2000; West et al., 2001; Barbour; Rees, 2004; Moezizadeh; Alimi, 2014; Schwendicke et al., 2014) e rugosidade (Field et al., 2010; Mann et al., 2014) como ferramentas para medir a degradação dental. Porém, o MCL permite realizar outros tipos de medidas além de medir o volume, o degrau formado, o perfil de desgaste e rugosidade superficial, como fazer a contagem de túbulos dentinários abertos, medir o diâmetro deles, bem como a área interna deles. Dessa forma, no presente estudo empregou-se o MCL para realizar grande parte das análises.

Outro método que pode ser empregado na avaliação da degradação dos tecidos é o FTIR que analisa as modificações químicas ocorridas na superfície apos os diferentes tratamentos superficiais, sendo um método considerado como uma técnica efetiva para medir os componentes orgânicos e inorgânicos presentes no tecido dental (Antunes et al., 2006). 0 comprimento de onda é emitido entre 4000 e $400 \mathrm{~cm}^{-1}$ para o substrato analisado e os espectros de absorção identificados são constituídos pela somatória das bandas de absorção originárias dos compostos químicos presentes no substrato, permitindo a leitura superficial da amostra.

A MEV também foi utilizada para observar morfologia da superfície dental, devido à informação detalhada em micrometros que oferece a imagem através deste microscópio (Levrini et al., 2014), mantendo a imagem com foco em todas as partes sem importar as profundidades (Field et al., 2010). 
Assim, ao analisar o fator erosão pode-se observar que o $\mathrm{HCl}$ líquido promoveu maior desgaste que o $\mathrm{HCl}$ na forma de gás, sendo que o $\mathrm{HCl}$ líquido associado à abrasão promoveu um incremento no desgaste que não foi observado na mesma maneira no gás associado a abrasão. A literatura possuem poucos dados para que se possa compara-los, apenas Higo et al. 2009 observou que a erosão dental pode ser mais severa e intensa com o ácido gástrico gasoso (refluxo gasoso) em comparação com o ácido gástrico líquido (refluxo líquido). Porém, são achados clínicos que podem ter outros fatores que levam a severidade do desgaste dental.

A diferença da rapidez do processo erosivo do $\mathrm{HCl}$ líquido e gasoso talvez se deva à caraterística do estado físico do ácido, na forma líquida as partículas no líquido estão mais próximas entre si e na forma gasosa estão mais separadas, o que possivelmente levou ao líquido ter maior quantidade de partículas em contato com a dentina em comparação ao gás e um maior efeito do ácido, considerando-se que talvez este efeito do HCl líquido fica mais evidente após varias exposições, além disso, o processo de agitação faz que o liquido seja sempre renovado e a ação mecânica do fluido remova os minerais expondo a subsuperfície. Por sua vez o gás não apresenta a mesma dinâmica de ação. Contudo, em uma situação clinica ocorre mais episódios de refluxo gasoso do que o liquido e no presente estudo, o delineamento foi determinado uma simulação com mesmo tempo e repetição.

No presente estudo, a abrasão através da escovação, mostra ser um fator importante para potencializar o desgaste dental em tecidos dentais erodidos por $\mathrm{HCl}$ líquido, possivelmente devido à fricção da escovação no tecido dental amolecido pela desmineralização com os ácidos (Grippo et al., 2004; Grippo et al., 2012), colaborando para perda de tecido dental (Wiegand; Schlueter, 2014). Por outro lado, o desgaste durante a abrasão depende de outros fatores como a duração, frequência (OsborneSmith et al., 1999; Ozgoz et al., 2010), força da escovação (Osborne-Smith et al., 1999; Soresen et al., 2002; Bradini et al., 2011; Wiegand et al., 2013), dureza das cerdas (Osborne-Smith et al., 1999; Bradini et al., 2011) e abrasividade da pasta dental (Osborne-Smith et al., 1999; Wiegand; Schlueter, 2014).

Ao se avaliar os tratamentos superficiais, observou-se que o tratamento com CPPACP associado ao laser Diodo promoveu o menor desgaste. Possivelmente tenha ocorrido uma ação sinérgica da pasta CPP-ACP com o efeito do laser Diodo. Na literatura a pasta CPP-ACP foi observada eficaz para promover o aumento da resistência da 
dentina à desmineralização (Yamaguchi et al., 2007; Azarpazhooh; Limeback, 2008; Piekarz et al., 2008; Serra et al., 2008; Bartlett, 2009; Neuhaus; Lussi, 2009; Ranjitkar et al., 2009a; Ranjitkar et al., 2009b; Gupta \& Prakash, 2011; Poggio et al., 2013; de Alencar et al., 2014; Reema et al., 2014; Stefański; Postek-Stefańska, 2014), prevenir a erosão (Somani et al., 2014) e promover menor perda do tecido dental pelo processo erosivo (Manton et al., 2010) e erosivo/abrasivo (Ranjitkar et al., 2009b). Provavelmente devido a que o CPP-ACP pode proporcionar reservatórios de fosfato e cálcio (Herod, 1991; Reynolds et al., 1997; Reynolds et al., 1998; Reema et al., 2014; Vukosavljevic et al., 2014) que ajudam na diminuição da perda de minerais pelo tecido e possivelmente poderiam ajudar a remineralizar a dentina erodida (Ranjitkar et al., 2009b).

Entretanto, apesar dos lasers Nd:YAG e Diodo serem considerados similares, apresentando comprimento de onda próximo no infravermelho (Rohanizadeh et al., 1999), pouca absorção pelos minerais (Umana et al., 2013) e afinidade pelas superfícies pigmentadas (Rohanizadeh et al., 1999; Umana et al., 2013), os lasers não mostraram os mesmos resultados no presente estudo. Possivelmente, devido a que a irradiação do laser Diodo de 980nm é absorvida pela água (Umana et al., 2013), tendo melhor interação com a superfície da dentina (Umana et al., 2013), oposto ao laser Nd:YAG, o qual é escassamente absorvido pela agua (Boari et al., 2009; Gholami et al., 2011).

Apesar de que a pasta CPP-ACP também mostrou ser efetiva sem a presença de laser Diodo, o efeito do laser Diodo provavelmente seja o mais fator importante para manter por mais tempo o fosfato e cálcio depositados pelo CPP-ACP.

Por outro lado, a pasta experimental de caseína não mostrou nenhum efeito para prevenir o desgaste após desafios. Possivelmente, o efeito protetor da caseína contra os ácidos não foi efetivo no pH 1,2, concordando com o estudo de Grenby et al., (2001), onde a caseína não foi efetiva ao inibir a demineralização da hidroxiapatita no pH 4,2.

Outro fator observado foi a rugosidade da superfície, a qual foi maior na superfície erodida com $\mathrm{HCl}$ gasoso após tratamentos preventivos, possivelmente devido às caraterísticas do gás, uma vez que ao apresentar partículas com total liberdade de movimento não proporcionou um efeito homogêneo e formou uma superfície irregular na dentina. Porém, quando foi realizada a escovação possivelmente as cerdas da escova junto ao gel dental (contendo sílica) regularizaram superfície desmineralizada pelo gás. A sílica presente no gel, também foi observada em promover a menor valor de 
rugosidade superficial em comparação com outras pastas abrasivas (de Menezes et al., 2004).

Quando foi analisada a rugosidade da pasta experimental, esta apresentou os maiores valores em comparação que os outros tratamentos após desafios erosivos e erosivos abrasivos, talvez devido a que a pasta experimental sem a ação do laser, manteve a presença de partículas de pasta na superfície da dentina e afetaram a superfície.

Com relação às caraterísticas dos túbulos, o $\mathrm{HCl}$ líquido sem abrasão mostrou ter um efeito maior para expor os de túbulos após tratamentos preventivos, possivelmente devido a que a solução de HCl líquido promoveu desobliteração dos túbulos.

Por outro lado, o $\mathrm{HCl}$ líquido quando foi associado à abrasão mostrou diminuição do número de túbulos, provavelmente a ação da escova com dentifrício na superfície da dentina promoveu a formação de um smear layer como resultado do desgaste pelo processo erosivo/abrasivo. Desta forma, possivelmente os túbulos ficaram cobertos pela camada de smear layer, não podendo ser visualizados. Foi observado em outro estudo que a superfície da dentina exposta à escovação apresenta a diminuição da permeabilidade e oclusão dos túbulos (Wang et al., 2010), considerando-se que os abrasivos na pasta contribuem à formação de smear layer ( Arrais et al., 2003; Wang et al, 2010). A composição do smear layer após exposição ao ácido foi observada ser constituída pela mistura de colágeno desorganizado e minerais (Spencer e al., 2001).

Com relação aos tratamentos preventivos, o CPP-ACP associada ou não ao laser Nd:YAG ou Diodo foi efetiva para diminuir a exposição dos túbulos após desafios erosivos com e sem abrasão. Possivelmente o efeito do CPP-ACP para depositar o fosfato e cálcio na superfície dental (Herod, 1991; Reynolds et al., 1997; Reynolds et al., 1998; Reema et al., 2014; Vukosavljevic et al., 2014) associado ao efeito de fusão, recristalização e oclusão do lúmen dos túbulos (Liu et al., 1997; Schaller et al., 1997; Yonaga et al., 1999; de Magalhães et al., 2004; Lan et al., 2004; Aranha et al., 2005; Naylor et al., 2006; Gholami et al., 2011; Umana et al., 2013) dos lasers, permitiu menor exposição de túbulos. A pasta experimental também teve diminuição dos túbulos quando associada ou nào ao laser Nd:YAG, talvez devido a que a caseína pode-se aderir aos cristais de hidroxiapatita e evitar a perda de cálcio e fosfato (White et al., 2011), o qual permitiu manter a estrutura da dentina estável, não expondo mais túbulos dentinários e ao mesmo tempo permitindo a deposição de alguns minerais contido na 
pasta. $\mathrm{O}$ efeito da pasta talvez foi potencializado pela radiação do laser $\mathrm{Nd}: Y A G$, a qual produz fusão, recristalização e oclusão do lúmen dos túbulos (Liu et al., 1997; Schaller et al., 1997; Rohanizadeh et al., 1999; Yonaga et al., 1999; Lan et al., 2000; Gaspirc; Skaleric, 2001; Hossain et al., 2001; de Magalhães et al.., 2004; Lan et al., 2004; Aranha et al., 2005; Santos et al., 2005; Naylor et al., 2006; Gholami et al., 2011). Porém, quando foi associada a pasta experimental ao laser Diodo a ação desta foi diminuída, talvez devido a que a pasta experimental presentou maior conteúdo de agua, e junto ao pigmento escuro provocou exagerada absorção da irradiação do laser Diodo, eliminando parte da pasta e ação dela para poder diminuir a quantidade de túbulos expostos.

Com relação á área e perímetro do lúmen nos túbulos após tratamentos preventivos, o $\mathrm{HCl}$ líquido e $\mathrm{HCl}$ gasoso com e sem abrasão foram similares, e o $\mathrm{HCl}$ líquido com abrasão promoveu menor área e perímetro do lúmen dos túbulos. Possivelmente o smear layer formado pelo processo erosivo do HCl líquido associado à abrasão diminuiu a abertura dos entrada dos túbulos expostos ao contrario do $\mathrm{HCl}$ gasoso que possivelmente não formou smear layer. Entretanto, a demineralização na dentina peritubular possivelmente seja similar no $\mathrm{HCl}$ líquido e no $\mathrm{HCl}$ gasoso com ou sem abrasão, a dentina quando é desmineralizada apresenta dissolução da dentina peritubular o qual leva ao alargamento do lúmen dos túbulos (ten Cate; Imfeld, 1996; Addy; Shellis, 2006), posteriormente as regiões intertubulares são afetadas (ten Cate; Imfeld, 1996; Addy; Shellis, 2006; Nylor et al., 2006; Lussi et al., 2011).

Com relação aos tratamentos preventivos, o CPP-ACP associado aos lasers Nd:YAG e Diodo e a pasta experimental com o laser Nd:YAG mostraram ser efetivos para diminuir à área e perímetro dos túbulos após desafios erosivos com e sem abrasão. Talvez o efeito do laser foi o fator principal que promoveu oclusão dos túbulos (Liu et al., 1997; Schaller et al., 1997; Yonaga et al., 1999; de Magalhães et al.., 2004; Lan et al., 2004; Aranha et al., 2005; Naylor et al., 2006; Gholami et al., 2011; Umana et al., 2013), porém quando foi associada a pasta experimental ao laser Diodo o efeito do laser foi interferido. A característica do laser diodo de ser absorvido facilmente pela água e pigmentos escuros (Umana et al., 2013) possivelmente foi o responsável deste achado. 0 que provavelmente pode ter ocorrido foi que a pasta experimental continha elevada quantidade de água que quando associou-se ao pigmento escuro provocou maior absorção da irradiação na pasta que na superfície da dentina. Esta hipótese concorda com as características morfológicas dos tratamentos após serem aplicados na superfície 
da dentina erodida, as quais foram observadas nas imagens da MEV. Nessas imagens os tratamentos com o CPP-ACP associados aos lasers e o tratamento com a pasta experimental associada ao laser Nd:YAG mostraram túbulos parcialmente ocluídos.

$\mathrm{Na}$ análise do FTIR após tratamentos preventivos, a pasta CPP-ACP associada ao laser diodo e a pasta experimental associada aos lasers Nd:YAG e diodo mostraram diminuição da relação amida III/fosfato, e a relação carbonato/fosfato não mostrou diferenças. Possivelmente a irradiação do laser promoveu modificação da superfície o qual levou à alteração da matriz orgânica da dentina, promovendo que a porção inorgânica da dentina fique em maior proporção na superfície da dentina. Este efeito possivelmente colaborou no aumento da resistência da dentina ao desgaste, concordando com o resultado observado no tratamento do CPP-ACP associado ao laser diodo, o qual promoveu menor desgaste da dentina. Porém o efeito da pasta associada ao laser Nd:YAG e diodo possivelmente seja muito superficial e posteriormente foi removido pelo desgaste da dentina através dos desafios erosivos associados ou não à abrasão.

Quando foi analisado o carbonato/fosfato foi observada maior diminuição com o tratamento com o CPP-ACP, o carbonato é substituído pelo fosfato quando o CPP-ACP atua na superfície desmineralizada, já que com relação à amida III/fosfato o valor foi similar. Desta forma, possivelmente esta ação do CPP-ACP influenciou ao aumento da resistência da dentina aos ácidos, já que a presença de fosfato promove cristais de hidroxiapatita menos solúveis aos ácidos (Lussi et al., 2011).

Apesar de observar resultados satisfatórios de alguns tratamentos para conter o processo de degradação da dentina radicular, nenhum foi capaz de paralisar totalmente a degradação da dentina, ou mesmo inibir possivelmente a hipersensibilidade dentinária visto que apesar da diminuição do número e diâmetro dos túbulos, todos os tratamentos mantiveram-os abertos. Assim, se faz necessário novos estudos para desenvolver produtos capazes de diminuir a progressão do processo erosivo-abrasivo, além de permitir um tecido com menor sensibilidade. 


\section{Conclusões}




\section{Conclusões}

Baseado na metodologia proposta e nos resultados obtidos pode-se concluir que:

- $\quad$ tratamento com CPP-ACP associado ao laser Diodo promoveu maior resistência da dentina à degradação quando exposta à erosão associada ou não com a abrasão.

- Os tratamentos preventivos realizados mostraram ter menor efeito no aumento da resistência da dentina à degradação quando foram expostos à erosão com $\mathrm{HCl}$ líquido, especialmente quando associada a abrasão. 


\section{Referências}

\section{Bibliográficas}




\section{Referências Bibliográficas}

Addy M, Shellis RP. Interaction between attrition,abrasion and erosion in tooth wear. Monogr Oral Sci. 2006;20:17-31.

Addy M, Hunter ML. Can tooth brushing damage your health? Effects on oral and dental tissues. Int Dent J. 2003;53 Suppl 3:177-86. Review.

Alavi G, Alavi A, Saberfiroozi M, Sarbazi A, Motamedi M, Hamedani Sh. Dental Erosion in Patients with Gastroesophageal Reflux Disease (GERD) in a Sample of Patients Referred to the Motahari Clinic, Shiraz, Iran. J Dent (Shiraz). 2014 Mar;15(1):33-8.

Ali DA, Brown RS, Rodriguez LO, Moody EL, Nasr MF. Dental erosion caused by silent gastroesophageal reflux disease. J Am Dent Assoc. 2002 Jun;133(6):734-7; quiz 768-9.

Almeida e Silva JS, Baratieri LN, Araujo E, Widmer N. Dental erosion: understanding this pervasive condition. J Esthet Restor Dent. 2011 Aug;23(4):205-16.

Amaechi BT, Higham SM, Edgar WM. Techniques for the production of dental eroded lesions in vitro. J Oral Rehabil. 1999;26(2):97-102.

Antunes A, de Rossi W, Zezell DM. Spectroscopic alterations on enamel and dentin after nanosecond Nd:YAG laser irradiation. Spectrochim Acta A Mol Biomol Spectrosc. 2006 Aug;64(5):1142-6.

Aranha AC, Domingues FB, Franco VO, Gutknecht N, Eduardo Cde P. Effects of Er:YAG and Nd:YAG lasers on dentin permeability in root surfaces: a preliminary in vitro study. Photomed Laser Surg. 2005 Oct;23(5):504-8.

Arrais CA, Micheloni CD, Giannini M, Chan DC. Occluding effect of dentifrices on dentinal tubules. J Dent. 2003 Nov;31(8):577-84.

Austin RS, Rodriguez JM, Dunne S, Moazzez R, Bartlett DW. The effect of increasing sodium fluoride concentrations on erosion and attrition of enamel and dentine in vitro. J Dent. 2010 Oct;38(10):782-7.

Austin RS, Stenhagen KR, Hove LH, Tveit AB, Moazzez RV, Bartlett DW. The effect of single-application fluoride treatment on simulated gastric erosion and erosion-abrasion of enamel in vitro. Int J Prosthodont. 2014 Sep-Oct;27(5):425-6.

Azarpazhooh A, Limeback H. Clinical efficacy of casein derivatives: a systematic review of the literature. J Am Dent Assoc. 2008 Jul;139(7):915-24.

Bahal P, Djemal S. Dental erosion from an excess of vitamin C. Case Rep Dent. 2014;2014:485387. 
Barbour ME, Rees JS. The laboratory assessment of enamel erosion: a review. J Dent. 2004 Nov;32(8):591-602.

Barbour ME, Shellis RP, Parker DM, Allen GC, Addy M. Inhibition of hydroxyapatite dissolution by whole casein: the effects of $\mathrm{pH}$, protein concentration, calcium, and ionic strength. Eur J Oral Sci. 2008 Oct;116(5):473-8.

Barron RP, Carmichael RP, Marcon MA, Sàndor GKB. Dental erosion in gastroesophageal reflux desease. J Can Dent Assoc. 2003;69(2):84-89.

Bartlett DW, Evans DF, Smith BG. The relationship between gastro-oesophageal reflux disease and dental erosion. J Oral Rehabil. 1996 May;23(5):289-97.

Bartlett DW, Coward PY. Comparison of erosive potential of gastric juice and a carbonated drink in vitro. J Oral Rehabil. 2001;28(11):1045-1047.

Bartlett DW. The role of erosion in tooth wear: aetiology, prevention and management. Int Dent J. 2005;55(4 Suppl 1):277-84.

Bartlett D. Intrinsic causes of erosion. Monogr Oral Sci. 2006;20:119-39.

Bartlett DW, Shah P. A critical review of non-carious cervical (wear) lesions and the role of abfraction, erosion, and abrasion. J Dent Res. 2006 Apr;85(4):306-12.

Bartlett D. Etiology and prevention of acid erosion. Compend Contin Educ Dent. 2009 Nov-Dec;30(9):616-20.

Benages A, Muñoz JV, Sanchiz V, Mora V, Mínguez M. Dental erosion as extraesophageal manifestation of gastro-esophageal reflux. Inter $J$ Gastroenterol Hepatol. 2006;55(7):1050-51.

Brandini DA, de Sousa AL, Trevisan CI, Pinelli LA, do Couto Santos SC, Pedrini D, Panzarini SR. Noncarious cervical lesions and their association with toothbrushing practices: in vivo evaluation. Oper Dent. 2011 Nov-Dec;36(6):581-9.

Boari HGD, Ana PA, Eduardo CP, Powell GL, Zezell DM. Absorption and thermal study of dental enamel when irradiated with Nd: YAG laser with the aim of caries prevention. Laser Phys. 2009; 19(7):1463-9.

Cheung A, Zid Z, Hunt D, McIntyre J. The potential for dental plaque to protect against erosion using an in vivo-in vitro model--a pilot study. Aust Dent J. 2005 Dec;50(4):22834.

Cochrane NJ, Cai F, Huq NL, Burrow MF, Reynolds EC. New approaches to enhanced remineralization of tooth enamel. J Dent Res. 2010 Nov;89(11):1187-97. 
de Alencar CR, Magalhães AC, de Andrade Moreira Machado MA, de Oliveira TM, Honório HM, Rios D. In situ effect of a commercial CPP-ACP chewing gum on the human enamel initial erosion. J Dent. 2014 Aug 28. pii: S0300-5712(14)00242-5.

de Magalhães MF, Matson E, de Rossi W, Alves JB. A morphological in vitro study of the effects of Nd:YAG laser on irradiated cervical dentin. Photomed Laser Surg. 2004 Dec;22(6):527-32.

de Menezes M, Turssi CP, Hara AT, Messias DC, Serra MC. Abrasion of eroded root dentine brushed with different toothpastes. Clin Oral Investig. 2004 Sep;8(3):151-5.

Derceli JR. Analise in vitro e in situ da erosao dentale de métodos de prevenção em pacientes portadores da Doenca do Refluxo Gastroesofagico (tese). São Paulo: Universidade de São Paulo, Faculdade de Odontologia de Ribeirão Preto FORP/USP; 2014.

Dominici JT, Eleazer PD, Clark SJ, Staat RH, Scheetz JP. Disinfection/sterilization of extracted teeth for dental student use. J Dent Educ. 2001;65(11):1278-1280.

Donovan, Terry, and Edward J. Swift. "Dental erosion." Journal of Esthetic and Restorative Dentistry 21.6 (2009): 359-364.

Dundar A, Sengun A. Dental approach to erosive tooth wear in gastroesophageal reflux disease. Afr Health Sci. 2014 Jun;14(2):481-6.

Farahmand F, Sabbaghian M, Ghodousi S, Seddighoraee N, Abbasi M. Gastroesophageal reflux disease and tooth erosion: a cross-sectional observational study. Gut Liver. 2013 May;7(3):278-81.

Field J, Waterhouse P, German M. Quantifying and qualifying surface changes on dental hard tissues in vitro. J Dent. 2010 Mar;38(3):182-90.

Firouzei MS, Khazaei S, Afghari P, Savabi G, Savabi O, Keshteli AH, Adibi P. Gastroesophageal reflux disease and tooth erosion: SEPAHAN systematic review no. 10. Dent Res J (Isfahan). 2011 Dec;8(Suppl 1):S9-S14.

Gaspirc B, Skaleric U. Morphology, chemical structure and diffusion processes of root surface after Er:YAG and Nd:YAG laser irradiation. J Clin Periodontol. 2001 Jun;28(6):508-16.

Gholami GA, Fekrazad R, Esmaiel-Nejad A, Kalhori KA. An evaluation of the occluding effects of Er;Cr:YSGG, $\mathrm{Nd}: \mathrm{YAG}, \mathrm{CO}_{2}$ and diode lasers on dentinal tubules: a scanning electron microscope in vitro study. Photomed Laser Surg. 2011 Feb;29(2):115-21. 
Gregory-Head BL, Curtis DA, Kim L, Cello J. Evaluation of dental erosion in patients with gastroesophageal reflux disease. J Prosthet Dent. 2000 Jun;83(6):675-80.

Grenby TH, Andrews AT, Mistry M, Williams RJ. Dental caries-protective agents in milk and milk products: investigations in vitro. J Dent. $2001 \mathrm{Feb}$;29(2):83-92.

Grippo JO, Simring M, Schreiner S. Attrition, abrasion, corrosion and abfraction revisited: a new perspective on tooth surface lesions. J Am Dent Assoc. 2004 Aug;135(8):1109-18; quiz 1163-5.

Grippo JO, Simring M, Coleman TA. Abfraction, abrasion, biocorrosion, and the enigma of noncarious cervical lesions: a 20-year perspective. J Esthet Restor Dent. 2012 Feb;24(1):10-23.

Gupta R, Prakash V. CPP-ACP complex as a new adjunctive agent for remineralisation: a review. Oral Health Prev Dent. 2011;9(2):151-65.

Herod EL. The effect of cheese on dental caries: a review of the literature. Aust Dent J. 1991 Apr;36(2):120-5.

Higo T, Mukaisho K, Ling ZQ, Oue K, Chen KH, Araki Y, Sugihara H, Yamamoto G, Hattori T. An animal model of intrinsic dental erosion caused by gastro-oesophageal reflux disease. Oral Dis. 2009 Jul;15(5):360-5.

Holbrook WP, Furuholm J, Gudmundsson K, Theodórs A, Meurman JH. Gastric reflux is a significant causative factor of tooth erosion. J Dent Res. 2009 May;88(5):422-6.

Hoppenbrouwers PM, Driessens FC, Borggreven JM. The mineral solubility of human tooth roots. Arch Oral Biol. 1987;32(5):319-22.

Hossain M, Nakamura Y, Kimura Y, Yamada Y, Kawanaka T, Matsumoto K. Effect of pulsed Nd:YAG laser irradiation on acid demineralization of enamel and dentin. J Clin Laser Med Surg. 2001 Apr;19(2):105-8.

Hughes JA, West NX, Parker DM, van den Braak MH, Addy M. Effects of pH and concentration of citric, malic and lactic acids on enamel, in vitro. J Dent. 2000 Feb;28(2):147-52.

Hunter ML, Addy M, Pickles MJ, Joiner A. The role of toothpastes and toothbrushes in the aetiology of tooth wear. Int Dent J. 2002;52:399-405.

Imfeld T. Dental erosion. Definition, classification and links. Eur J Oral Sci. 1996;104(2):151-55. 
Kreulen CM, Van 't Spijker A, Rodriguez JM, Bronkhorst EM, Creugers NH, Bartlett DW. Systematic review of the prevalence of tooth wear in children and adolescents. Caries Res. 2010;44(2):151-9.

Kumar VL1, Itthagarun A, King NM. The effect of casein phosphopeptide-amorphous calcium phosphate on remineralization of artificial caries-like lesions: an in vitro study. Aust Dent J. 2008 Mar;53(1):34-40.

Lan WH, Chen KW, Jeng JH, Lin CP, Lin SK. A comparison of the morphological changes after Nd-YAG and CO2 laser irradiation of dentin surfaces. J Endod. 2000 Aug;26(8):4503.

Lan WH, Lee BS, Liu HC, Lin CP. Morphologic study of Nd:YAG laser usage in treatment of dentinal hypersensitivity. J Endod. 2004 Mar;30(3):131-4.

Lazarchik DA, Filler SJ. Effects of gastroesophageal reflux on the oral cavity. Am J Med. 1997 Nov 24;103(5A):107S-113S.

Lazarchik DA, Filler SJ. Dental erosion: predominant oral lesion in gastroesophageal reflux disease. Am J Gastroenterol. 2000 Aug;95(8 Suppl):S33-8.

Levrini L, Di Benedetto G, Raspanti M. Dental wear: a scanning electron microscope study. Biomed Res Int. 2014;2014:340425.

Liberali S. Oral impact of gastro-oesophageal reflux disease: a case report. Aust Dent J. 2008 Jun;53(2):176-9. .

Liu HC, Lin CP, Lan WH. Sealing depth of Nd:YAG laser on human dentinal tubules. J Endod. 1997 Nov;23(11):691-3.

Lussi A. Dental erosion--novel remineralizing agents in prevention or repair. Adv Dent Res. 2009;21(1):13-6.

Lussi A, Schlueter N, Rakhmatullina E, Ganss C. Dental erosion--an overview with emphasis on chemical and histopathological aspects. Caries Res. 2011;45 Suppl 1:2-12.

Lussi A, Megert B, Peter Shellis R, Wang X. Analysis of the erosive effect of different dietary substances and medications.Br J Nutr. 2012 Jan;107(2):252-262.

Maia AM, Longbottom C, Gomes AS, Girkin JM. Enamel erosion and prevention efficacy characterized by confocal laser scanning microscope. Microsc Res Tech. 2014 Jun;77(6):439-45. 
Mann C, Ranjitkar S, Lekkas D, Hall C, Kaidonis JA, Townsend GC, Brook AH. Threedimensional profilometric assessment of early enamel erosion simulating gastric regurgitation. J Dent. 2014 Nov;42(11):1411-21.

Manton DJ, Cai F, Yuan Y, Walker GD, Cochrane NJ, Reynolds C, Brearley-Messer LJ, Reynolds EC. Effect of casein phosphopeptide-amorphous calcium phosphate added to acidic beverages on enamel erosion in vitro. Aust Dent J. 2010 Sep;55(3):275-9.

McCarthy R. Dental erosion--current perspectives for general practice. J Ir Dent Assoc. 2012 Oct-Nov;58(5):241-4.

Meurman JH, Drysdale T, Frank RM. Experimental erosion of dentin. Scand J Dent Res. 1991 Dec;99(6):457-62.

Milosevic, A. (2010). Dental Erosion in a Series of Referred Patients was Statistically Associated With Gastric Reflux, Acidic Drink Intake of more than $0.5 \mathrm{~L}$ per day, and Low Salivary Buffering Capacity. Journal of Evidence Based Dental Practice, 10(3), 176-178.

Moazzez R, Bartlett D, Anggiansah A. Dental erosion, gastro-oesophageal reflux disease and saliva: how are they related? J Dent. 2004;32:489-494.

Moezizadeh M, Alimi A. The effect of casein phosphopeptide-amorphous calcium phosphate paste and sodium fluoride mouthwash on the prevention of dentine erosion: An in vitro study. J Conserv Dent. 2014 May;17(3):244-9.

Moraes-Filho J, Cecconello I, Gama-Rodrigues J, Castro L, Henry MA, Meneghelli UG, Quigley E; Brazilian Consensus Group. Brazilian consensus on gastroesophageal reflux disease: proposals for assessment, classification, and management. Am J Gastroenterol. 2002 Feb;97(2):241-8.

Naylor F, Aranha AC, Eduardo CP, Arana-Chavez VE, Sobral MAP. Micromorphological analysis of dentinal structure after irradiation with $\mathrm{Nd}$ :YAG laser and immersion in acidic beverages. Photomed Laser Surg. 2006;24:745-752.

Neuhaus KW, Lussi A. Casein phosphopeptide--amorphous calcium phosphate (CPPACP) and its effect on dental hard tissues. Schweiz Monatsschr Zahnmed. 2009;119(2):110-116.

Osborne-Smith KL, Burke FJ, Wilson NH. The aetiology of the non-carious cervical lesion. Int Dent J. 1999 Jun;49(3):139-43.

Ozgoz M, Arabaci T, Sumbullu MA, Demir T. Relationship between handedness and toothbrush-related cervical dental abrasion in left-and right-handed individuals. J Dent Sci. 2010;5(4):177-82. 
Pace F, Pallotta S, Tonini M, Vakil N, Bianchi Porro G. Systematic review: gastrooesophageal reflux disease and dental lesions. Aliment Pharmacol Ther. 2008 Jun;27(12):1179-86.

Picos A, Chisnoiu A, Dumitrasc DL. Dental erosion in patients with gastroesophageal reflux disease. Adv Clin Exp Med. 2013 May-Jun;22(3):303-7. Review.

Piekarz C, Ranjitkar S, Hunt D, McIntyre J. An in vitro assessment of the role of Tooth Mousse in preventing wine erosion. Aust Dent J. 2008 Mar;53(1):22-5.

Poggio C, Lombardini M, Vigorelli P, Ceci M. Analysis of dentin/enamel remineralization by a CPP-ACP paste: AFM and SEM study. Scanning. 2013 Nov-Dec;35(6):366-74.

Rahiotis C, Vougiouklakis G. Effect of a CPP-ACP agent on the demineralization and remineralization of dentine in vitro. J Dent. 2007;35(8):695-698.

Ranjitkar S, Kaidonis JA, Townsend GC, Vu AM, Richards LC. An in vitro assessment of the effect of load and $\mathrm{pH}$ on wear between opposing enamel and dentine surfaces. Arch Oral Biol. 2008 Nov;53(11):1011-6.

Ranjitkar S, Kaidonis JA, Richards LC, Townsend GC. The effect of CPP-ACP on enamel wear under severe erosive conditions. Arch Oral Biol. 2009a Jun;54(6):527-32.

Ranjitkar S, Rodriguez JM, Kaidonis JA, Richards LC, Townsend GC, Bartlett DW. The effect of casein phosphopeptide-amorphous calcium phosphate on erosive enamel and dentine wear by toothbrush abrasion. J Dent. 2009b;37(4):250-254.

Ranjitkar S, Kaidonis JA, Smales RJ. Gastroesophageal reflux disease and tooth erosion. Int J Dent. 2012a;2012:479850.

Ranjitkar S, Smales RJ, Kaidonis JA. Oral manifestations of gastroesophageal reflux disease. J Gastroenterol Hepatol. 2012b Jan;27(1):21-7.

Reema SD, Lahiri PK, Roy SS. Review of casein phosphopeptides-amorphous calcium phosphate. Chin J Dent Res. 2014;17(1):7-14.

Rees JS. The role of cuspal flexure in the development of abfraction lesions: a finite element study. Eur J Oral Sci. 1998 Dec;106(6):1028-32.

Reynolds EC. Anticariogenic complexes of amorphous calcium phosphate stabilized by casein phosphopeptides: a review. Spec Care Dentist. 1998 Jan-Feb;18(1):8-16.

Reynolds EC. Remineralization of enamel subsurface lesions by casein phosphopeptidestabilized calcium phosphate solutions. J Dent Res. 1997 Sep;76(9):1587-95. 
Roesch-Ramos L, Roesch-Dietlen F, Remes-Troche JM, Romero-Sierra G, Mata-Tovar Cde J, Azamar-Jácome AA, Barranca-Enríquez A. Dental erosion, an extraesophageal manifestation of gastroesophageal reflux disease. The experience of a center for digestive physiology in Southeastern Mexico. Rev Esp Enferm Dig. 2014 Feb;106(2):927.

Rohanizadeh R, LeGeros RZ, Fan D, Jean A, Daculsi G. Ultrastructural properties of laserirradiated and heat-treated dentin. J Dent Res. 1999 Dec;78(12):1829-35

Santos C, Sousa-Neto MD, Alfredo E, Guerisoli DM, Pecora JD, Comelli Lia RF. Morphologic evaluation of the radicular dentine irradiated with Nd:YAG laser under different parameters and angles of incidence. Photomed Laser Surg. 2005 Dec;23(6):590-5.

Schaller HG, Weihing T, Strub JR. Permeability of dentine after Nd:YAG laser treatment: an in vitro study. Journal of Oral Rehabilitation 1997; 24: 274-81.

Scheutzel P. Etiology of dental erosion--intrinsic factors. Eur J Oral Sci. 1996 Apr;104(2 ( Pt 2)):178-90.

(a) Schlueter N, Jaeggi T, Lussi A. Is dental erosion really a problem?. Adv Dent Res. 2012 Sep;24(2):68-71.

(b) Schlueter N, Glatzki J, Klimek J, Ganss C. Erosive-abrasive tissue loss in dentine under simulated bulimic conditions. Arch Oral Biol. 2012 Sep;57(9):1176-82.

Schroeder PL, Filler SJ, Ramirez B, Lazarchik DA, Vaezi MF, Richter JE. Dental Erosion and Acid Reflux Disease. Ann Intern Med. 1995;122:809-815.

Schwendicke F, Felstehausen G, Carey C, Dörfer C. Comparison of four methods to assess erosive substance loss of dentin. PLoS One. 2014 Sep 17;9(9):e108064.

Serra MC, Messias DC, Turssi CP. Control of erosive tooth wear: possibilities and rationale. Braz Oral Res. 2009;23 Suppl 1:49-55.

Sifrim D1, Silny J, Holloway RH, Janssens JJ. Patterns of gas and liquid reflux during transient lower oesophageal sphincter relaxation: a study using intraluminal electrical impedance. Gut. 1999 Jan;44(1):47-54.

Sifrim D, Holloway R, Silny J, Xin Z, Tack J, Lerut A, Janssens J. Acid, nonacid, and gas reflux in patients with gastroesophageal reflux disease during ambulatory 24-hour $\mathrm{pH}$ impedance recordings. Gastroenterology. 2001 Jun;120(7):1588-98.

Somani, R., Jaidka, S., Singh, D. J., \& Arora, V. (2014). Remineralizing potential of various agents on dental erosion. J Oral Biol Craniofacial Res. 2014;4(2):104-108. 
Sorensen JA, Nguyen HK. Evaluation of toothbrush-induced dentin substrate wear using an in vitro ridged-configuration model. Am J Dent. 2002 Nov;15 Spec No:26B-32B.

Spears IR. A three-dimensional finite element model of prismatic enamel: a re-appraisal of the data on the Young's modulus of enamel. J Dent Res. 1997 Oct;76(10):1690-7.

Spencer P1, Wang Y, Walker MP, Swafford JR. Molecular structure of acid-etched dentin smear layers--in situ study. J Dent Res. 2001 Sep;80(9):1802-7.

Stefański T, Postek-Stefańska L. Possible ways of reducing dental erosive potential of acidic beverages. Aust Dent J. 2014 Sep;59(3):280-8.

ten Cate JM, Imfeld T. Dental erosion, summary. Eur J Oral Sci. 1996 Apr;104(2 ( Pt 2)):241-4.

Tutuian R, Vela MF, Hill EG, Mainie I, Agrawal A, Castell DO. Characteristics of symptomatic reflux episodes on Acid suppressive therapy. Am J Gastroenterol. 2008; 103(5):1090-1096.

Umana M, Heysselaer D, Tielemans M, Compere P, Zeinoun T, Nammour S. Dentinal tubules sealing by means of diode lasers (810 and $980 \mathrm{~nm}$ ): a preliminary in vitro study. Photomed Laser Surg. 2013 Jul;31(7):307-14.

Van't Spijker, Rodriguez JM, Kreulen CM, Bronkhorst EM, Bartlett DW, Creugers NH. Prevalence of tooth wear in adults. Int J Prosthodont. 2009;22(1):35-42.

Vukosavljevic D, Custodio W, Buzalaf MA, Hara AT, Siqueira WL. Acquired pellicle as a modulator for dental erosion. Arch Oral Biol. 2014 Jun;59(6):631-8.

Walter C, Kress E, Götz H, Taylor K, Willershausen I, Zampelis A. The anatomy of noncarious cervical lesions. Clin Oral Investig. 2014 Jan;18(1):139-46.

Wang Z, Sa Y, Sauro S, Chen H, Xing W, Ma X, Jiang T, Wang Y. Effect of desensitising toothpastes on dentinal tubule occlusion: a dentine permeability measurement and SEM in vitro study. J Dent. 2010 May;38(5):400-10. .

West NX, Hughes JA, Addy M. Erosion of dentine and enamel in vitro by dietary acids: the effect of temperature, acid character, concentration and exposure time. J Oral Rehabil. 2000 Oct;27(10):875-80.

West NX, Hughes JA, Addy M.. The effect of $\mathrm{pH}$ on the erosion of dentine and enamel by dietary acids in vitro. J Oral Rehabil. 2001 Sep;28(9):860-4. 
White JM, Adams GL. Microhardness and scanning electron microscopy analysis of Nd:YAG laser and acid treatment effects in dentin. Scanning Microsc. 1996;10(2):329336; discussion 337.

White AJ, Gracia LH, Barbour ME. Inhibition of dental erosion by casein and caseinderived proteins. Caries Res. 2011;45 (1):13-20.

Wiegand A, Burkhard JP, Eggmann F, Attin T. Brushing force of manual and sonic toothbrushes affects dental hard tissue abrasion. Clin Oral Investig. 2013 Apr;17(3):81522. doi: $10.1007 /$ s00784-012-0788-z.

Wiegand A, Schlueter N. The role of oral hygiene: does toothbrushing harm? Monogr Oral Sci. 2014;25:215-9.

Wood I, Jawad Z, Paisley C, Brunton P. Non-carious cervical tooth surface loss: a literature review. J Dent. 2008 Oct;36(10):759-66.

Yamaguchi K, Miyazaki M, Takamizawa T, Inage $H$, Kurokawa H. Ultrasonic determination of the effect of casein phosphopeptide-amorphous calcium phosphate paste on the demineralization of bovine dentin. Caries Res. 2007;41(3):204-7.

Yonaga, K., Kimura, Y., and Matsumoto, K. Treatment of cervical dentin hypersensitivity by various methods using pulsed Nd:YAG laser. J. Clin. Laser Med Surg. 1999;17:205210.

Zero DT. Etiology of dental erosion--extrinsic factors. Eur J Oral Sci. 1996 Apr;104(2 ( Pt 2)):162-77. 
Anexo 1 


\section{UNIVERSIDADE DE SÃO PAULO}

Faculdade de Odontologia de Ribeirão Preto

Comitê de Ética em Pesquisa

Of.ATAC.CEP/52911/FORP-USP/21.12.2011

Ref. processo n. ${ }^{\circ} \underline{2011.1 .1370 .58 .0}$

CAAE n. ${ }^{\circ} 0073 \cdot 0.138 .000-11$

Senhor(a) Pesquisador(a):

Informamos que o Comitê de Ética em Pesquisa, em sua $126^{a}$ Sessão, realizada em 15 de dezembro de 2011, aprovou o desenvolvimento do projeto de pesquisa envolvendo seres humanos, intitulado "Efeito dos lasers Nd:YAG e CO2 na dentina erodida $e$ abrasionada".

$\mathrm{Na}$ oportunidade, lembramos da necessidade de serem entregues, na secretaria do CEP, os Relatórios Parciais em $\underline{30}$ de novembro de 2012 e em $\underline{31 \text { de agosto de }}$

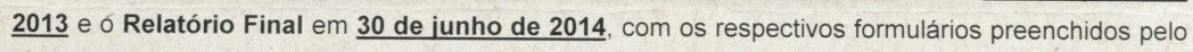
pesquisador responsável.

Lembramos ainda que, quando da submissão do relatório a este Comitê, quaisquer inclusões ou modificações no projeto original deverão ser comunicadas e justificadas ao CEP, através do formulário supracitado.

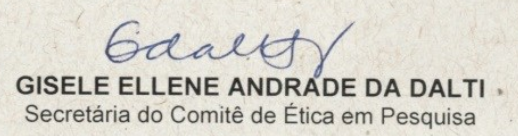

IImo(a). Sr(a).

PG. CARMEN VICTORIA TORRES TORO (Profa. Dra. Regina Guenka Palma Dibb)

Departamento de Odontologia Restauradora

desta Faculdade

AVENIDA DO CAFÉ, S/N. ${ }^{\circ}$ - TEL. (16) 3602-4123/3963 - FAX (16) 3602-4102

14040-904 - RIBEIRÃO PRETO - SP - BRASIL 